\title{
RAQUEL FERRARI MARCHESI
}

\section{Anemia aplástica adquirida - avaliação da biópsia de medula óssea na identificação de prognóstico desfavorável, aferido pela evolução para SMD /LMA - um estudo comparativo em crianças e adultos}

Tese apresentada à Faculdade de Medicina da Universidade de São Paulo para obtenção do título de Doutora em Ciências

Programa de Patologia

Orientadora: Profa. Dra. Maria Cláudia Nogueira Zerbini

Coorientadora: Profa. Dra. Elvira Deolinda Rodrigues Pereira Velloso

São Paulo 


\section{Dados Internacionais de Catalogação na Publicação (CIP)}

Preparada pela Biblioteca da

Faculdade de Medicina da Universidade de São Paulo

Creprodução autorizada pelo autor

Marchesi, Raquel Ferrari

Anemia aplástica adquirida - avaliação da biópsia de medula óssea na identificação de prognóstico desfavorável, aferido pela evolução para smd /Ima - um estudo comparativo em crianças e adultos / Raquel Ferrari Marchesi -São Paulo, 2017.

Tese(doutorado)--Faculdade de Medicina da Universidade de São Paulo. Programa de Patologia.

Orientadora: Maria Claudia Nogueira Zerbini.

Coorientadora: Elvira Deolinda Rodrigues Pereira Velloso..

Descritores: 1.Anemia aplástica adquirida 2.Aplasia medular 3.Síndrome mielodisplásica 4.Citopenia refratária da infância 5.Leucemia mieloide aguda 6.Biópsia 7.Medula óssea 8.Imuno-histoquímica 9.Blastos 10. CD34

USP/FM/DBD-235/17 
A meu marido Pedro e a meu filho Teodoro, meus amores! 


\section{AGRADECIMENTOS}

A meu amado marido Pedro Luiz Guimarães Costa e meu filho Teodoro Luiz Marchesi Costa, por serem fontes inesgotáveis de amor, coragem e inspiração.

A meus pais Luiz Marchesi Filho e Terezinha Ferrari Marchesi e meus irmãos Luiz Marchesi Neto e Henrique Ferrari Marchesi, pela minha formação pessoal.

A meu sogro Paulo Luiz Aguirre Costa, pelo apoio em muitos momentos.

A minha orientadora Professora Dra. Maria Claudia Nogueira Zerbini, por quem tenho profunda admiração, pela confiança e dedicação dispensadas.

A minha coorientadora Dra Elvira Deolinda Rodrigues Pereira Velloso, a quem tive o privilégio de conhecer durante a realização desta pesquisa, por toda paciência, disposição e solicitude.

A Dra. Marlene Pereira Garanito que, gentilmente, cedeu dados dos pacientes pediátricos.

Ao Professor Dr Raymundo Soares de Azevedo Neto, pela paciência ao realizar conosco a análise estatística do estudo.

A Cristina Aiko Kumeda, pelo auxílio profissional na realização dos exames de FISH.

A minha equipe de trabalho do Laboratório APC, pelo companheirismo e apoio emocional.

A Dra. Sheila Aparecida Coelho Siqueira, pelo apoio profissional.

Ao pessoal da técnica do Laboratório de Histopatologia, em especial a Kelly, e da técnica de Imuno-histoquímica, em especial a Ângela e a Cristina, pela boa vontade.

Ao Thiago Rezende da pós-graduação, pelos esclarecimentos prestados.

Agradeço aos Pacientes. 
"Tudo vale a pena

Se a alma não é pequena."

Fernando Pessoa 


\section{Normalização adotada}

Esta tese está de acordo com as seguintes normas, em vigor no momento desta publicação:

Referências: adaptado de Internacional Committee of Medical Journals Editors (Vancouver).

Universidade de São Paulo. Faculdade de Medicina. Divisão de Biblioteca e Documentação. Guia de apresentação de dissertações, teses e monografias. Elaborado por Anneliese Carneiro da Cunha, Maria Julia de A. L. Freddi, Maria F. Crestana, Marinalva de Souza Aragão, Suely Campos Cardoso, Valéria Vilhena. $3^{\underline{a}}$ ed. São Paulo: Divisão de Biblioteca e Documentação; 2011.

Abreviaturas dos títulos dos periódicos de acordo com List of Journals Indexed in Index Medicus. 


\section{SUMÁRIO}

Lista de abreviaturas

Lista de figuras

Lista de tabelas

Resumo

Summary

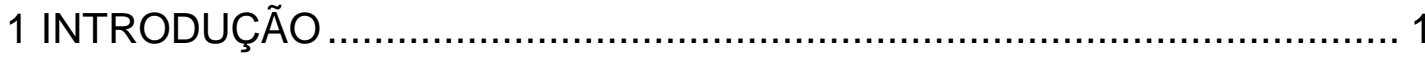

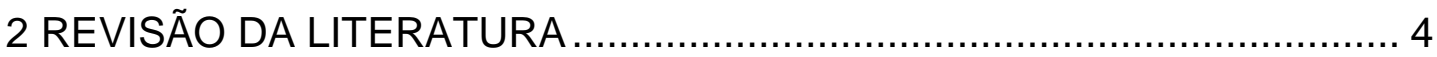

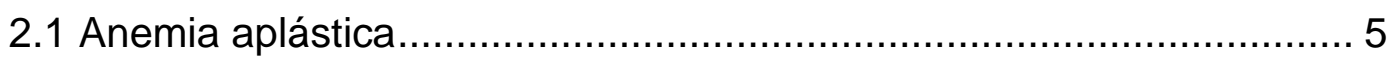

2.1.1 Definição …................................................................ 5

2.1.2 Epidemiologia ......................................................... 5

2.1.3 Fisiopatologia, diagnóstico e morfologia............................... 5

2.1.4 Tratamento .................................................................... 7

2.1.5 Alterações genéticas e evolução clonal.............................. 7

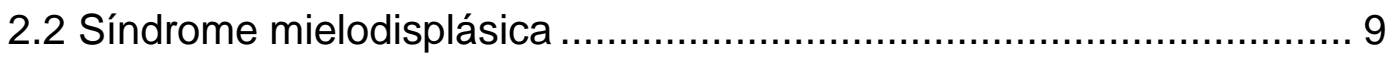

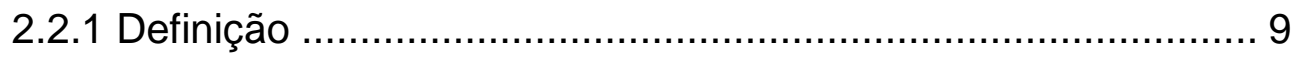

2.2.2 Epidemiologia ............................................................ 9

2.2.3 Fisiopatologia, diagnóstico e morfologia............................ 10

2.2.4 Alterações genéticas ...................................................... 11

2.2.5 Síndromes mielodisplásicas na infância............................. 12

2.3 Considerações sobre o diagnóstico diferencial entre AAA e SND hipoplásica ......................................................................... 14

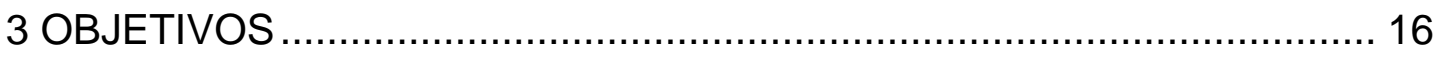

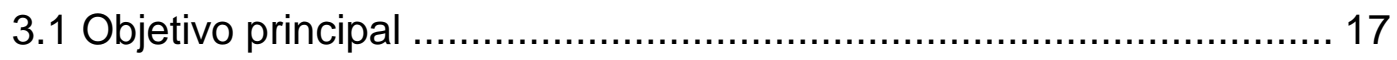

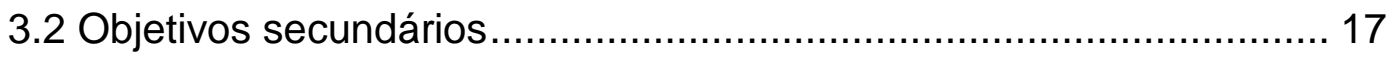

4 CASUÍSTICA E MÉTODOS ......................................................... 18

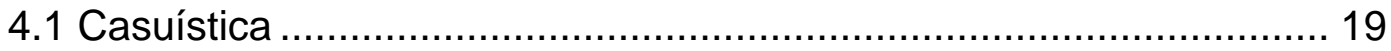

4.2 Métodos ............................................................................. 20

4.2.1 Coleta de dados clínicos ............................................... 20

4.2.2 Achados laboratoriais e morfológicos ............................... 21

4.2.2.1 Hemograma ...................................................... 21

4.2.2.2 Mielograma ................................................... 22

4.2.2.3 Biópsia de medula óssea ..................................... 22

4.2.2.3.1 Parâmetros morfológicos e imunihistoquímicos analisados ...................... 23

4.2.2.3.2 Processamento do fragmento de biópsia de medula óssea...................... 27

4.2.2.3.3 Exame imuno-histoquímico (IHQ) ............. 28 
4.2.2.4.1 Citogenética convencional - cariótipo …..... 30

4.2.2.4.2 Citogenética molecular - hibridização "in situ" por fluorescência (FISH) .............. 30

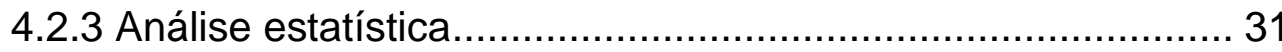

5 RESULTADOS

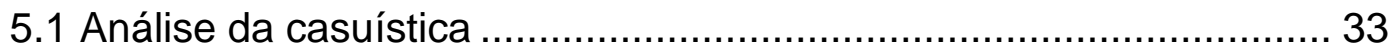

5.2 Avaliação das amostras de biópsias de medula óssea....................... 36

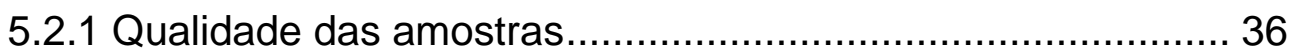

5.2.2 Parâmetros morfológicos / imuno-histoquímicos estudados ...................................................................... 40

5.2.2.1 Comparação dos achados morfológicos / imunohistoquímicos em crianças e adultos

5.2.2.2 Comparação dos achados morfológicos / imunohistoquímicos em pacientes que evoluíram e que não evoluíram para SMD/LMA

5.2.2.3 Comparação dos achados morfológicos / imunohistoquímicos no grupo total, em adultos e crianças que evoluíram e que não evoluíram para SMD/LMA.

5.2.3 Avaliação de critérios de Bennett e Orazi e de Baumann et al. aos grupos

5.2.4 Avaliação do índice proliferativo (Ki-67) em relação à celularidade geral do grupo total......................................... 55

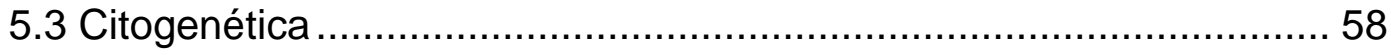

5.4 Descrição dos 12 pacientes que evoluíram para SMD/LMA .............. 59

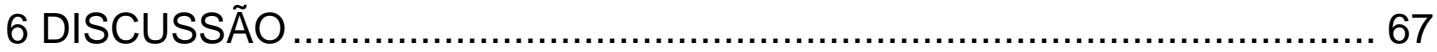

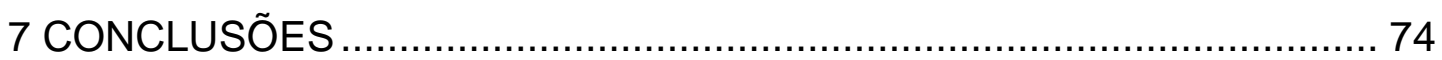

8 REFERÊNCIAS.

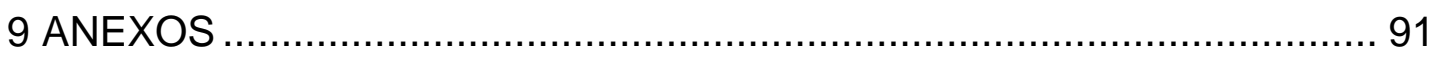

Anexo 1 - Análise dos pacientes previamente tratados .......................... 92

Anexo 2 - Avaliação de sobrevida livre de evento dos pacientes segundo faixa etária e gravidade da anemia aplástica ........... 93

Anexo 3 - Comparação dos achados morfológicos/imunohistoquímicos em crianças com menos de 14 anos e grupo com 14 anos ou mais................................................ 95

Anexo 4 - Resultados de estudos citogenéticos .................................... 96 


\section{LISTAS}

\section{ABREVIATURAS}

AA

AAA

$A L I P$

ASLX1

ATG

Anemia aplástica

Anemia aplástica adquirida

do inglês: abnormally localized immature precursors do inglês: additional sex combs like 1 gene

do inglês: anti-thymocyte globulin

$B C O R / B C O R L 1$ do inglês: BCL6 corepressor/BCL6 corepressor like 1

$\mathrm{BMO}$

Biópsia de medula óssea

CRI

Citopenia refratária da infância

CsA

Ciclosporina A

CSMD1

do inglês: CUB and Sushi multiple domains 1 gene

DNMT3

do inglês: DNA methyltransferase 3 alpha gene

FISH

do inglês: Fluorescent in situ hybridization

$\mathrm{HE}$

hematoxilina e eosina

HPN

Hemoglobinúria paroxística noturna

IFNy

interferon gamma

IHQ

Imuno-histoquímica

ISCN

do inglês: International System for Human Cytogenetic

Nomenclature

LMA Leucemia mieloide aguda

$\mathrm{MO}$

Medula óssea

MPO

mieloperoxidase

OMS

Organização Mundial da Saúde

PIGA

do inglês: phosphatidylinositol glycan anchor biosynthesis class $A$

RUNX1

do inglês: runt related transcription factor 1 gene

SF3B1

do inglês: splicing factor $3 b$ subunit 1

SMD

Síndrome mielodisplásica

SMD-h

Síndrome mielodisplásica hipocelular

SRSF2

do inglês: serine and arginine rich splicing factor 2 gene 
TCR

TET2

$T N F \alpha$

TP53 do inglês: $T$-cell receptor

do inglês: tet methylcytosine dioxygenase 2 gene

do inglês: tumor necrosis factor alpha

do inglês: tumor protein p53 gene 


\section{FIGURAS}

Figura 1 - Artefato de descolamento (HE, 50x) ……............................. 36

Figura 2 - Artefato de hemorragia (HE, 100x) …………………........ 37

Figura 3 - Artefato de fragmentação (HE, 100x) …………………...... 37

Figura 4 - Distribuição irregular do tecido hematopoético em paciente que não evoluiu para SMD/LMA, com área de maior celularidade ao lado de área com celularidade muito baixa (hematoxilina e eosina, 100x)

Figura 5 - Localização anormal de precursores imaturos da série granulocítica ao HE (400x) em paciente de 18 anos que não evoluiu para SMD/LMA

Figura 6 - Localização anormal de precursores imaturos da série granulocítica ao HE (400x) em paciente de 18 anos que não evoluiu para SMD/LMA

Figura 7 - Localização anormal de precursores imaturos da série granulocítica em paciente de 18 anos que não evoluiu à marcação imuno-histoquímica para MPO (elementos granulocíticos em marrom, 400x)....

Figura 8 - Localização anormal de precursores imaturos da série granulocítica em paciente de 18 anos que não evoluiu para SMD/LMA, à marcação imuno-histoquímica para Glicoforina A (elementos eritroides em marrom e granulocíticos em azul) (glicoforina A, 200x)

Figura 9 - Agrupamento de mais de 20 células nucleadas da série eritrocítica ao HE (400x) em paciente de 16 anos que não evoluiu para SMD/LMA

Figura 10 - Agrupamento de mais de 20 células nucleadas da série eritrocítica ao HE (400x) em criança de 4 anos que evoluiu para SMD/LMA

Figura 11 - Agrupamento de mais de 20 células nucleadas da série eritrocítica com formas jovens (seta) (Glicoforina A, 200x) ..... 45

Figura 12 - Agrupamento de mais de 20 células nucleadas da série eritrocítica ao HE (400x) com mitoses (setas)

Figura 13 - Megacariócitos em agregados (HE, 200x) ……………….... 46

Figura 14 - Megacariócitos hipolobados (setas) (HE, 200x)..................... 46 
Figura 15 - Megacariócito binucleado (seta) (HE, 200x) …...................... 47

Figura 16 - Megacariócito multinucleado (seta) (HE, 200x) ..................... 47

Figura 17 - Blasto CD34-positivo entre dois vasos (seta) (CD34, 200x) ... 48

Figura 18 - Reticulogênese grau 2 (de 0 a 4) e grau 1 (de 0 a 3) (coloração para reticulina, 200x) .............................................. 48

Figura 19 - Sobrevida livre de eventos, conforme os critérios de Orazi .... 53

Figura 20 - Sobrevida livre de eventos, conforme os critérios de

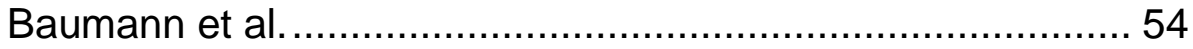

Figura 21 - Índice proliferativo ao Ki-67 alto (90\% das células nesse campo) no tecido hematopoético (Ki-67, 200x) ....................... 55

Figura 22 - Correlação positiva entre celularidade medular e índice

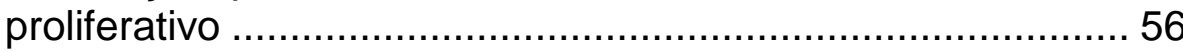

Figura 23 - Índice proliferativo ao Ki-67 alto (aproximadamente 100\% das células nesse campo) no tecido hematopoético de amostra com baixa celularidade (Ki-67, 200x) .

Figura 24 - Índice proliferativo ao Ki-67 baixo (cerca de 5\% das células nesse campo) no tecido hematopoético de amostra com celularidade relativamente mais alta (Ki-67, 200x)

Figura 25 - Biópsia de MO na data do diagnóstico da AAA referente ao paciente 1 (HE, 100x)

Figura 26 - Biópsia de MO na data do diagnóstico da AAA referente ao paciente 2 (HE, 100x)

Figura 27 - Biópsia de MO na data do diagnóstico da AAA referente ao paciente 3 (HE, 100x)

Figura 28 - Biópsia de MO na data do diagnóstico da AAA referente ao paciente 4 (HE, 100x)

Figura 29 - Biópsia de $\mathrm{MO}$ na data do diagnóstico da AAA referente ao paciente 5 (HE, 100x)

Figura 30 - Biópsia de $M O$ na data do diagnóstico da AAA referente ao paciente 6 (HE, 100x)

Figura 31 - Biópsia de $\mathrm{MO}$ na data do diagnóstico da AAA referente ao paciente 7 (HE, 100x) 
Figura 32 - Biópsia de MO na data do diagnóstico da AAA referente ao paciente 8 (HE, 100x)

Figura 33 - Biópsia de $\mathrm{MO}$ na data do diagnóstico da AAA referente ao paciente 9 (HE, 100x)

Figura 34 - Biópsia de $\mathrm{MO}$ na data do diagnóstico da AAA referente ao paciente $10(\mathrm{HE}, 100 \mathrm{x})$

Figura 35 - Biópsia de $\mathrm{MO}$ na data do diagnóstico da AAA referente ao paciente 11 (HE, 100x)

Figura 36 - Biópsia de $\mathrm{MO}$ na data do diagnóstico da AAA referente ao paciente 12 (HE, 100x) 
TABELAS

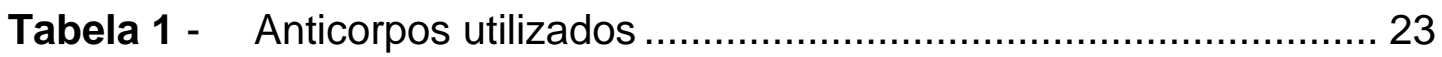

Tabela 2 - Descrição dos grupos total, adulto e pediátrico ……………... 34

Tabela 3 - Descrição do grupo total, que não evoluiu para SMD/LMA e que evoluiu para SMD/LMA ............................................... 35

Tabela 4 - Qualidade das BMO dos grupos total, adulto e pediátrico ...... 39

Tabela 5 - Qualidade das BMO do grupo total, que não evoluiu para SMD/LMA e que evoluiu para SMD/LMA ................................. 39

Tabela 6 - Análise comparativa dos parâmetros Ml entre grupo adulto e pediátrico

Tabela 7 - Análise comparativa dos parâmetros MI entre grupo que evoluiu e que não evoluiu para SMD/LMA ............................... 50

Tabela 8 - Análise comparativa dos parâmetros Ml entre grupo total, adulto e pediátrico que evoluiu e que não evoluiu para SMD/LMA.

Tabela 9 - Correlação entre celularidade e índice proliferativo pelo teste Rô de Spearman .......................................................... 56

Tabela 10 - Resumo dos resultados de citogenética ................................ 58

Tabela 11 - Descrição morfológica resumida dos 12 pacientes que evoluíram para SMD/LMA 


\section{RESUMO}

Marchesi RF. Anemia aplástica adquirida - avaliação da biópsia de medula óssea na identificação de prognóstico desfavorável, aferido pela evolução para SMD /LMA - um estudo comparativo em crianças e adultos [Tese]. São Paulo: Faculdade de Medicina, Universidade de São Paulo; 2017.

Anemia aplástica adquirida (AAA) é doença rara e seu diagnóstico diferencial inclui a Síndrome mielodisplásica hipocelular (SMD-h). A evolução de AAA para SMD/LMA (Síndrome mielodisplásica/Leucemia mieloide aguda) ocorre em até $15 \%$ dos casos. Este estudo propõe-se a comparar parâmetros histológicos e imuno-histoquímicos de pacientes adultos e crianças com AAA que evoluíram e não para SMD/LMA. Seu objetivo é avaliar a ocorrência dos critérios morfológicos/imunofenotípicos nas biópsias de medula óssea do grupo pediátrico (<19 anos) com o grupo de adultos, comparar esses critérios associados à evolução para SMD/LMA nestes dois grupos e verificar se estes critérios superpõem-se àqueles descritos na literatura na SMD-hipocelular do adulto e, mais recentemente, na SMD pediátrica (Citopenia refratária da infância - CRI). Espera-se trazer uma contribuição para a discussão da intersecção entre essas entidades e a AAA, estudando essa "zona cinzenta" do ponto de vista dos pacientes com AAA, particularmente aqueles que progrediram para SMD/LMA. Foram analisadas, retrospectivamente, 118 biópsias de medula óssea ao diagnóstico de AAA, idiopática ou não, realizadas no Hospital das Clínicas da Faculdade de Medicina da Universidade de São Paulo entre 1993 e 2012. O diagnóstico de AAA foi estabelecido de acordo com critérios clássicos. A evolução de AAA para SMD ou LMA foi considerada na presença de: disgranulopoese ou dismegacariopoese acentuadas, mais de $15 \%$ de sideroblastos em anel, blastos em sangue periférico ou mais de $5 \%$ de blastos na medula óssea ao mielograma e/ou à biópsia de medula óssea ou na presença de estudo citogenético (FISH ou cariótipo) da medula óssea, apresentando monossomia ou deleção do braço longo do cromossomo 7. Todas as biópsias foram submetidas à análise morfológica e imuno-histoquímica (MPO, Glicoforina A, Fator VIII, CD34, CD117 e Ki-67) por dois hematopatologistas sem conhecimento prévio da evolução dos pacientes. As variáveis qualitativas nominais foram analisadas pelo teste exato de Fisher para verificar se houve desproporção significativa entre os grupos. As variáveis qualitativas ordinais foram analisadas para a diferença entre os grupos pelo teste de MannWhitney. O nível de significância adotado foi $5 \%(p=0,05)$. A correlação entre os valores de celularidade geral das amostras e seu índice proliferativo foi avaliada pelo teste não paramétrico Rô de Spearman. Setenta e um pacientes $(60,2 \%)$ eram do gênero masculino com mediana de idade 24,4 anos (mínimo de 7 meses até 76 anos), 42 do grupo pediátrico e 76 adultos, e tempo de seguimento de 5,1 anos (de 1 mês a 22,1 anos). Doze (10,2\%) (seis em cada grupo) pacientes evoluíram para SMD/LMA. Avaliação dos parâmetros 
morfológicos e imuno-histoquímicos mostrou distribuição irregular do tecido hematopoético em 59 (50\%) casos, mediana de celularidade geral de $10 \%$ (de $1 \%$ a $40 \%$ ), distúrbio de maturação da série granulocítica (critério 1) em três $(2,5 \%)$ casos, localização anormal da eritropoiese em 13 (11\%) casos, agregados de pelo menos 20 precursores eritroides (critério 2), em 54 (45,7\%) casos, presença de formas jovens eritroides (proeritroblastos) (critério 3) em $32(27,1 \%)$ casos, aumento do número de mitoses dos elementos eritroides (critério 4) em 24 (20,3\%) casos, displasia de megacariócitos (micromegacariócitos, megacariócitos bi ou multinucleados e elementos hipo ou monolobados) (critério 5) em 15 (12,7\%) casos, localização anormal de megacariócitos em quatro $(3,3 \%)$ casos, megacariócitos CD34-positivos não foram identificados, blastos CD34-positivos em 11 (9,3\%) casos, reticulogênese discretamente aumentada (grau 1) em três $(2,5 \%)$ casos e índice proliferativo (Ki-67) com mediana de 30 (de 0\% a 90\%). Critérios descritos por Bennett e Orazi sugestivos de SMD-h (critérios 1 e/ou 5) foram detectados em $16(13,6 \%)$ casos. Critérios descritos por Baumann et al. sugestivos de SMD da infância (critérios $2+3$ com ou sem 4) foram observados em $30(25,4 \%)$ casos. Não houve diferença estatística nos achados morfológicos/imuno-histoquímicos entre a população total, adultos e crianças que evoluíram e que não evoluíram para SMD/LMA, incluindo a presença de critérios Bennett e Orazi para SMD-h do adulto. Houve diferença quanto aos critérios de Baumann et al. para $\mathrm{CRI}$, e o grupo que não evoluiu para SMD/LMA apresentou com mais frequência os critérios do que o que evoluiu $(p=0,036)$, ao contrário do previamente suposto. No entanto, ao testar esta hipótese no grupo adulto separado do pediátrico, a diferença estatística não foi comprovada. Houve uma correlação estatisticamente significante entre os valores da celularidade geral das amostras e seu índice proliferativo $(p<$ 0,001 ). Pacientes adultos e pediátricos com AAA, incluindo os que evoluíram para SMD/LMA, têm características morfológicas/imuno-histoquímicas semelhantes. Algumas alterações descritas por Baumann et al. para SMD pediátrica são também encontradas em casos pediátricos e de adultos com AAA. Além disso, o índice proliferativo pode ser aumentado em casos de AAA, este dado não tem correlação com a evolução para SMD/LMA. Alterações morfológicas/imuno-histoquímicas em biópsias de medula óssea em AAA não identificaram um grupo com maior risco de progressão para SMD/LMA em nossa casuística.

Descritores: anemia aplástica adquirida, aplasia medular, síndrome mielodisplásica, citopenia refratária da infância, leucemia mieloide aguda, biópsia, medula óssea, imuno-histoquímica, blastos, CD34. 


\section{SUMMARY}

Marchesi RF. Acquired aplastic anemia - bone marrow histology complemented by immunohistochemistry in identifying unfavorable prognosis, defined by progression to MDS/AML - a comparison between children and adults [Thesis]. São Paulo: "Faculdade de Medicina, Universidade de São Paulo"; 2017.

Acquired Aplastic Anemia (AAA) is a rare disease which progresses to MDS / AML in up to $15 \%$ of cases. When this happens, hematopathologists are asked whether the diagnosis of hypocellular Myelodisplastic Syndrome (h-MDS) would not have been confused morphologically with aplastic anemia. This study aims to identify morphological/immunophenotypical findings that could predict this adverse prognosis in adults and children $(<19 \mathrm{y})$ diagnosed as AAA and verify if those criteria match with the ones described in literature in adult h-MDS and, more recently, in pediatric MDS (Refractory cytopenia of childhood - RCC), contributing to the discussion of this "grey zone". We retrospectively analyzed 118 patients/bone marrow (BM) biopsies at the moment of AAA diagnosis at Clinical Hospital of São Paulo Medical School from 1993 to 2012. Diagnosis of AAA was carried out according to classical criteria. Evolution to MDS or AML was considered in the presence of at least one of the findings: significant dysgranulopoiesis or dysmegakaryocytopoiesis, more than $15 \%$ ring sideroblasts, blasts in peripheral blood or more than $5 \%$ blasts in bone marrow smear and/or biopsy, or in the presence of monosomy or deletion of the long arm of chromosome 7 by cytogenetic analysis (FISH or karyotype) of the BM. All biopsies were submitted to morphological and immunophenotypic (MPO, Glycophorin A, Factor VIII, CD34, CD117 and Ki67) evaluation by two hematopathologists without previous knowledge about the evolution of the patients. Nominal qualitative variables were analyzed by using Fisher's exact test to check significant disproportion between the groups. The ordinal qualitative variables were analyzed for differences between groups by Mann-Whitney test. The significance level was $5 \%(p=0.05)$. The correlation between the overall cellularity values of the samples and their proliferative index was evaluated by nonparametric Spearman Rô test. Seventy-one $(60,2 \%)$ were male, median age 24.4 years (7 months to 76 years old), 42 belongs to the pediatric group and 76 to the adults group. Median follow-up was $5.1 \mathrm{y}$ (range, 1 month to 22.1 years). Twelve patients (12\%) (6 in each group) progressed to MDS/AML. Evaluation of morphological/immunohistochemical parameters showed irregular distribution of hematopoietic tissue in $59(50 \%)$ cases, median BM overall cellularity of $10 \%$ (range, 1 to $40 \%$ ), marrow dysgranulopoiesis (criteria 1) in $3(2,5 \%)$ cases, abnormal localization of erythropoiesis in $13(11 \%)$ cases, clusters of at least 20 erythroid precursors (criteria 2) in $54(45.7 \%)$ cases, increased number of proerythroblasts (criteria 3 ) in $32(27,1 \%)$ cases, increased number of mitoses of the erythroid elements (criteria 4$)$ in $24(20,3 \%)$ cases, marrow 
dysplasia of megakaryocytes (micromegakaryocytes, two or more separeted nuclei, small round nuclei) (criteria 5) in $15(12,7 \%)$ cases, abnormal localization of megakaryocytes in $4(3,3 \%)$ cases, CD34-positive megakaryocytes were not identified, CD34-positive blast cells (criteria 6) in 11 $(9,3 \%)$ cases, increment in reticulin fibers in $3(2,5 \%)$ cases, and median proliferative index (Ki-67) 30 (range, 0 to $90 \%$ ). Criteria described by Bennett and Orazi suggestive of h-SMD (criteria 1 and/or 5) were detected in 16 $(13,6 \%)$ cases. Criteria described by Baumann et al suggestive of childhood MDS (criteria $2+3$ with or without 4 ) were observed in $30(25.4 \%)$ cases. There was no statistical difference in morphological/immunohistochemical findings among total population, adults and children who developed and did not develop MDS/AML, including the presence of Bennett and Orazi criteria for h-MDS. Regarding Baumann et al criteria were more frequently identified in the group that did not progress to MDS/AML than the one that did $(p=0,036)$, the opposite of what was expected. But when the criteria were tested in pediatric and adults' groups separately, the statistical significance was no longer observed. There was a statistical significant correlation between the overall cellularity values of the samples and their proliferative index $(p=0,001)$. Adult and pediatric patients with AAA, including those that progress to MDS/AML, have similar morphological/immunohistochemical characteristics. Some changes described by Baumann et al for pediatric MDS are also found in pediatric and adults' cases with AAA. In addition, the proliferative index may be increased in cases of $A A A$ and this finding has no correlation with progression to MDS/AML. Morphological/immunohistochemical changes in bone marrow biopsies in AAA have failed to identify a group at higher risk for progression to MDS/AML in our series.

Descriptors: acquired aplastic anemia, bone marrow failure, myelodysplastic syndrome, refractory cytopenia of childhood, acute myeloid leukemia, biopsy, bone marrow, immunohistochemistry, blasts, CD34. 
1 Introdução 


\section{INTRODUÇÃO}

Anemia aplástica (AA) ou aplasia medular, classificada como congênita ou adquirida, é uma doença hematológica rara e heterogênea caracterizada pela redução da produção de eritrócitos, granulócitos e plaquetas, resultando em pancitopenia no sangue periférico, de gravidade variável e, mais raramente, combinações de bicitopenias e monocitopenias podem ocorrer nesta doença. Estas alterações são secundárias à falência da medula óssea, que é substituída por tecido adiposo em grau variável, na ausência de células neoplásicas e de fibrose medular ${ }^{1}$. Até o momento, os mecanismos etiopatogênicos propostos para explicar a insuficiência medular na anemia aplástica adquirida (AAA) são a lesão direta das células primitivas da linhagem hematopoética, a anormalidade subjacente das células hematopoéticas e o mecanismo imunomediado - atualmente o mais aceito e conforme o qual, ocorre agressão e apoptose imunomediada das células tronco e células progenitoras da medula óssea (MO), a partir da produção descontrolada de citocinas incluindo IFNy e TNFa por células T ativadas ${ }^{2}$. Na maioria dos casos, como a determinação da causa da AAA não é possível, é classificada como idiopática. A gravidade da aplasia é determinada pelo critério internacional de Camitta e colaboradores ${ }^{3 ;}$, que classifica a AA em grave, muito grave e não grave, sendo que os pacientes portadores de $A A$ grave $e$ muito grave são os de eleição para o tratamento. A AAA é, com mais frequência, observada em crianças e seu diagnóstico diferencial inclui as falências medulares congênitas e a Síndrome mielodisplásica (SMD), que nessa faixa etária apresenta-se, frequentemente, hipocelular sob a forma de Citopenia refratária da infância (CRI).

A relação entre a $A A A$ e a $C R I$, e como consequência o diagnóstico diferencial entre elas, vem sendo motivo de controvérsia e de dificuldades diagnósticas, clínica e morfologicamente. É fato bem documentado a ocorrência de evolução clonal, incluindo a Hemoglobinúria paroxística noturna (HPN), a SMD e a LMA, em cerca de 10\%-20\% dos pacientes com o 
diagnóstico de AAA nos 10 anos seguintes ao diagnóstico ${ }^{5}$. A frequente escassez de material representativo nos esfregaços das punções de MO, determinada pela sua hipocelularidade, faz com que a biópsia de medula óssea (BMO) torne-se material valioso para a abordagem diagnóstica nessas condições. Poucos dados da literatura vêm abordando esse aspecto de forma sistemática e com casuística representativa, e têm referido de maneira geral a contribuição da BMO no diagnóstico diferencial entre pacientes com diagnóstico de AAA grave nas crianças e CRI 6; 7;8, ou AAA e SMD /LMA hipocelulares nos adultos $9 ; 10 ; 11$.

Este projeto propôs-se a analisar de forma sistemática uma coorte de pacientes pediátricos com diagnóstico de $\mathrm{AAA}$, identificando possíveis parâmetros ao exame histológico complementado com o exame imunohistoquímico que possam identificar os pacientes com evolução para SMD/LMA. Os resultados observados foram comparados com uma coorte de pacientes adultos com diagnóstico de AAA, no sentido de se verificar se existe um comportamento similar dos achados histológicos/imunofenotípicos discriminantes da evolução dessa doença nas duas faixas etárias. 
2 Revisão da Literatura 


\section{REVISÃO DA LITERATURA}

\subsection{ANEMIA APLÁSTICA}

\subsubsection{Definição}

Anemia aplástica é definida como citopenia múltipla com hipoplasia das três linhagens da $M O$ na ausência de neoplasia e aumento das fibras reticulínicas, indicando uma falha básica em produzir elementos hematopoéticos normais. Ela pode ser constitucional/congênita ou adquirida, sendo esta última a mais comum e tipicamente caracterizada por uma destruição autoimune de células progenitoras, que pode ser desencadeada por fatores ambientais/exógenos identificáveis (secundária) ou não ter causa óbvia (idiopática). É classificada conforme sua gravidade em não grave, grave e muito grave e pode se apresentar associada ou não à HPN 12 .

\subsubsection{Epidemiologia}

Trata-se de doença rara cuja incidência varia de dois casos por milhão por ano dentre os americanos ${ }^{13}, 2-3$ na Europa ${ }^{14}, 5,16$ na Coréia ${ }^{15}$ e 1,6 na América Latina ${ }^{16}$. Tem distribuição bifásica com picos entre 10-25 anos e acima dos $60{ }^{14}$. Esta incidência é ainda menor na população pediátrica de 0 a 18 anos ${ }^{17}$.

\subsubsection{Fisiopatologia, diagnóstico e morfologia}

A AAA pode ser idiopática ou secundária. $\mathrm{Na}$ forma idiopática e, provavelmente, em algumas secundárias, as células-tronco parecem sofrer um ataque autoimune mediado por células $T$ ativadas, limitando sua habilidade de manter a hematopoese ${ }^{12}$. Ocorre uma acentuada diminuição do número de células-tronco, chegando a menos de $1 \%$ da população original. 
A fração de células-tronco CD34+ está diminuída na doença e relaciona-se ao grau de severidade. Em especial, é conhecido o papel das células T CD8+, e o das células T CD4+ é menos conhecido, mas, todas parecem ter algum grau de clonalidade com restrição de sequências de TCR ${ }^{17}$.

A AAA secundária pode estar relacionada com uma lista exaustiva de causas, dentre elas, hepatites virais, vírus Epstein-Barr, HIV, enterovírus, produtos químicos (solventes orgânicos, inseticidas, agrotóxicos) e drogas terapêuticas (anticonvulsivantes e anti-inflamatórias).

$O$ primeiro elemento diagnóstico refere-se à quantificação das citopenias, assim definidas como, pelo menos, duas das seguintes: (i) hemoglobina abaixo de $10 \mathrm{~g} / \mathrm{dL}$; (ii) leucopenia menor que $3.500 / \mathrm{mm}^{3}$ (ou neutropenia abaixo de $1.500 / \mathrm{mm}^{3}$ ) e (iii) plaquetopenia menor que $50.000 / \mathrm{mm}^{3}$. A morfologia avaliada por meio da biópsia de MO mostra redução da celularidade a $25 \%$ do valor normal para a idade ou redução significativa da hematopoese (menos de 30\% de tecido hematopoético, incluindo as três linhagens) em contexto de hipocelularidade (menos de $50 \%$ do normal para a idade) ${ }^{12}$. Dosagens de vitamina B12, folato e perfil de autoanticorpos devem ser realizadas. $O$ segundo elemento diagnóstico importante refere-se à exclusão de AA constitucional (anemia de Fanconi, entre outras) e de neoplasias substituindo as linhagens hematopoéticas na MO (tricoleucemia, LMA e leucemias linfoblásticas agudas), uma vez que todas podem se apresentar com hipocelularidade da MO. O terceiro elemento envolve a tentativa de identificação de causa desencadeante. E, finalmente, verificar a presença do clone de HPN por citometria de fluxo, que prediz boa resposta ao tratamento imunossupressor ${ }^{12}$.

Morfologicamente, observa-se aplasia das três linhagens celulares. Grupamentos de células eritroides com número aumentado de eritroblastos imaturos, particularmente, proeritroblastos e micromegacariócitos estão caracteristicamente ausentes. Linfócitos, plasmócitos e mastócitos podem estar focalmente aumentados ou dispersos e após terapia imunossupressora, o quadro histológico pode mimetizar o da CRI ${ }^{6}$. 


\subsubsection{Tratamento}

No grupo etário pediátrico, a indicação do tratamento depende da classificação da AAA. Os pacientes com AAA grave e muito grave têm terapêutica bem definida. Nos casos em que o paciente dispõe de doador compatível, o transplante de células tronco hematopoéticas é o tratamento de escolha, especialmente ao grupo de pacientes jovens. Para os indivíduos sem doador compatível, aplica-se a terapia imunossupressora com imunoglobulina antitimocítica (ATG) associada à Ciclosporina A (CsA) que, até o momento, é a terapia de escolha e resulta em taxa de resposta entre $60 \%$ e $80 \%$. Aproximadamente $20 \%$ a $40 \%$ dos pacientes são refratários a esse tratamento e requerem nova terapêutica imunossupressora ou transplante de $\mathrm{MO}$, que promove maior sobrevida livre de transformação clonal. A complicação mais grave do uso crônico de imunossupressores é o desenvolvimento de doença clonal. Esta condição, provavelmente, está relacionada ao aumento da sobrevida decorrente do uso de imunossupressores, que favoreceria a aquisição de anormalidades cromossômicas e o desenvolvimento de SMD e expansão de clones da HPN ${ }^{5}$.

Pela citometria de fluxo, é possível detectar células de HPN nos pacientes com AAA e os que apresentam baixo percentual de populações clonais têm melhor resposta aos imunossupressores ${ }^{18}$. Ao longo da evolução da doença, 2,1\% a 19\% dos casos podem evoluir com expansão deste clone e hemólise, mas a razão disso permanece desconhecida 5 .

\subsubsection{Alterações genéticas e evolução clonal}

As anormalidades citogenéticas mais comumente detectadas incluem trissomia do cromossomo 8 , trissomia do 6 , deleção do $5 q$ e anormalidades do cromossomo 13. Atenção especial deve ser dada à presença de monossomia do cromossomo 7 , particularmente em crianças, que deve alertar para o diagnóstico de SMD, dado que estas possuem prognóstico reservado 
e quadro clínico caracterizado por CRI ou LMA ${ }^{19}$. A questão que permanece é se essa evolução é resultado de um defeito preexistente em uma célulatronco ou de uma imprecisão morfológica no diagnóstico inicial da doença ${ }^{20}$. Geralmente, o clone encontrado na AAA é pequeno, sendo visualizado em uma pequena porcentagem das metáfases e pode ser transitório. Na trissomia do cromossomo 8, há alterações imunológicas que se assemelham às da AAA e estes pacientes respondem ao tratamento imunossupressor ${ }^{19}$. Anormalidades genéticas somáticas clonais vêm sendo detectadas em vários trabalhos. A teoria mais aceita para explicar esse fenômeno tem sido a do "gargalo de garrafa", em que as células-tronco mais resistentes ao ataque dos linfócitos $\mathrm{T}$ têm uma vantagem proliferativa e, durante a recuperação da hematopoese após intervenção com imunossupressores, aumentam sua replicação levando à expansão do clone mutante resistente ${ }^{21}$. A frequência dessas mutações varia, alguns trabalhos mostram $4 \%$ a $11 \%$ dos casos de AA $^{22 ;}$, 23 outros de um terço até $67 \%$ dos pacientes com mutações somáticas, que costumam ocorrer precocemente no curso da doença, aumentam de frequência conforme a idade e que, geralmente, ocorrem como mecanismo de escapar à resposta imune e aumentar a taxa de proliferação hematopoética, sem necessariamente se correlacionar com prognóstico ${ }^{24 ; 25}$. A hematopoese clonal pode ocorrer mesmo em pacientes que não desenvolvem doença clonal maligna, isso vem sendo denominado hematopoese clonal de potencial indeterminado 22; 26; 27. Mutações dos genes PIGA e BCOR/BCORL1 são estáveis ao longo do curso da doença. No entanto, há trabalhos que mostram que cerca de $19 \%$ dos casos de AA apresentam mutações somáticas "desfavoráveis", incluindo mutações nos genes ASXL1, RUNX1, CSMD1e $D N M T 3 A$, que predispõem a uma evolução mais rápida para SMD, pior sobrevida e pior resposta a imunossupressores 22; 23; 28; 29 . O encurtamento telomérico é observado, com frequência, em granulócitos e linfócitos periféricos dos pacientes com AAA e parece ter relação com pior resposta ao tratamento e maior risco de progressão para SMD 30; 31 . Acima de tudo, 0 contexto clínico em que os clones "desfavoráveis" surgem parece ser 
importante e as alterações genéticas atualmente identificadas por NGS (next generation sequencing) precisam ser interpretadas com cautela ${ }^{32}$.

\subsection{SÍNDROME MIELODISPLÁSICA}

\subsubsection{Definição}

As Síndromes Mielodisplásicas são um grupo heterogêneo de neoplasias clonais hematopoéticas, caracterizadas por hematopoiese inefetiva que se manifestam com citopenia(s), displasia morfológica de 1 ou mais linhagens hematopoéticas e propensão à progressão para LMA ${ }^{33}$. Clinicamente, os pacientes apresentam-se com citopenia(s) persistente(s) (mais de 6 meses) sem causa definida, já que outras doenças sistêmicas podem estar associadas à citopenia(s) e displasia, como as doenças autoimunes, neoplasias, falência renal ou hepática e infecções sistêmicas. Mais de $80 \%$ dos pacientes apresentam anemia e cerca de $15 \%$, pancitopenia 34.

\subsubsection{Epidemiologia}

Na população geral, sua incidência é 4,9 por 100.000 pessoas por ano em adultos ${ }^{35}$; em homens idosos (acima de 70 anos) aumenta para até 59,8. Além disso, é 5.000 vezes maior em adultos em relação às crianças nos Estados Unidos da América ${ }^{36}$. Há diferença das características da neoplasia em relação a etnia. Recentemente, um estudo latino-americano de 1.080 pacientes com SMD de novo mostrou que os brasileiros apresentam maior porcentagem da SMD com excesso de blastos (antiga anemia refratária com excesso de blastos), mas não houve diferença quanto à estratificação de risco citogenético entre brasileiros, argentinos e chilenos ${ }^{37}$. 


\subsubsection{Fisiopatologia, diagnóstico e morfologia}

A patogênese da doença é extremamente complexa e heterogênea, envolve fatores ambientais, incluindo tratamentos medicamentosos e história familiar. Atualmente, com sequenciamento genético de última geração, numerosas mutações vêm sendo relacionadas à doença ${ }^{38}$.

O diagnóstico envolve avaliação morfológica do esfregaço de sangue periférico bem como do aspirado de $\mathrm{MO}$ e da BMO em contexto clínico compatível, além de dados laboratoriais e citogenéticos/moleculares. São prérequisitos citopenia periférica persistente em uma ou mais das três linhagens e exclusão de outras doenças hematopoéticas ou não hematopoéticas como causa primária da citopenia, a menos que haja excesso de blastos ou alterações $\quad$ genéticas compatíveis com 0 diagnóstico ${ }^{39}$.

Os critérios-chave para o diagnóstico são a contagem de blastos e a displasia, também utilizados para a subclassificação da doença. Critérios decisivos incluem a) pelo menos $10 \%$ das células de, pelo menos, uma linhagem deve ser displástica, sendo a eritroide a mais frequente; b) 15\% ou mais sideroblastos em anel ou $5 \%$ ou mais na presença de mutação do SF3B1; c) contagem de blastos de 5\% a 19\% e/ou alterações genéticas típicas, d) presença de anormalidades citogenéticas clonais definidoras de SMD (del(5q), monossomia do 7, del(7q) e outras) ${ }^{39 ; 40 ; 41}$ O valor da BMO é bem estabelecido e permite a avaliação acurada da celularidade, linhagem predominante, alterações estromais, dismegacariocitopoese e alterações na distribuição arquitetural dos elementos das três linhagens hematopoiéticas. Esta última inclui a observação de ALIPs (abnormally localized immature precursors - precursores mieloides imaturos anormalmente localizados), relacionados a um subtipo de SMD mais agressivo, com maior incidência de progressão para LMA 42.

A técnica imuno-histoquímica (IHQ) é um recurso complementar importante utilizado em biópsias; ajuda não só a definir as alterações displásicas e arquiteturais das diferentes linhagens celulares, assim como a 
proporção e distribuição dos blastos CD34 positivos ${ }^{43 ; 44 ; 45}$. O uso do antígeno CD34 é muito útil na marcação e, consequentemente, a estimativa da proporção de blastos na identificação dos ALIPs, bem como na marcação de megacariócitos alterados, expressando de forma anômala este marcador no citoplasma ${ }^{42}$. Além disso, a presença de agregados celulares CD34 positivos (>2 células) é um fator de risco independente para progressão para LMA ${ }^{46}$. Nos casos em que os blastos mieloides são CD34 negativos, o CD117 pode ser aplicado como marcador alternativo, devendo, entretanto, ser levada em consideração sua expressão adicional em mastócitos e precursores da série eritroide. O painel imuno-histoquímico mínimo inclui CD34, CD117 e marcadores de megacariócitos, como CD61, CD42 e FVIII, e para mastócitos, como a triptase de mastócitos. Marcadores para as diferentes linhagens e para excluir doenças na MO não relacionadas à SMD, como os linfomas, também são úteis ${ }^{43}$. O exame IHQ como técnica de avaliação complementar ao exame morfológico tem assumido importância crescente na avaliação diagnóstica das doenças que acometem a MO, levando, mais recentemente, os pesquisadores a desenvolver grupos de trabalho com a finalidade de padronização

e controle externo de qualidade ${ }^{47}$.

\subsubsection{Alterações genéticas}

Em 50\% dos casos são detectadas anormalidades cromossômicas, nenhuma específica da doença; sendo as mais frequentes a deleção dos braços longos dos cromossomos 5, 7 e 20, monossomia do cromossomo 7, trissomia do 8 e cariótipos complexos que podem ser analisadas por estudo de cariótipo convencional (banda G) e por FISH (fluorescent in situ hybridization) ${ }^{35 ; 48 ; 49 ; 50 . ~ A s ~ m e s m a s ~ a l t e r a c ̧ o ̃ e s ~ o c o r r e m ~ e m ~ p a c i e n t e s ~ c o m ~}$ SMD-h. Anormalidades cromossômicas numéricas dos cromossomos 7 e 8 (monossomia do 7 e trissomia do 8 ) ${ }^{51}$ e cariótipos complexos estão associados a maior risco de transformação leucêmica $52 ; 53 ; 54$. A monossomia do cromossomo 7 é a anormalidade citogenética com mais frequência 
observada na evolução clonal (para SMD ou LMA) a partir da AA 5; 55 . Atualmente, com o advento do sequenciamento genético de última geração, observou-se que quase $90 \%$ dos pacientes com SMD apresentam, pelo menos, uma mutação somática dentre os 40 grupos de genes mais frequentemente mutados em neoplasias mieloides, dentre eles, os genes TET2, DNMT3A, ASLX1, TP53, SRSF2, SF3B1 e RUNX1, e isso pode estar relacionado a prognóstico ${ }^{56}$. Uma nova proposta de estratificação de risco foi proposta com base nas novas descobertas da relação entre mutações genéticas e prognóstico. $O$ modelo baseado apenas no perfil dos genes mutados foi similarmente efetivo ao IPSS-R em estratificar risco, mas, quando combinado ao perfil clínico dos pacientes (com idade, gênero, citopenias, contagem de blastos e citogenética), foi superior em termos de eficiência em relação ao IPSS-R isolado ${ }^{57}$.

\subsubsection{Síndromes Mielodisplásicas na infância}

As SMD são muito incomuns na infância. Sua incidência anual por milhão é de 1-2 em crianças contra 40 nos adultos ${ }^{58}$, correspondendo a menos de $5 \%$ de todas as neoplasias hematopoiéticas em pacientes com menos de 14 anos ${ }^{10}$. A maioria dos casos é idiopática/de novo, 23,9\% estão associadas à doença constitucional/herdada e 7,4\%, à terapia. Muitas das características morfológicas, imunofenotípicas e genéticas observadas nas SMD dos adultos também o são em crianças, mas há algumas diferenças significativas 58 ; 59 .

Muitos fatores podem dificultar o diagnóstico em crianças como: idade do indivíduo, quanto mais jovem, menos pronunciadas são as características displásticas; anemia isolada, que é a principal manifestação no adulto, é incomum na criança, que se apresenta com maior frequência com neutropenia e trombocitopenia; hipocelularidade é mais comumente observada em crianças, variando de $11 \%$ a $60 \%$ dos casos e podendo exceder $70 \%$ nos de baixo grau. Este fator pode levar à confusão diagnóstica com AA ou outras doenças que cursem com falência de $\mathrm{MO}$ em crianças. Anormalidades no 
cromossomo 7 são vistas com maior frequência nas crianças, cerca de $30 \%$ $40 \%$ dos casos contra $10 \%$ dos adultos $58 ; 59$. Em uma análise retrospectiva sobre SMD em 67 crianças, 32 apresentaram monossomia do cromossomo 7 e 15 progrediram para uma forma avançada de SMD ${ }^{60}$. A presença de cariótipos estruturalmente complexos (três ou mais aberrações cromossômicas, incluindo, pelo menos, uma aberração estrutural) é fator de risco independente para predizer pior prognóstico em crianças com SMD avançada ${ }^{61}$.

Citopenia refratária da infância $(\mathrm{CRI})$ é uma SMD caracterizada por citopenia persistente com menos de $5 \%$ de blastos na $\mathrm{MO}$ e menos de $2 \%$ no sangue periférico. Apesar de ser necessária a displasia morfológica para 0 diagnóstico, isto é apenas um dos aspectos. A avaliação de uma amostra adequada de $\mathrm{MO}$ é indispensável e cerca de $75 \%$ das crianças apresentam hipocelularidade da MO. Esta é uma entidade provisória pela Organização Mundial da Saúde (OMS) de 2008 e continua sendo pela OMS de $2016{ }^{41}$. É o tipo mais comum de SMD da infância, correspondendo a $50 \%$ dos casos ${ }^{6 ;}$.

O quadro clínico inclui astenia, sangramentos, febre e infecções. Hepatoesplenomegalia não é uma manifestação característica. Mais de $20 \%$ dos pacientes não mostram sinais ou sintomas. Três quartos dos pacientes apresentam trombocitopenia; metade, anemia e um quarto, leucopenia. Macrocitose (hemácias) é encontrada na maioria dos pacientes ${ }^{7}$.

Critérios morfológicos mínimos para o diagnóstico ao aspirado de $\mathrm{MO}$ incluem alterações displásicas em, pelo menos, 10\% dos precursores eritroides e granulocíticos/neutrófilos, bem como micromegacariócitos inequívocos ou núcleos hipolobados ou multinucleação de megacariócitos. À $\mathrm{BMO}$, alguns agregados de, pelo menos, 20 precursores eritroides devem ser identificados, bem como número aumentado de proeritroblastos e de mitoses; não há critérios mínimos para a série granulocítica. Em geral, os megacariócitos encontram-se reduzidos em número ou mesmo ausentes, sendo difícil identificar as características displásticas acima descritas. Vale ressaltar que a ausência de megacariócitos não exclui o diagnóstico de CRI. 
Aumento no número de células CD34-positivas, assim como na AA não é observado. O grande diferencial morfológico entre CRI e AA na infância é que, nesta última, a série eritroide está ausente ou apresenta apenas pequenos focos de até 10 precursores com maturação preservada e os megacariócitos não mostram qualquer característica displástica ${ }^{7}$.

A presença de anormalidade genética é importante na confirmação diagnóstica da CRI. Em amostras com celularidade normal ou aumentada, o número de pacientes com monossomia do cromossomo 7 e sem resultados avaliáveis é $19 \%$ e $8 \%$, respectivamente. Quando a amostra é hipocelular, o que ocorre em cerca de $80 \%$ das CRI, a identificação de monossomia do cromossomo 7 cai para $9 \%$ e o número de casos inconclusivos sobe para $16 \%$ 6.

Diagnósticos diferenciais incluem uma série de doenças, como infecções, sobretudo as virais, deficiência de vitamina B12 e folato, HPN, doenças autoimunes, doenças geneticamente herdadas de falência da $\mathrm{MO}$, como anemia de Fanconi, disqueratose congênita e outras 7. Morfologicamente, o diagnóstico de CRI é indistinguível dessas doenças, por isso, a correlação com a clínica é essencial. O tratamento consiste em transplante de $\mathrm{MO}$, que é a única terapia curativa, mas agentes imunossupressores também podem ser utilizados.

\subsection{CONSIDERAÇÕES SOBRE O DIAGNÓSTICO DIFERENCIAL ENTRE AAA E SMD HIPOPLÁSICA}

A incidência de transição de AAA para LMA é discutida há muitos anos e isso, parcialmente, se explicou quando foi reconhecida uma forma hipocelular da SMD (SMD-h). Como a AAA é muito heterogênea em termos de etiologia, é possível admitir que haja uma via patogenética no sentido da evolução para LMA; no entanto, a SMD é, reconhecidamente, uma doença clonal neoplásica, com maior risco de se transformar ${ }^{62}$. Bennett e Orazi ${ }^{11}$ estudaram critérios diagnósticos para distinguir LMA e SMD-h da AAA em 
adultos e relatam que as dificuldades variam desde a definição de "hipocelularidade" até a real distinção entre essas entidades. Eles estabeleceram um limite mínimo de $5 \%$ de blastos na MO, na ausência de displasia significativa, para o diagnóstico de SMD e menos que $1 \%$ de blastos na AAA. A presença de megacariócitos facilmente identificáveis em uma $\mathrm{MO}$ desorganizada e a detecção de aumento da reticulogênese favorecem SMD, bem como a identificação dos ALIPs, importante contribuição da biópsia nesses casos. Ainda assim, critérios diagnósticos não estão bem estabelecidos. Clinicamente, os pacientes com SMD-h têm pior evolução que a AAA, mesmo que o grau de citopenia da AAA seja maior. $O$ tratamento utilizado vem sendo semelhante para as duas doenças e os pacientes com SMD-h recebem-no com menos frequência que os com AAA, provavelmente, pelo menor grau de citopenia. No entanto, a evolução da SMD-h sugere que algum tratamento seja ministrado a esses pacientes independente da citopenia e no sentido de prevenir a conversão para leucemia, utilizando agentes hipometilantes ou transplante de $\mathrm{MO}$, considerando-se o risco a longo prazo de conversão de SMD para LMA com o uso de imunossupressores. Há casos em que o diagnóstico inicial de SMD-h é alterado para AAA e, viceversa, durante a evolução e apenas pesquisa e experiência podem mudar essa realidade ${ }^{63}$. Em crianças, este diferencial é ainda mais desafiador, considerando-se que metade dos casos de SMD são hipocelulares, correspondendo à $\mathrm{CRI}$ 20; 33. Atualmente, discute-se a possibilidade de considerar, como SMD-h, os casos de AAA com mutações genéticas consideradas desfavoráveis ${ }^{23}$. 
3 Objetivos 


\section{OBJETIVOS}

\subsection{OBJETIVO PRINCIPAL}

1. Avaliar parâmetros morfológicos/imuno-histoquímicos em BMO de portadores de AAA que possam predizer evolução clínica para SMD e/ou LMA.

\subsection{OBJETIVOS SECUNDÁRIOS}

1. Comparar a ocorrência dos critérios morfológicos/imuno-histoquímicos nas BMO do grupo pediátrico ( $<19$ anos) com o grupo de adultos.

2. Comparar o comportamento de critérios morfológicos/imunohistoquímicos associados à evolução para SMD/LMA no grupo etário pediátrico com o grupo de adultos.

3. Verificar se esses critérios superpõem-se àqueles descritos na literatura na SMD-h do adulto e, mais recentemente, na SMD pediátrica (CRI), contribuindo para a discussão da interface entre essas entidades e a AAA.

4. Verificar se existem evidências de proliferação celular avaliada por meio do Ki-67 nos casos de AAA em crianças e adultos.

5. Verificar se estão presentes blastos CD34-positivos nos casos de AAA em crianças e adultos. 
4 Casuística e Métodos 


\section{CASUÍSTICA E MÉTODOS}

\section{CASUÍSTICA}

Para este estudo, foram selecionados, inicialmente, 180 pacientes diagnosticados com Anemia Aplástica Adquirida (AAA) referidos no Instituto da Criança da Faculdade de Medicina da Universidade de São Paulo e no Serviço de Hematologia do Hospital das Clínicas da Faculdade de Medicina da Universidade de São Paulo entre 1993 e 2012.

Foram excluídos os pacientes com falências medulares constitucionais e síndromes que se relacionam com progressão para LMA, como a Síndrome de Down, deleções mitocondriais (síndrome de Pearson), doenças herdadas de falência da medula óssea (Anemia de Fanconi por teste de DEB, disqueratose congênita por clínica ou estudo de comprimento telomérico) e anemia adquirida durante recuperação hematológica. Tais critérios foram revisados a partir dos prontuários dos pacientes e dos resultados evolutivos dos exames laboratoriais, incluindo exames citogenéticos/moleculares utilizados para diagnóstico dessas doenças.

Critérios de inclusão constituíram pacientes com AAA idiopática ou secundária que tinham material de $\mathrm{BMO}$ avaliável ao diagnóstico ou à admissão nos serviços referidos acima. Inicialmente, foram excluídos 22 pacientes, pois não havia material disponível para estudo anatomopatológico no Serviço (material retirado do arquivo pelos próprios pacientes). Dentre os pacientes restantes (158), não foi possível obter o prontuário, em espécie ou eletrônico, de 12 pacientes, por questões administrativas e logísticas do Hospital das Clínicas, inviabilizando avalição adequada do seguimento clínico dos mesmos, resultando 146 pacientes. Destes, nove foram excluídos por insuficiência quantitativa do material anatomopatológico, restando um total de 137 pacientes. Os 15 pacientes que vieram de outros serviços já em tratamento com imunossupressores também foram excluídos (vide Anexo 1), restando 122 pacientes. Após a análise morfológica do material, quatro 
pacientes foram excluídos por apresentar celularidade medular preservada para a idade cronológica ao diagnóstico, resultando um total final de 118 pacientes.

Melhora clínica com resposta ao tratamento proposto para AAA excluiu os pacientes da pesquisa de evolução para SMD/LMA. A evolução da doença de AAA para SMD ou LMA foi considerada na presença de: disgranulopoese ou dismegacariocitopoese importantes, mais de $15 \%$ de sideroblastos em anel, blastos em sangue periférico ou mais de $5 \%$ de blastos na medula óssea ao mielograma e/ou à BMO ou na presença de estudo citogenético (FISH ou cariótipo) da medula óssea apresentando monossomia ou deleção do braço longo do cromossomo $7^{33}$.

A pesquisa foi aprovada pela Comissão de Ética para Análise de Projetos de Pesquisa (CAPPesq) da Diretoria Clínica do Hospital das Clínicas da Faculdade de Medicina da Universidade de São Paulo sob o Protocolo de Pesquisa Número do Parecer: 249.707 com data da Relatoria: 06/03/2013 (Parecer consubstanciado do CEP).

\subsection{MÉTODOS}

\subsubsection{Coleta de dados clínicos}

A coleta de dados clínicos foi realizada para todos os pacientes que dispunham de prontuário no arquivo do Hospital das Clínicas e Instituto da Criança, sendo observados os seguintes dados:

- Data de nascimento e gênero;

- Data da admissão e da biópsia de medula óssea;

- Uso de medicamentos e doenças de base ao diagnóstico;

- Medicamentos utilizados para o tratamento da AAA

* CsA

${ }^{*}$ ATG

* corticoides 
- Datas e resultados de testes citogenéticos; e

- Data do evento final para o objetivo do trabalho:

* data do transplante de medula óssea

* data da evolução para SMD/LMA (data do exame que definiu tal diagnóstico)

* data da última consulta ao seguimento

* data do óbito

\subsubsection{Achados laboratoriais e morfológicos}

Os achados morfológicos foram observados em esfregaços de sangue periférico $(\mathrm{SP})$, de $\mathrm{MO}$ e $\mathrm{BMO}$ à data do diagnóstico da $\mathrm{AAA}$.

\subsubsection{Hemograma}

Os hemogramas foram realizados pelo Laboratório Central do Instituto Central do HCFMUSP e foram computados como relevantes para diagnóstico de aplasia medular a presença de, pelo menos, dois dos três critérios: hemoglobina abaixo de $10 \mathrm{~g} / \mathrm{dL}$; leucopenia menor que $3.500 / \mathrm{mm}^{3}$ (ou neutropenia abaixo de $1.500 / \mathrm{mm}^{3}$ ) e plaquetopenia menor que $50.000 / \mathrm{mm}^{3}$. Os critérios de gravidade foram determinados conforme Camitta e cols. ${ }^{3}$ do seguinte modo:

- grave (medula óssea com celularidade $<25 \%$ ou $25 \%$ a $50 \%$ com $<30 \%$ de células hematopoéticas residuais associadas a, pelo menos, dois dos seguintes parâmetros em SP: neutrófilos $<500 / \mathrm{mm}^{3}$, plaquetas $<20.000 / \mathrm{mm}^{3}$, reticulócitos $<20.000 / \mathrm{mm}^{3}$ );

- muito grave (mesma definição de anemia aplástica grave associada a

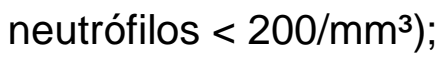

- não grave (paciente que não preencheram os critérios anteriormente citados). 


\subsubsection{Mielograma}

Os aspirados medulares ou "imprints" das BMO foram realizados e avaliados por médicos capacitados do SH-HCFMUSP. As lâminas foram submetidas à coloração de Leishman e de Perls.

A análise morfológica foi realizada sempre que possível em 250 células para determinação da contagem diferencial, incluindo o número de blastos e determinação de displasia. Na presença de mais de $50 \%$ de eritroblastos, os blastos mieloides foram determinados dentro das células não eritroides ${ }^{33}$.

A presença de displasia foi avaliada nas três séries hematopoéticas, obedecendo aos critérios da OMS (2008) como a presença de displasia em, pelo menos, $10 \%$ de células de uma determinada linhagem.

A coloração de Perls (coloração de azul da Prússia) foi utilizada para determinação do percentual de sideroblastos em anel em 100 eritroblastos. Sideroblasto em anel é definido pela presença de, pelo menos, cinco grânulos de ferro com distribuição perinuclear circundando, pelo menos, um terço do núcleo ${ }^{64}$.

\subsubsection{Biópsia de medula óssea}

As biópsias de $\mathrm{MO}$ dos pacientes foram obtidas do arquivo da Divisão de Anatomia Patológica do Instituto Central do Hospital das Clínicas, sendo avaliados os parâmetros a seguir pela patologista orientada do Projeto e, a seguir, pela patologista orientadora, revistos em conjunto os casos de dúvida em microscópio de duas cabeças. O diagnóstico de AAA foi realizado pelo achado em BMO de redução da celularidade a $25 \%$ do valor normal para a idade ou redução significativa da hematopoese (menos de $30 \%$ de tecido hematopoético, incluindo as três linhagens) em contexto de hipocelularidade (menos de $50 \%$ do normal para a idade) ${ }^{12}$, associado a critérios clínicolaboratoriais ${ }^{1}$. 
Para análise das BMO, foram utilizadas as colorações de Hematoxilina e Eosina $(\mathrm{HE})$, reticulina e reações imuno-histoquímicas, usando os anticorpos primários relatados nos dados da Tabela 1.

Tabela 1 - Anticorpos utilizados

\begin{tabular}{lcccc}
\hline \multicolumn{1}{c}{ Antígeno } & Clone & Marca & Diluição & $\begin{array}{c}\text { Linhagem/Padrão de } \\
\text { marcação }\end{array}$ \\
\hline Mieloperoxidase & $\begin{array}{c}\text { Policlonal } \\
\text { coelho }\end{array}$ & Dako & $1: 12.000$ & $\begin{array}{c}\text { Série } \\
\text { Glicoforina A }\end{array}$ \\
JC159 & Dako & $1: 10.000$ & $\begin{array}{c}\text { Série eritrocítica/membranoso } \\
\text { Série }\end{array}$ \\
Fator VIII & F8/86 & Dako & $1: 2.000$ & $\begin{array}{c}\text { megacariocítica/citoplasmático } \\
\text { Blastos mieloides e }\end{array}$ \\
CD34 & QBEnd 10 & Novocastra & $1: 100$ & $\begin{array}{c}\text { magacariócitos/membranoso } \\
\text { e citoplasmático }\end{array}$ \\
CD117 & C-kit & Dako & $1: 500$ & $\begin{array}{c}\text { Blastos mieloides e } \\
\text { mastócitos/membranoso } \\
\text { Núcleos em fase }\end{array}$ \\
Ki-67 & MIB-1 & Dako & $1: 100$ & \begin{tabular}{c} 
puliferativa/nuclear \\
\hline
\end{tabular}
\end{tabular}

\subsection{Parâmetros morfológicos e imuno-histoquímicos analisados}

1. Tamanho da biópsia no maior eixo (em milímetros) - o comprimento ideal é $2,0 \mathrm{~cm}$; no entanto, $1,0 \mathrm{~cm}$ pode conter material suficiente para diagnóstico ${ }^{65}$.

2. Número de espaços intertrabeculares - pelo menos dez devem ser avaliados ${ }^{33}$.

3. Amostra subcortical: S (sim) ou N (não).

4. Artefatos: $\operatorname{Sim}(\mathrm{S})$ ou Não $(N)$; se $S$ - intensidade: $1+$ a $3+$, incluindo hemorragia $(H)$, fragmentação $(F)$, arrancamento $(A)$ e pinçamento $(P)$.

5. Distribuição irregular do tecido hematopoiético: S ou N.

6. Celularidade geral

a. Dado numérico (\%) - estimativa visual 66 
b. Em relação à idade cronológica: 2 (aumentada), 1 (normal) ou 0 (diminuída).

7. Série granulocítica (HE e IHQ - mieloperoxidase):

a. Celularidade:

- Dado numérico da proporção de tecido hematopoético presente na amostra em relação ao tecido adiposo (\%) - estimativa visual;

- Em relação à idade cronológica: 2 (aumentada), 1 (normal) ou 0 (diminuída);

b. Distúrbio de arquitetura/maturação - localização anômala de precursores imaturos (ALIP): S ou N;

Precursores imaturos anormalmente localizados (ALIP abnormally localized immature precursors): achado de, pelo menos, três agregados (3-5 células) ou agrupamentos (mais de 5 células) de blastos localizados na porção central da medula óssea, separados de estruturas vasculares e superfícies trabeculares ${ }^{42}$.

8. Série eritrocítica (HE e IHQ - glicoforina A):

a. Celularidade:

- Dado numérico da proporção de elementos da SV em relação aos elementos nucleados da $\mathrm{MO}(\%)$ - estimativa visual;

- Em relação à idade cronológica: 2 (aumentada), 1 (normal) ou 0 (diminuída);

b. Distúrbio arquitetural: Sim ou Não - desorganização das colônias de eritroblastos e presença de grupamentos de eritroblastos em região peritrabecular;

c. Agrupamentos/colônias com 20 células nucleadas ou mais: $\mathrm{S}$ ou $\mathrm{N}$ 7

d. Presença de formas jovens caracterizadas por proeritroblastos: $\mathrm{S}$ ou $\mathrm{N}^{7}$; 
e. Presença de mitoses: $\mathrm{S}$ ou $\mathrm{N}^{7}$;

f. Presença de atipias citológicas: $c+d+e$ ou $c+d$ ou $c+e$ ou $d+e$, dentre os itens acima.

9. Relação série granulocítica-série eritrocítica (HE e IHQ - MPO e Glicoforina A).

10. Série megacariocítica (HE e IHQ - FVIII):

a. Celularidade:

- Número de células na amostra: $<10$ 67, 10 a 24, > ou = 25 células 68 ;

- Celularidade: 2 (aumentada), 1 (normal) ou 0 (diminuída).

b. Características displásticas: $\mathrm{S}$ ou $\mathrm{N}$ - características de megacariócitos displásticos (presentes em mais de 10\% dos elementos da amostra ${ }^{68}$ ): micromegacariócitos - tamanho semelhante ao do promielócito, megacariócitos binucleados pequenos, megacariócitos multinucleados - núcleos pequenos separados, megacariócitos com núcleo redondo - não lobulado ${ }^{67}$.

c. Distúrbio de arquitetura: $\mathrm{S}$ ou $\mathrm{N}$ - localização atípica na borda endosteal a agregados de duas células ou mais sem células intervenientes 69 .

d. Avaliação do CD34: positivo (>ou=20\% de todos os megacariócitos da biópsia) ou negativo $(<20 \%)^{70}$.

11. Blastos (HE e IHQ - CD34 e CD117)

a. Dado numérico $(\%):<1 ; 1-5 ; 6-10 ; 10-20 ;>20$;

b. Distribuição: I ou A - Isolados (I) - 1 célula ou Agregados (A) - duas ou mais células ${ }^{46}$.

12. Contagem de índice proliferativo (IHQ - Ki-67): estimativa visual em porcentagem (\%) de células marcadas em relação ao total de células 
nucleadas avaliadas em uma superfície de $10 \mathrm{~mm}^{2}$ ou no total de superfície da amostra ${ }^{10}$.

13. Reticulogênese (coloração de prata para reticulina)

a. Semiquantificação de 0 a $3^{71}$

- MF 0: reticulina linear esparsa;

- MF 1: rede de reticulina com várias interseções, especialmente, perivasculares;

- MF 2: aumento difuso e intenso com extensas interseções, feixes de colágeno focais e/ou osteosclerose focal;

- MF 3: aumento difuso e intenso com muitas interseções e bandas densas de colágeno, geralmente, associada à osteosclerose significativa.

b. Semiquantificação de 0 a $4^{72}$

- 0: sem fibras demonstráveis de reticulina;

- 1+: apenas fibras individuais finas ocasionais;

- 2+: rede de fibras finas ao longo de quase toda a amostra, sem fibras grossas demonstráveis;

- 3+: rede de fibras difusas com esparsas fibras grossas, mas sem colágeno verdadeiro;

- 4+: rede de fibras grossas difusa com áreas de colagenização.

14. Avaliação dos critérios morfológicos e imuno-histoquímicos para SMD-h conforme Bennett e Orazi ${ }^{11}$ : distúrbio de maturação da série granulocítica caracterizado por ALIPs e/ou displasia de megacariócitos (micromegacariócitos, megacariócitos binucleados ou multinucleados e elementos hipo ou monolobados) e/ou aumento no número de blastos CD34-positivos (>5\%).

15. Avaliação dos critérios morfológicos e imuno-histoquímicos para CRI segundo Baumann et al. ${ }^{7}$ : displasia eritroide caracterizada por agregados 
de pelo menos 20 precursores eritroides com presença de formas jovens eritroides (proeritroblastos) com ou sem aumento do número de mitoses dos elementos.

\subsection{Processamento do fragmento de biópsia de medula óssea}

O processamento da biópsia de $M O$, no que diz respeito à fixação e descalcificação, sofreu modificações ao longo do tempo, obedecendo a um dos seguintes protocolos gerais:

I. Fixação em formalina salina a $10 \%$ ou líquido de Bouin por 6 a 24 horas com posterior descalcificação em ácido nítrico a 10\% por cerca de 3 horas.

II. Fixação em formol salino a 10\%, tamponado por período mínimo de 6 horas, seguido de descalcificação em EDTA* onde permanece por 4 horas.

III. Do EDTA ou ácido nítrico passa para o processador de tecidos para a rotina habitual.

${ }^{*}$ EDTA:

EDTA sódico p.a (TITRIPLEX III)........................ 0,7 g

Tartarato de sódio e potássio p.a ........................... 8,6 g

Ácido clorídrico p.a........................................ 99,2 mL

Água destilada q.s.p. ou deionizada.....................1000 mL

Validade de 1 ano em temperatura ambiente. 


\subsection{Exame imuno-histoquímico (IHQ)}

Os procedimentos técnicos relativos às reações de IHQ obedeceram aos protocolos convencionais, descritos a seguir:

1. Desparafinização e hidratação - os cortes histológicos foram desparafinizados em três banhos de xilol à temperatura ambiente durante 20 minutos cada. Posteriormente, foram hidratados em sequência decrescente de etanol (absoluto, 95\% e 70\%) e água corrente durante 5 minutos cada.

2. Bloqueio da peroxidase endógena - em câmara escura com cinco incubações em água oxigenada a 3\% por 10 minutos cada. Em seguida, as lâminas foram lavadas em água corrente e água destilada por 5 minutos cada e submersas em solução salina tamponada (PBS) pH 7,4.

3. Recuperação dos sítios antigênicos:

- Câmara de pressão controlada por microprocessador (Pascal) $121^{\circ} \mathrm{C}$ por 3 minutos. Após esse tempo, a temperatura e pressão caem até atingir $90^{\circ} \mathrm{C}$ por 10 segundos.

- Panela de pressão por 2 minutos.

- Panela a vapor durante 25 minutos após o aquecimento do tampão por 20 minutos.

Utilizado tampão TRIS/EDTA $10 \mathrm{mM} / 1 \mathrm{mM}$ com $\mathrm{pH}$ variável na dependência do anticorpo primário utilizado. A seguir, as lâminas foram lavadas em água corrente e água destilada por 5 minutos cada.

4. Bloqueio de proteínas inespecíficas do tecido com incubação em solução de leite desnatado (Molico, Nestlé - marca registrada) a 10\% durante 30 minutos à temperatura ambiente.

5. Incubação com o Anticorpo primário - as lâminas foram incubadas overnight em câmara úmida na geladeira a $4^{\circ} \mathrm{C}$ com os anticorpos primários. 
6. Incubação com o sistema de detecção / amplificação - após serem lavadas em PBS pH 7,4, por duas vezes, durante 5 minutos cada, as lâminas foram incubadas com Novo Link Polymer Detection System (Novocastra).

7. Cromógeno e contracoloração - as reações realizadas foram visualizadas por meio do cromógeno diaminobenzidina (3,3'-diaminobenzidine, SIGMA Chemical Co., St. Louis, MO/USA, código D5637) a 0,03\% acrescido de $1,2 \mathrm{~mL}$ de água oxigenada a $3 \%$. A intensidade da cor foi controlada ao microscópio óptico pelos controles positivos que acompanharam cada reação. Os cortes assim processados foram lavados em água corrente por 5 minutos, contracorados com hematoxilina de Carazzi por 24 segundos, lavados em água corrente, desidratados em etanol $(95 \%$ e absoluto) e diafanizados em xilol.

8. Montagem das lâminas - com resina Permount (FISHER Scientific, Fair Lawn, NJ/USA, código SP15-100).

9. Leitura e interpretação das lâminas - a caracterização da positividade para cada anticorpo foi feita de forma a complementar a análise morfológica, estimando-se a proporção de cada linhagem hematopoética e dos blastos de forma semiquantitativa, assim como sua distribuição topográfica.

Controles positivos e negativos atestaram a validade das reações para cada anticorpo utilizado.

Os controles negativos das reações foram obtidos pela omissão do anticorpo primário, que foi substituído por PBS.

Os controles positivos corresponderam a fragmentos de medula óssea de material de autópsia, processados em conjunto com as lâminas dos casos. 


\subsubsection{Citogenética}

\subsection{Citogenética convencional - Cariótipo}

Os exames de citogenética convencional (cariótipo) e FISH foram realizados no Laboratório de citogenética do SH-HCFMUSP. O cariótipo foi realizado em amostras de $\mathrm{MO}$ em culturas, utilizando meio RPMI suplementado por soro bovino fetal a $5 \%$, em incubadora de $\mathrm{CO}_{2}$ por 24 a 48 horas, sem utilização de agentes mitogênicos, seguido por bandamento $\mathrm{G}^{73}$. As imagens arquivadas foram resgatadas e revisadas no mesmo Laboratório, e a análise foi realizada por um observador capacitado e os resultados descritos de acordo com as normas internacionais de nomenclatura ISCN $2013^{74}$. O cariótipo foi considerado satisfatório quando 10 ou mais metáfases foram analisadas.

\subsection{Citogenética Molecular - hibridização “in situ” por fluorescência (FISH)}

A técnica de hibridização "in situ" por fluorescência (FISH) para pesquisa da monossomia/deleção do cromossomo 7 foi realizada sempre que possível em amostras (fixadas em metanol e ácido acético, excedentes da preparação do cariótipo) da data do diagnóstico da aplasia medular e da data da evolução para leucemia ou data do último exame citogenético realizado.

O procedimento técnico foi realizado com a sonda "LSI D7S48(7q31) ORANGE, CEP7 GREEN Probes-Vysis, Inc", seguindo as recomendações do fabricante. A análise foi realizada em microscópio de fluorescência (OlympusBX60), com objetiva de imersão (100X), equipado com filtros de banda simples de espectros: verde, vermelho e azul, e filtro de banda tripla (filtro com os três espectros). A análise foi realizada em 100 núcleos interfásicos, por um observador capacitado e os resultados descritos de acordo com as normas do ISCN $2013^{74}$. O valor de referência foi determinado previamente no laboratório, seguindo normas internacionais 55; 75 . Casos 
apresentando mais que $10 \%$ de núcleos interfásicos com apenas um sinal verde e um vermelho e com dois sinais verdes e um vermelho foram considerados como positivos para monossomia 7 ou deleção $7 q$, respectivamente.

\subsubsection{Análise estatística}

A análise estatística dos dados foi realizada, utilizando-se o programa SPSS versão 16.0. As variáveis qualitativas nominais foram analisadas pelo teste de Fisher para verificar se havia desproporção significativa entre os grupos. As variáveis qualitativas ordinais foram analisadas para a diferença entre os grupos pelo teste de Mann-Whitney. O nível de significância adotado foi $5 \%(p=0,05)$. A sobrevida livre de eventos dos pacientes foi calculada pelo método de Kaplan-Meier, desde o diagnóstico até a data de um dos seguintes eventos: transplante de MO, evolução para SMD/LMA, óbito ou data do último contato com o paciente na ausência dos anteriores. A comparação das curvas de sobrevida foi realizada pelo teste de log-rank com nível de significância de $5 \%(\alpha=0,05)$. 
5 Resultados 


\section{RESULTADOS}

\subsection{ANÁLISE DA CASUÍSTICA}

Os resultados da análise descritiva clínica estão resumidos nos dados das Tabelas 2 e 3 . Dados de sobrevida livre de evento relacionada à faixa etária e à gravidade da AAA dos pacientes estão descritos no Anexo 2.

Do grupo total de pacientes (118), 71 eram do gênero masculino e 47 do feminino. A mediana de idade ao diagnóstico foi 24,4 anos (7 meses de vida até 76 anos), e 42 pacientes tinham menos de 19 anos. Oito apresentavam AAA secundária (três eram portadores de hepatite não $A$ não B não $C$, um de hepatite $A$, um de timoma, um de malária, um de mucopolissacaridose e um de doença reumatológica). Setenta e sete tiveram diagnóstico de Anemia Aplástica Grave (AAG), 17 não grave (AAnG) e 24 muito grave (AAmG). Todos os pacientes foram acompanhados clinicamente com tempo médio de seguimento de 6,0 anos (mediana de 5,0). Do total de pacientes, 12 evoluíram com SMD/LMA em 4,8 anos em média (nenhum dos pacientes que evoluiu para SMD/LMA havia sido previamente tratado). Dezoito pacientes foram submetidos a transplante de medula óssea e houve 35 óbitos.

Do grupo pediátrico de pacientes (42), 25 eram do gênero masculino e 17 do feminino. A mediana de idade ao diagnóstico foi 9,8 anos ( 7 meses de vida até 18 anos), e 21 pacientes tinham menos de 10 anos. Seis pacientes tinham AAA secundária nesse grupo. Vinte e oito tiveram diagnóstico de Anemia aplástica grave (AAG), dois não grave (AAnG) e 12 muito grave (AAmG). Todos os pacientes foram acompanhados clinicamente com tempo médio de seguimento de 5,7 anos (mediana de 5,1). Sete pacientes foram submetidos a transplante de medula óssea e houve 16 óbitos.

Do grupo adulto de pacientes (76), 46 eram do gênero masculino e 30 do feminino. A mediana de idade ao diagnóstico foi 33,2 anos (de 19 a 76 anos). Dois pacientes tinham AAA secundária nesse grupo. Quarenta e nove 
tiveram diagnóstico de Anemia aplástica grave (AAG), 15 não grave (AAnG) e 12 muito grave (AAmG). Todos os pacientes foram acompanhados clinicamente com tempo médio de seguimento de 6,1 anos (mediana de 4,8). Onze pacientes submetidos a transplante de medula óssea e houve 18 óbitos.

Do grupo total de 118 pacientes, 12 evoluíram para SMD/LMA, sendo seis adultos e seis crianças. Seis eram do gênero masculino e seis do feminino. A mediana de idade ao diagnóstico de AAA foi 17,2 anos, com idade mínima de 2,7 anos até 66,1 anos. Apenas um paciente, do grupo pediátrico, apresentava doença associada ao diagnóstico (malária). Quatro receberam diagnóstico de Anemia aplástica grave (AAG), um não grave (AAnG) e sete muito grave (AAmG). Todos os pacientes foram acompanhados clinicamente com tempo médio de seguimento de 4,6 anos (mediana de 4,3). Dois pacientes foram submetidos a transplante de medula óssea e houve seis óbitos.

Tabela 2 - Descrição dos grupos total, adulto e pediátrico

\begin{tabular}{lccc}
\hline & $\begin{array}{c}\text { Grupo total } \\
(118)\end{array}$ & $\begin{array}{c}\text { Grupo adulto } \\
(76)\end{array}$ & $\begin{array}{c}\text { Grupo pediátrico } \\
(42)\end{array}$ \\
\hline $\begin{array}{l}\text { Gênero masculino:feminino } \\
\text { Idade ao diagnóstico (anos) } \\
\text { (mediana/mín/máx) }\end{array}$ & $1,51: 1$ & $1,53: 1$ & $1,47: 1$ \\
AAA secundária n (\%) & $24,4 / 0,58 / 76$ & $33,2 / 19 / 76$ & $9,8 / 0,58 / 18$ \\
AAG n (\%) & $8(6,7)$ & $2(2,6)$ & $6(14,2)$ \\
AAnG n (\%) & $77 /(65,2)$ & $49(64,5)$ & $28(66,7)$ \\
AAmG n (\%) & $17(14,4)$ & $15(19,7)$ & $2(4,8)$ \\
Tempo de seguimento (anos) & $24(20,4)$ & $12(15,8)$ & $12(28,5)$ \\
(mediana/mín/máx) & $5,1 / 0,08 / 22,17$ & $4,8 / 0,08 / 22,17$ & $5,1 / 0,08 / 19,5$ \\
Pacientes transplantados n (\%) & $18(15,2)$ & $11(14,4)$ & $7(16,7)$ \\
Óbitos n (\%) & $35(29,6)$ & $18(23,6)$ & $16(38,0)$ \\
\hline
\end{tabular}

AAA: Anemia aplástica adquirida; AAG: Anemia aplástica grave; AAnG: Anemia aplástica não grave; AAmG: Anemia aplástica muito grave 
Tabela 3 - Descrição do grupo total, que não evoluiu para SMD/LMA e que evoluiu para SMD/LMA

\begin{tabular}{|c|c|c|c|}
\hline & $\begin{array}{l}\text { Grupo total } \\
\quad(118)\end{array}$ & $\begin{array}{c}\text { Grupo } \\
\text { não evoluiu } \\
\text { SMD/LMA (106) }\end{array}$ & $\begin{array}{c}\text { Grupo } \\
\text { evoluiu } \\
\text { SMD/LMA (12) }\end{array}$ \\
\hline Gênero masculino:feminino & $1,51: 1$ & $1,58: 1$ & $1: 1$ \\
\hline $\begin{array}{l}\text { Idade ao diagnóstico (anos) } \\
\text { (mediana/mín/máx) }\end{array}$ & $24,4 / 0,58 / 76$ & $26,1 / 0,58 / 76$ & $17,9 / 2,7 / 66,1$ \\
\hline AAA secundária $n(\%)$ & $8(6,7)$ & $7(6,6)$ & $1(8,3)$ \\
\hline AAG n (\%) & $77(65,2)$ & $73(68,9)$ & $4(33,3)$ \\
\hline AAnG n (\%) & $17(14,4)$ & $16(15,1)$ & $1(8,3)$ \\
\hline AAmG n (\%) & $24(20,4)$ & $17(16,0)$ & $7(58,4)$ \\
\hline $\begin{array}{l}\text { Tempo de seguimento (anos) } \\
\text { (mediana/mín/máx) }\end{array}$ & $5,1 / 0,08 / 22,17$ & $5,2 / 0,08 / 22,17$ & $4,3 / 0,5 / 11,42$ \\
\hline Pacientes transplantados $\mathrm{n}(\%)$ & $18(15,2)$ & $16(15,1)$ & $2(16,7)$ \\
\hline Óbitos n (\%) & $35(29,6)$ & $29(27,3)$ & $6(50,0)$ \\
\hline
\end{tabular}

AAA: Anemia aplástica adquirida; AAG: Anemia aplástica grave; AAnG: Anemia aplástica não grave; AAmG: Anemia aplástica muito grave. 


\subsection{AVALIAÇÃO DAS AMOSTRAS DE BIÓPSIA DE MEDULA ÓSSEA}

\subsubsection{Qualidade das amostras}

O resumo da análise da qualidade das amostras encontra-se nos dados das Tabelas 4 e 5.

Quanto à qualidade das amostras para o grupo total, o tamanho das biópsias foi, em média, 1,5 \pm 1,9 cm (mediana de 1,3); o número de espaços intertrabeculares teve média de 9,3 \pm 4,6 espaços por biópsia (mediana de 9); $18(15,2 \%)$ amostras eram subcorticais; a maior parte tinha algum grau de artefato (92 amostras), incluindo descolamento (66 delas) (Figura 1), hemorragia (38) (Figura 2) e fragmentação (4) (Figura 3), e uma amostra pode ter mais de um tipo de artefato com intensidade variando de 1 a 3+, a maior parte (54) com apenas $1+$.

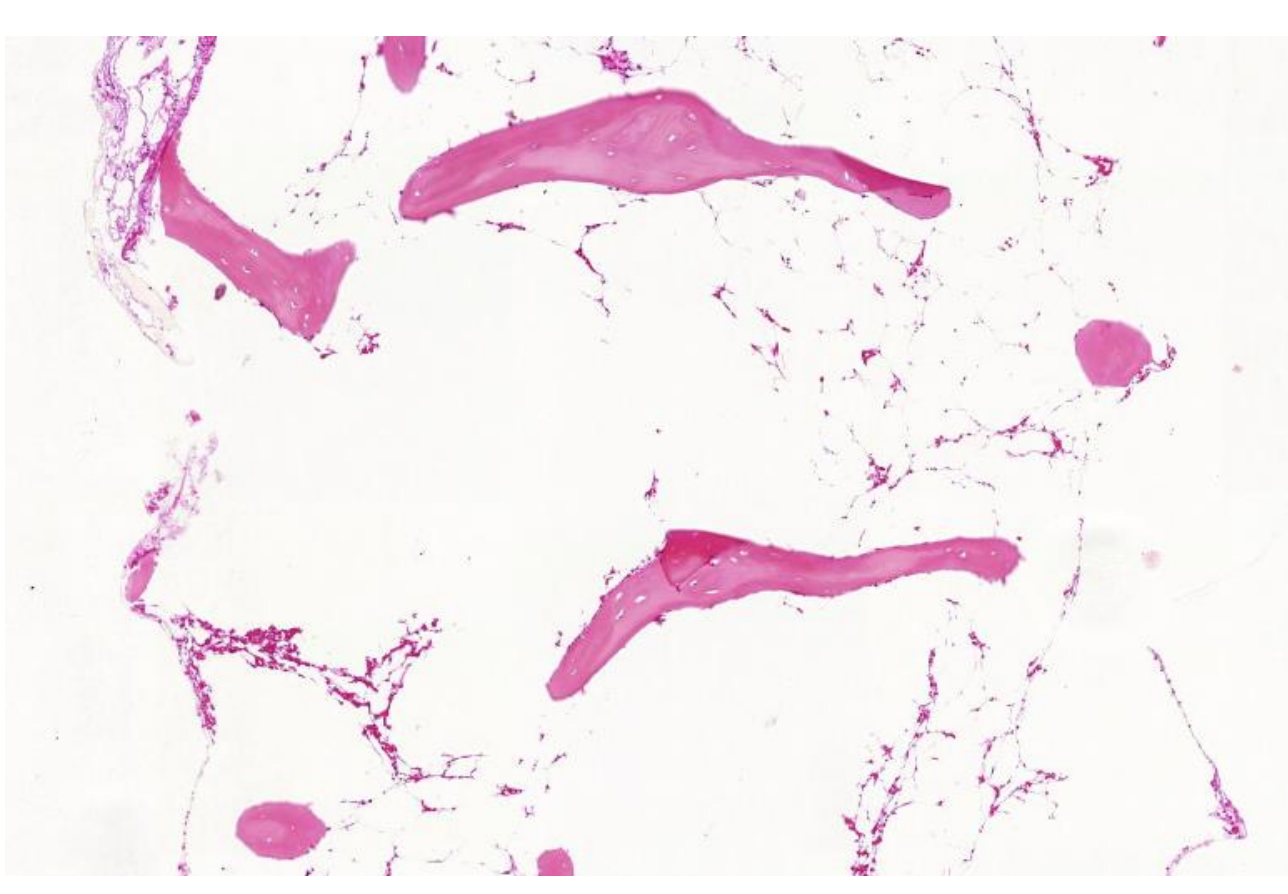

Figura 1 - Artefato de descolamento (HE, 50x) 


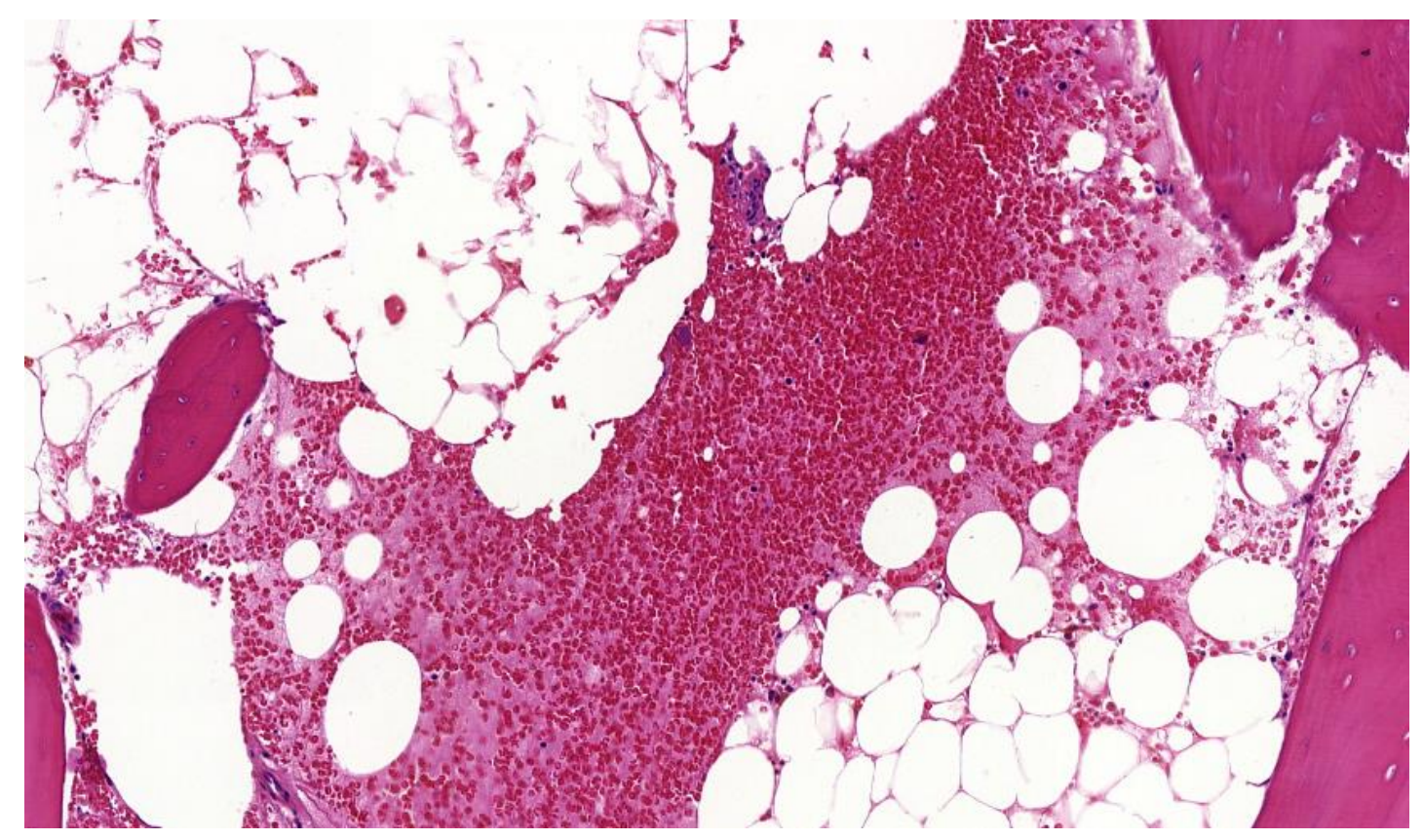

Figura 2 - Artefato de hemorragia (HE, 100x)

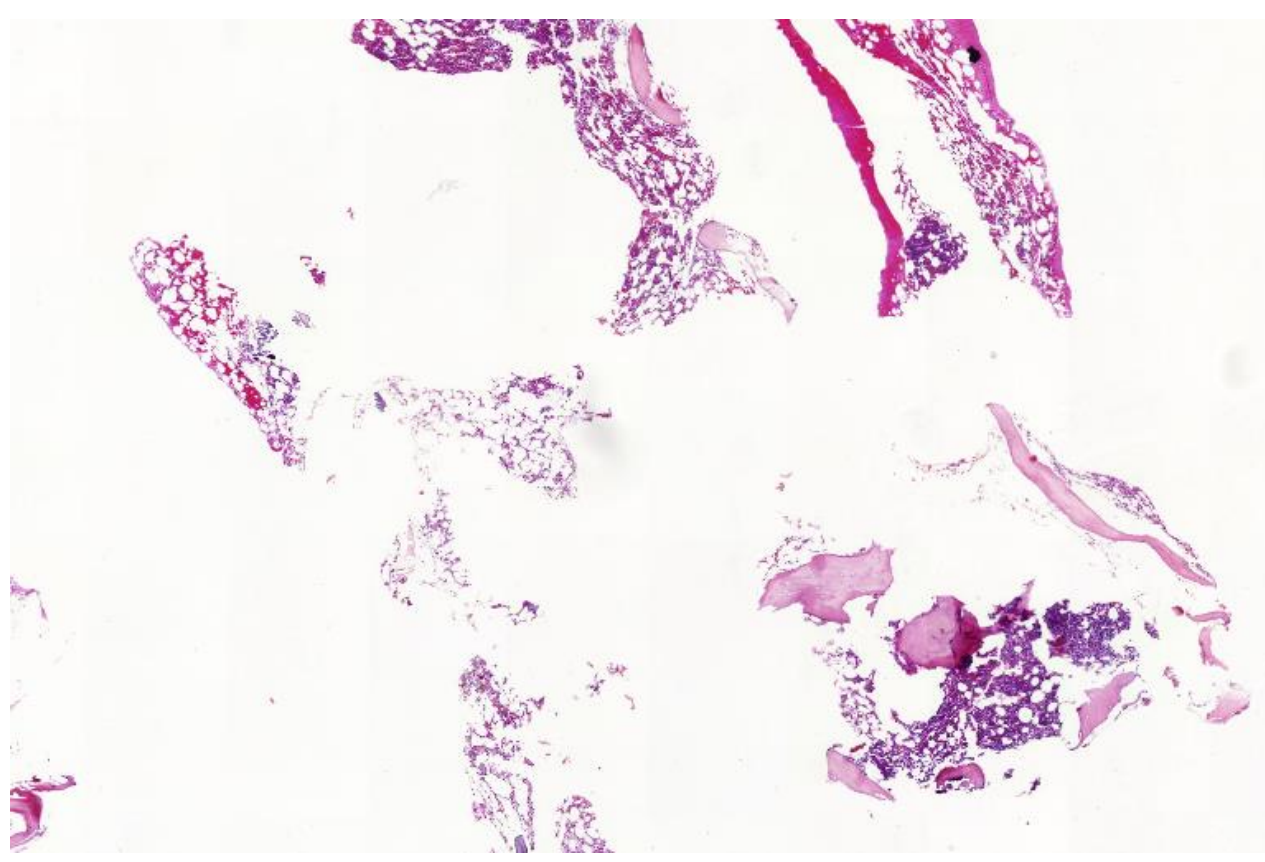

Figura 3 - Artefato de fragmentação (HE, 100x) 
Quanto à qualidade das amostras para o grupo pediátrico, o tamanho das biópsias foi, em média, $1,7 \pm 2,5 \mathrm{~cm}$ (mediana de 1,1); o número de espaços intertrabeculares teve média de 8,5 \pm 4,8 espaços por biópsia (mediana de 8); 10 (23,8\%) amostras eram subcorticais e 32 não o eram; a maior parte tinha algum grau de artefato (36 amostras), incluindo descolamento (22 delas), hemorragia (19) e fragmentação (2), e uma amostra pode ter mais de um tipo de artefato com intensidade variando de 1 a 3+, 21 com apenas 1+, $11 \mathrm{com} \mathrm{2+e} 4 \mathrm{com} 3+$.

Quanto à qualidade das amostras para o grupo adulto, o tamanho das biópsias foi, em média, $1,4 \pm 1,5 \mathrm{~cm}$ (mediana de 1,3); o número de espaços intertrabeculares teve média de 9,7 $\pm 4,5$ espaços por biópsia (mediana de 9); apenas oito (10,5\%) amostras eram subcorticais e 68 não o eram. A maior parte tinha algum grau de artefato (56 amostras), incluindo descolamento (44 delas), hemorragia (19) e fragmentação (2), e uma amostra pode ter mais de um tipo de artefato com intensidade variando de 1 a $3+, 33$ com apenas 1+, 17 com 2+ e 6 com 3+.

Quanto à qualidade das amostras do grupo que evoluiu para $S M D / L M A$, o tamanho das biópsias foi, em média, $1,3 \pm 0,5 \mathrm{~cm}$ (mediana de 1,3); o número de espaços intertrabeculares teve média de 10,8 $\pm 5,5$ espaços por biópsia (mediana de 9,5); duas $(0,16 \%)$ amostras eram subcorticais; a maior parte tinha algum grau de artefato (nove amostras), incluindo descolamento (seis delas), hemorragia (6) e fragmentação (1), e uma amostra pode ter mais de um tipo de artefato com intensidade variando de 1 a 3+, 5 com apenas 1+, 1 com 2+ e 3 com 3+. 
Tabela 4 - Qualidade das BMO dos grupos total, adulto e pediátrico

\begin{tabular}{|c|c|c|c|}
\hline & $\begin{array}{l}\text { Grupo total } \\
\quad(118)\end{array}$ & $\begin{array}{l}\text { Grupo adulto } \\
\text { (76) }\end{array}$ & $\begin{array}{c}\text { Grupo } \\
\text { pediátrico } \\
(42)\end{array}$ \\
\hline $\begin{array}{l}\text { Tamanho das biópsias (média e mediana } \\
\text { em } \mathrm{cm} \text { ) }\end{array}$ & 1,5 e 1,3 & 1,4 e 1,3 & 1,7 e 1,1 \\
\hline $\begin{array}{l}\text { Número de espaços intertrabeculares } \\
\text { (média e mediana) }\end{array}$ & 9,3 e 9,0 & 9,7 e 9,0 & 8,5 e 8,0 \\
\hline Amostras subcorticais n (\%) & $18(15,2)$ & $8(10,5)$ & $10(23,8)$ \\
\hline Presença de artefatos n (\%) & $92(77,9)$ & $56(73,6)$ & $36(85,7)$ \\
\hline Artefato mais frequente & $\begin{array}{l}\text { descolament } \\
\quad 0\end{array}$ & $\begin{array}{c}\text { descolament } \\
0\end{array}$ & $\begin{array}{c}\text { descolament } \\
\text { o }\end{array}$ \\
\hline Grau 1 de artefatos & 54 & 33 & 21 \\
\hline Grau 2 de artefatos & 28 & 17 & 11 \\
\hline Grau 3 de artefatos & 10 & 6 & 4 \\
\hline
\end{tabular}

Tabela 5 - Qualidade das BMO do grupo total, que não evoluiu para SMD/LMA e que evoluiu para SMD/LMA

\begin{tabular}{lccc}
\hline & $\begin{array}{c}\text { Grupo total } \\
(118)\end{array}$ & $\begin{array}{c}\text { Grupo } \\
\text { não evoluiu } \\
\text { SMD/LMA } \\
(106)\end{array}$ & $\begin{array}{c}\text { Grupo } \\
\text { evoluiu } \\
\text { SMD/LMA } \\
(12)\end{array}$ \\
\hline $\begin{array}{l}\text { Tamanho das biópsias (média e mediana } \\
\text { em cm) }\end{array}$ & 1,5 e 1,3 & 1,5 e 1,3 & 1,3 e 1,3 \\
$\begin{array}{l}\text { Número de espaços intertrabeculares } \\
\text { (média e mediana) }\end{array}$ & 9,3 e 9,0 & 9,1 e 9,0 & 10,8 e 9,5 \\
Amostras subcorticais $n(\%)$ & $18(15,2)$ & $16(15,0)$ & $2(16,6)$ \\
Presença de artefatos $n(\%)$ & $92(77,9)$ & $83(78,3)$ & $9(75)$ \\
Artefato mais frequente & descolamento & descolamento & descolamento \\
Grau 1 de artefatos & 58 & 49 & 5 \\
Grau 2 de artefatos & 29 & 27 & 1 \\
Grau 3 de artefatos & 10 & 7 & 3 \\
\hline
\end{tabular}


Do grupo total inicial, apenas nove de 146 amostras foram excluídas do estudo inicialmente por não apresentar material em quantidade avaliável (amostras constituídas essencialmente por coágulo sanguíneo ou tecido adiposo/conjuntivo/ósseo sem tecido hematopoético). O tamanho médio foi menor que o recomendado pela International Council for Standardization in Hematology (ICSH) ${ }^{65}$ de 2,0 cm, mas atingiu o comprimento de $1,5 \mathrm{~cm}$ e teve número médio próximo de 10 espaços intertrabeculares recomendados pela OMS ${ }^{33}$. A média variou em torno de $1,5 \mathrm{~cm}$ e mediana de 1,3 e apresentou quantidade média de espaços intertrabeculares de 9,4 e mediana de 9,0. A presença de artefatos foi bastante frequente (quase $80 \%$ do total), mas a maioria foi por descolamento parcial (nível 1 de intensidade) do material das trabéculas ósseas, ainda assim permitindo visualização adequada do tecido hematopoético e de suas alterações celulares, tanto quanto são adequados para avaliação os coágulos de medula óssea. O grupo pediátrico apresentou menor número de espaços intertrabeculares avaliáveis (mediana de 8,0 contra 10,0 do adulto), maior número de amostras subcorticais ( $23,8 \%$ contra $9,8 \%$ ) e maior frequência de artefatos (85,7\% contra $75,3 \%$ ), denotando a maior dificuldade de obtenção de material da população pediátrica e tornando maior seu valor, pois os procedimentos necessários são mais complexos. Os grupos com evolução favorável (EF) e com evolução desfavorável (ED) tiveram parâmetros de qualidade bastante semelhantes (Tabela 5), já que mesclam adultos e crianças, que são distintos entre si como observado acima (Tabela 4).

\subsubsection{Parâmetros morfológicos / imuno-histoquímicos estudados}

Critérios morfológicos de medula óssea (anteriormente mencionados no item Metodologia) estão descritos nos dados das Tabelas dos itens 5.2.2.1, 5.2.2.2 e 5.2.2.3. Presença de distribuição irregular do tecido hematopoético foi identificada em 59 pacientes (50\%) (Figura 4). Presença de distúrbio maturação da série granulocítica foi identificada em três (2\%) dos pacientes (Figuras 5, 6, 7 e 8), caracterizada por localização anormal de precursores 
imaturos. Agrupamentos de elementos nucleados da série eritrocítica foram identificados em 54 (45,7\%) dos pacientes (Figuras 9 e 10), com formas jovens (Figura 11) em 32 (27,1\%) e mitoses em 24 (20,3\%) (Figura 12). Quarenta e dois $(35,5 \%)$ dos pacientes apresentaram um ou mais megacariócitos à BMO (Figura 13), 15 (12,7\%) com displasia caracterizada por ausência de lobulação (Figura 14) em todos eles (12,7\%), binucleação (Figura 15) em apenas dois (1,6\%) e multinucleação em 3 (2,5\%) (Figura 16). A presença de blastos CD34-positivos foi observada em 11 (9,3\%) casos (Figura 17), sempre isolados, constituindo menos de $1 \%$ da celularidade. Reticulogênese aumentada foi identificada em três casos (Figura 18), os mesmos casos que apresentaram reticulogênese grau $1 \mathrm{em}$ escala de 0 a 3, foram avaliados como grau 2 em escala de 0 a 4.

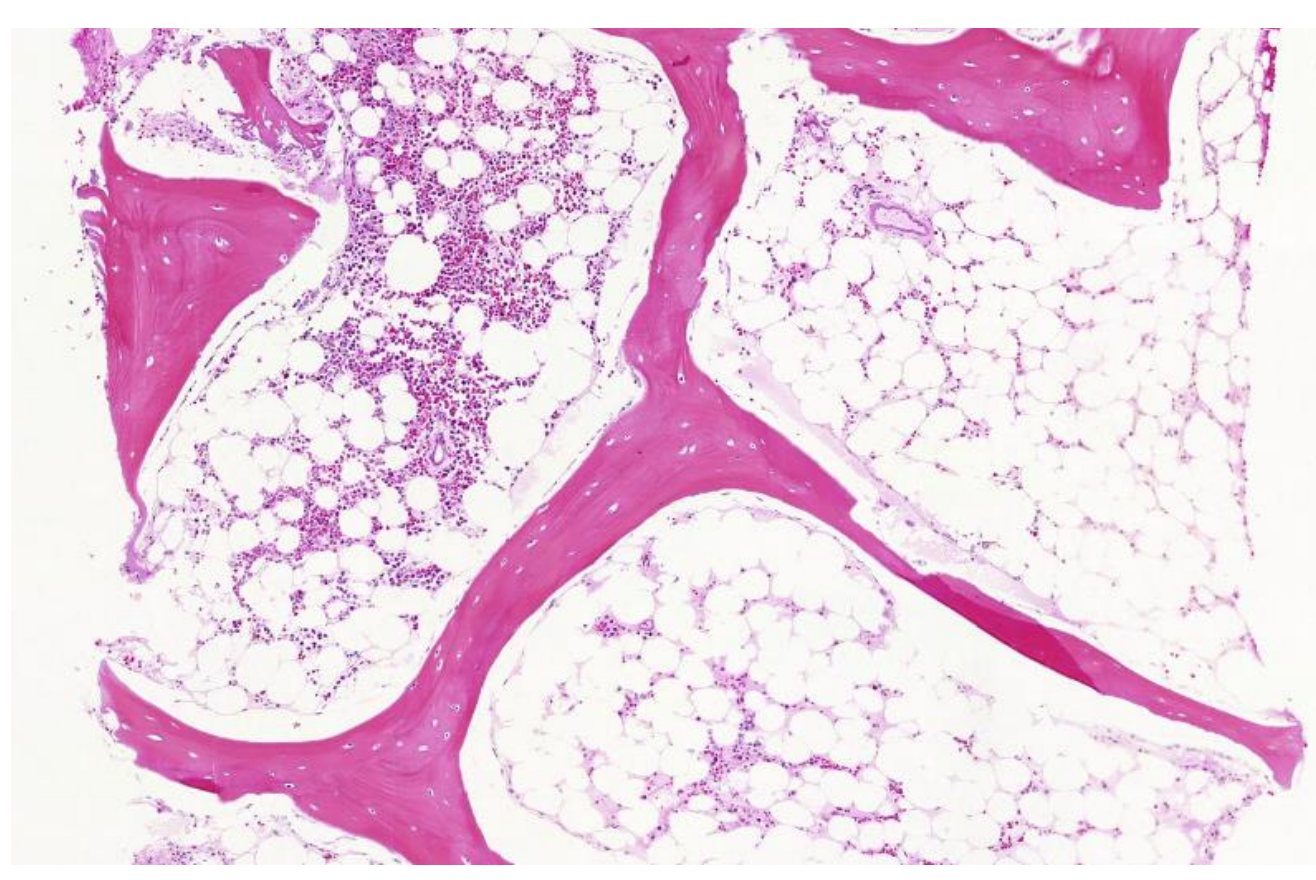

Figura 4 - Distribuição irregular do tecido hematopoético em paciente que não evoluiu para SMD/LMA, com área de maior celularidade ao lado de área com celularidade muito baixa (hematoxilina e eosina, 100x) 


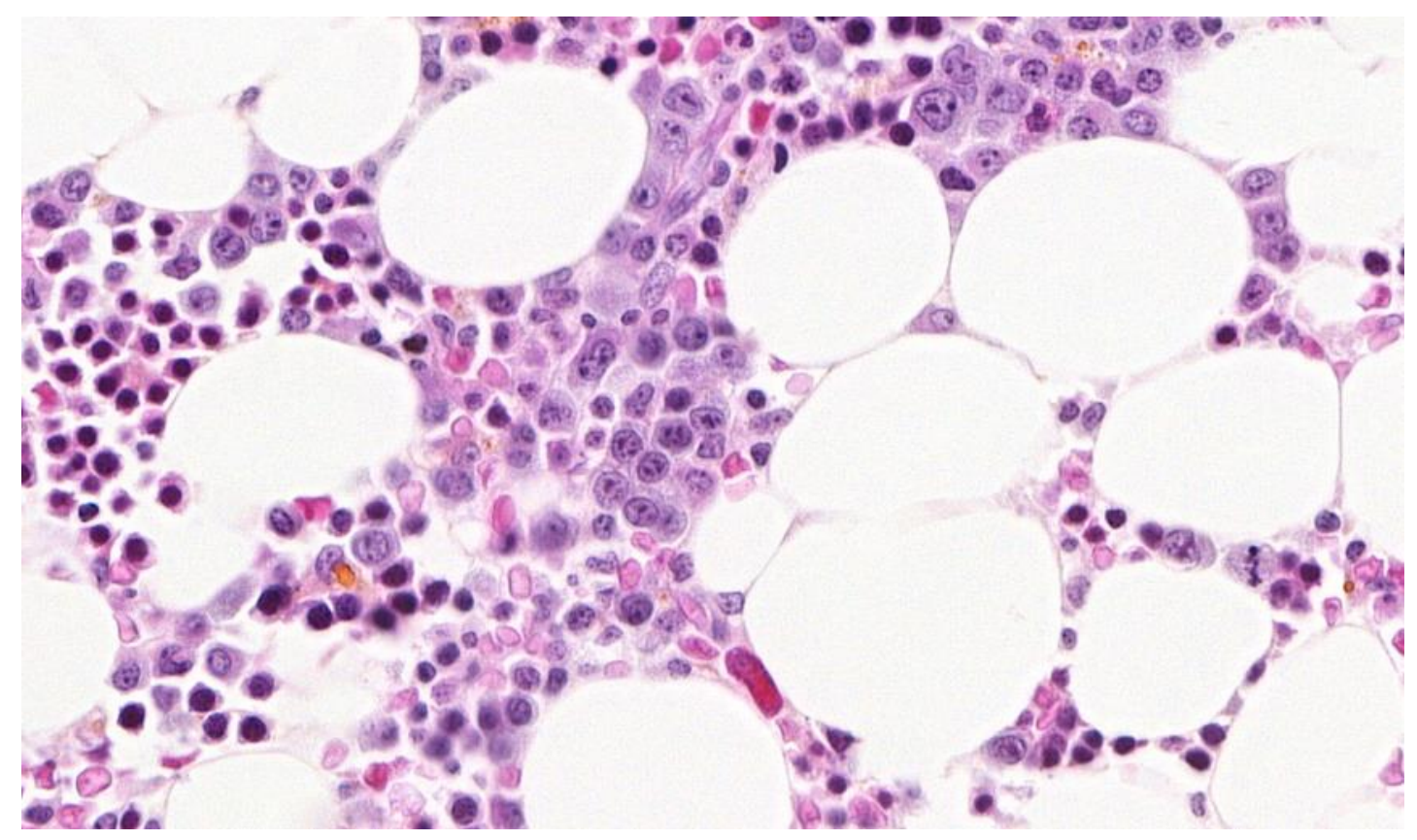

Figura 5 - Localização anormal de precursores imaturos da série granulocítica ao HE (400x) em paciente de 18 anos que não evoluiu para SMD/LMA

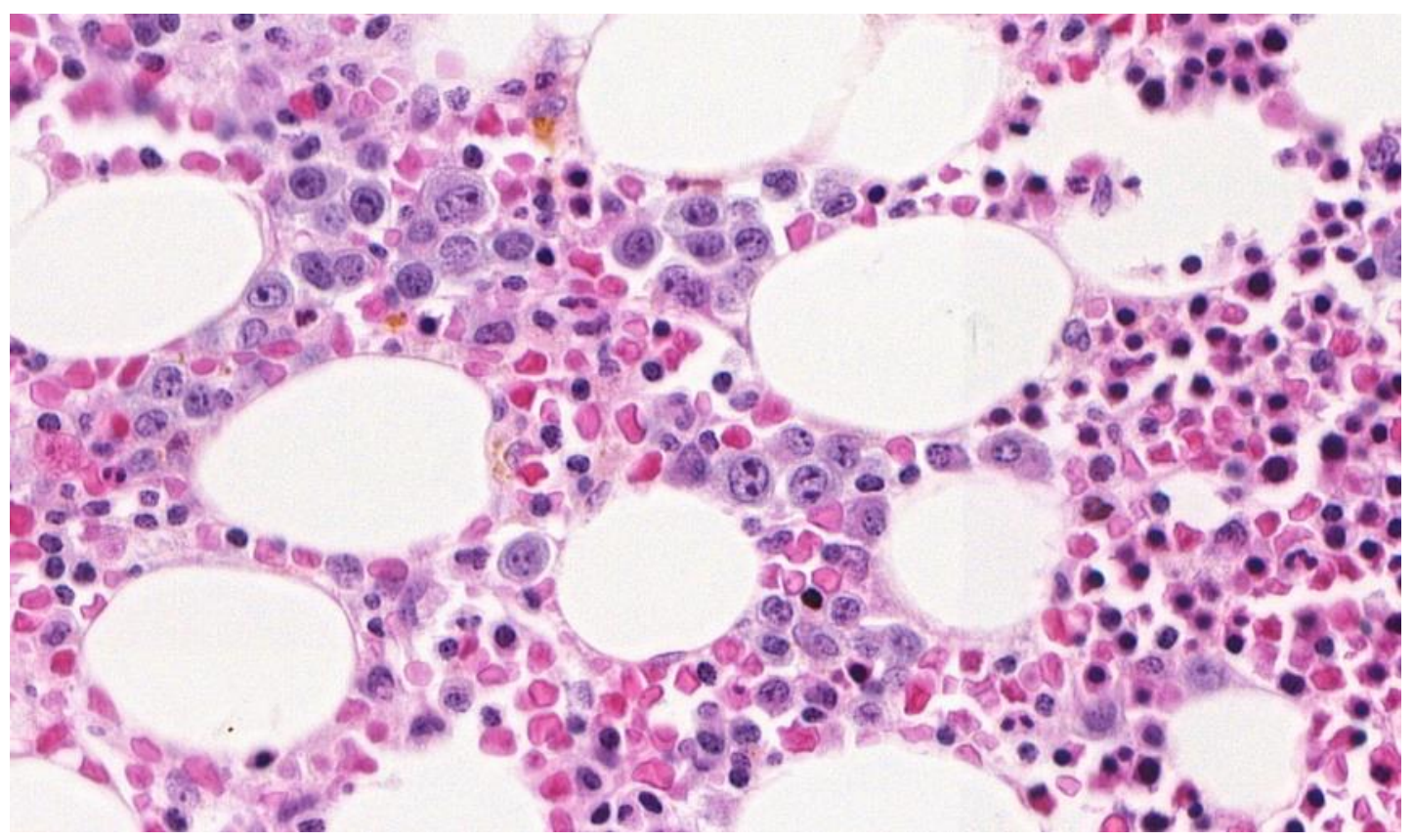

Figura 6 - Localização anormal de precursores imaturos da série granulocítica ao HE (400x) em paciente de 18 anos que não evoluiu para SMD/LMA 


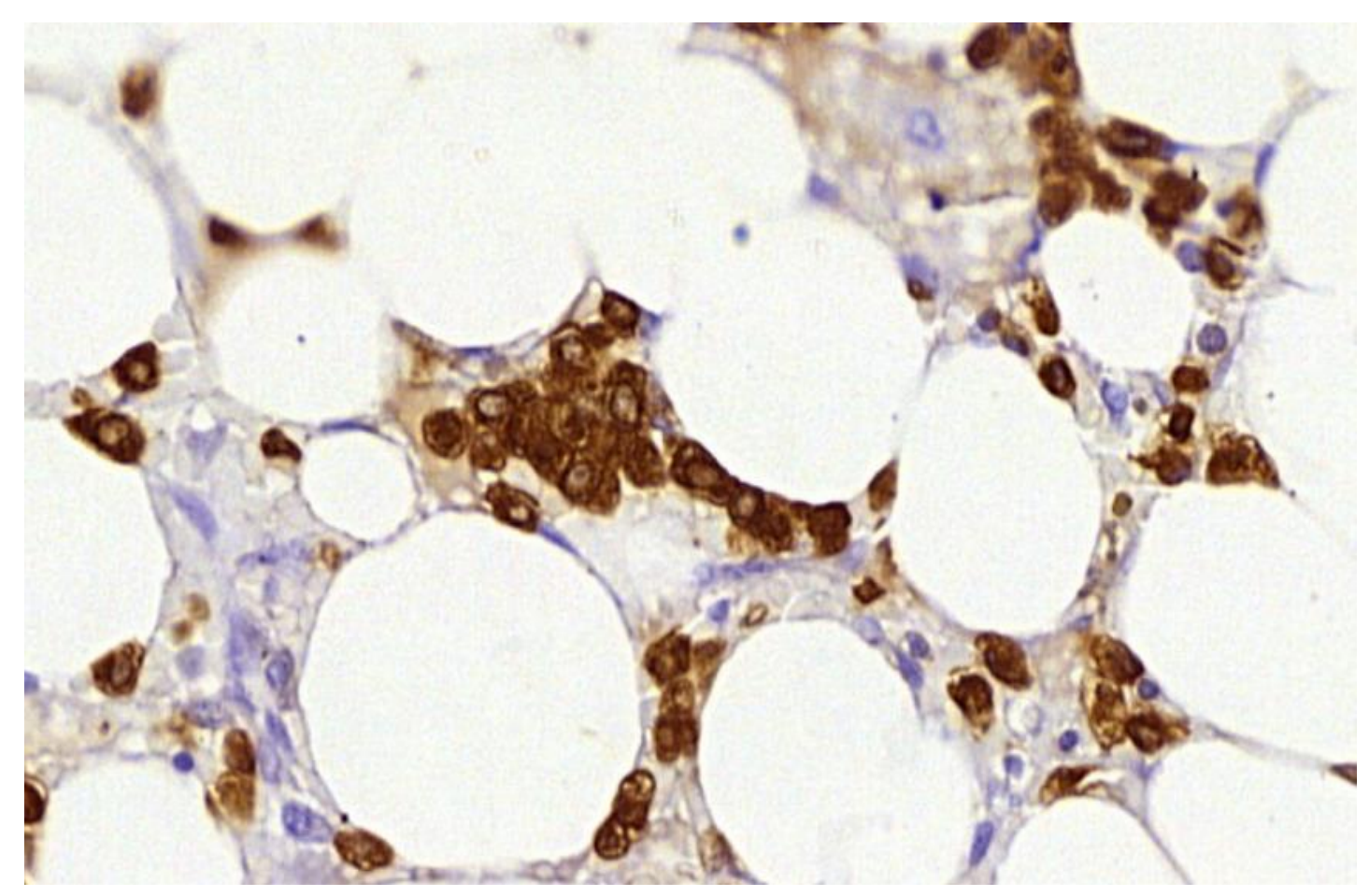

Figura 7 - Localização anormal de precursores imaturos da série granulocítica em paciente de 18 anos que não evoluiu à marcação imuno-histoquímica para MPO (elementos granulocíticos em marrom, 400x)

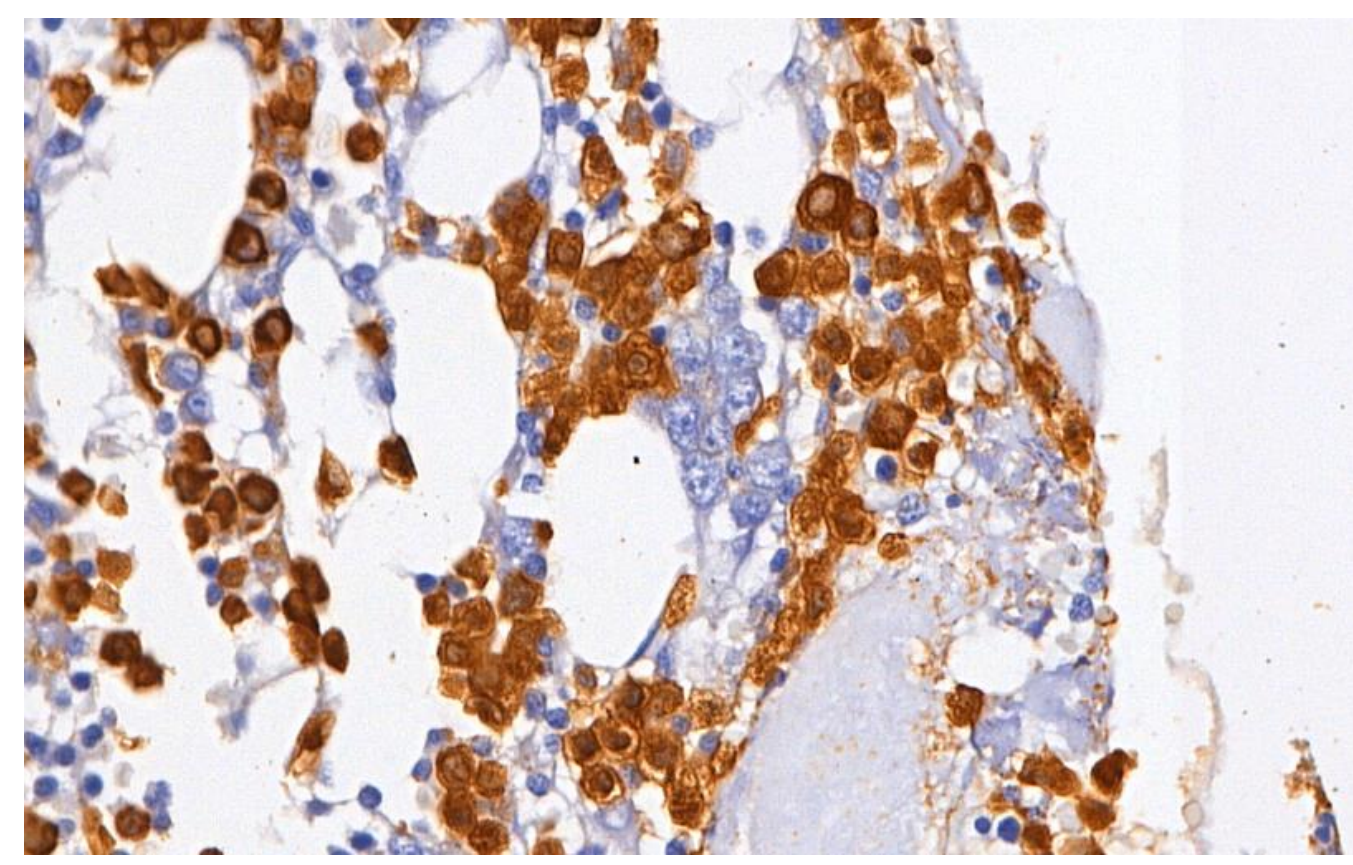

Figura 8 - Localização anormal de precursores imaturos da série granulocítica em paciente de 18 anos que não evoluiu para SMD/LMA, à marcação imuno-histoquímica para Glicoforina $A$ (elementos eritroides em marrom e granulocíticos em azul) (glicoforina $A, 200 x$ ) 


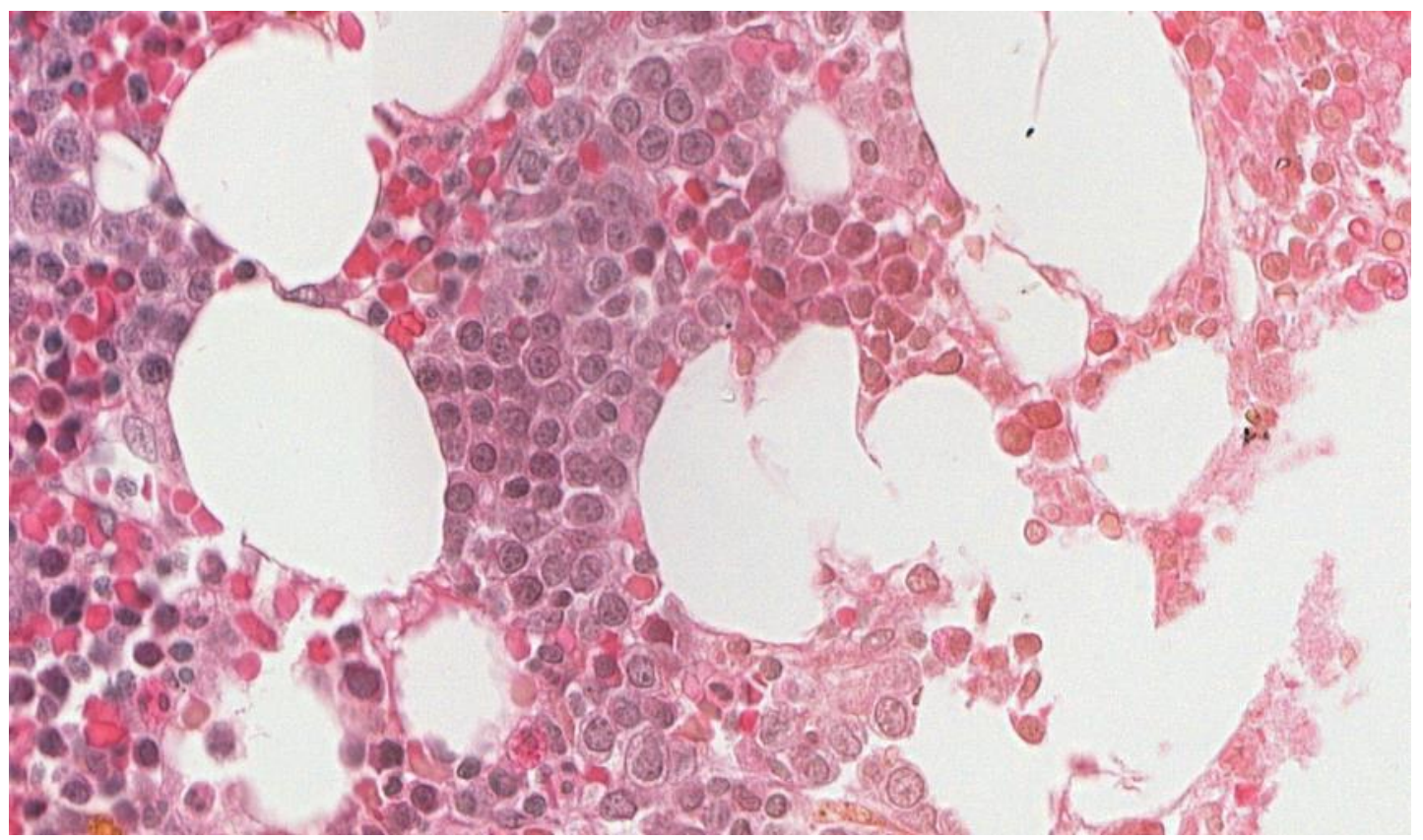

Figura 9 - Agrupamento de mais de 20 células nucleadas da série eritrocítica ao $\mathrm{HE}$ (400x) em paciente de 16 anos que não evoluiu para SMD/LMA

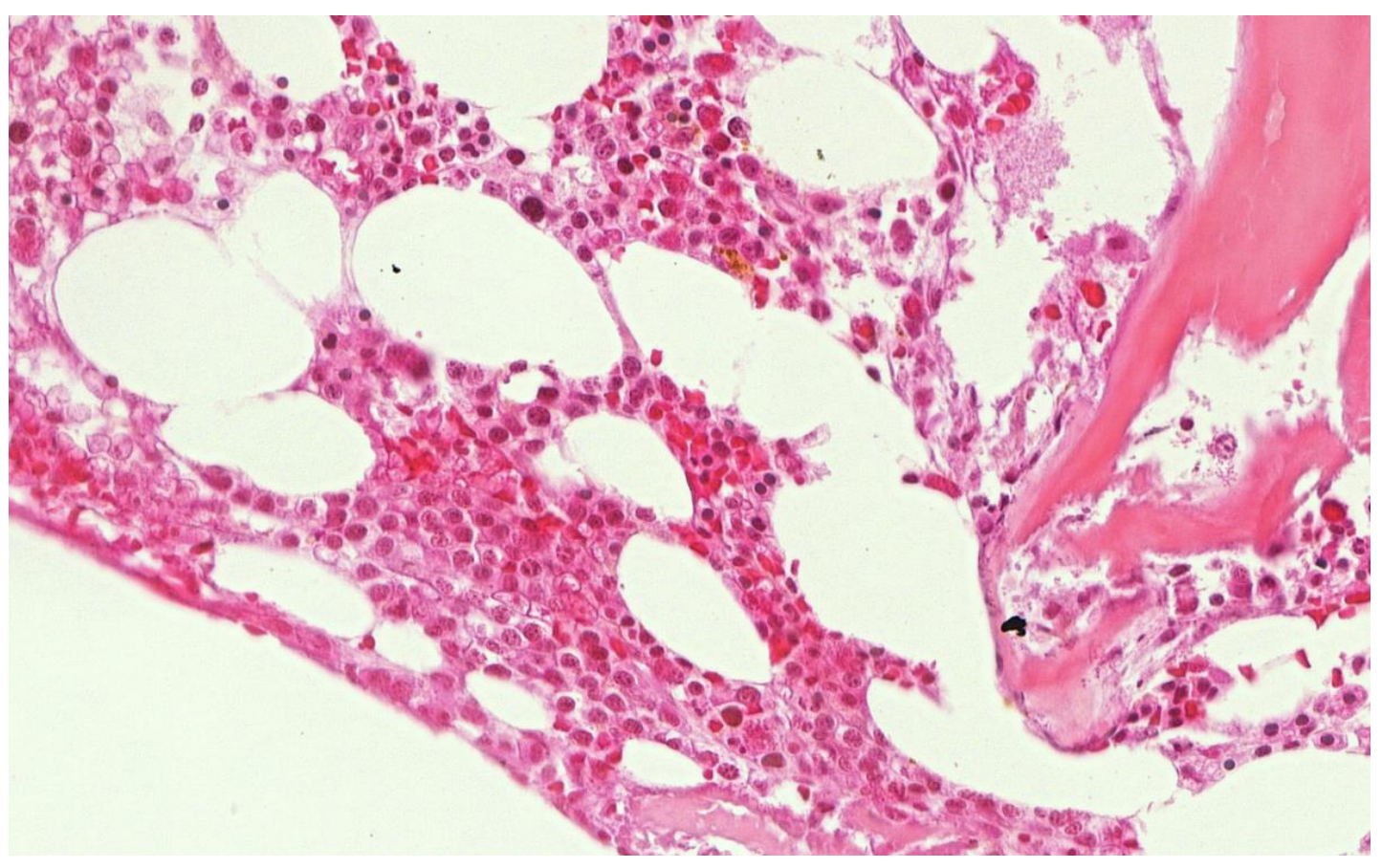

Figura 10 - Agrupamento de mais de 20 células nucleadas da série eritrocítica ao HE (400x) em criança de 4 anos que evoluiu para SMD/LMA 


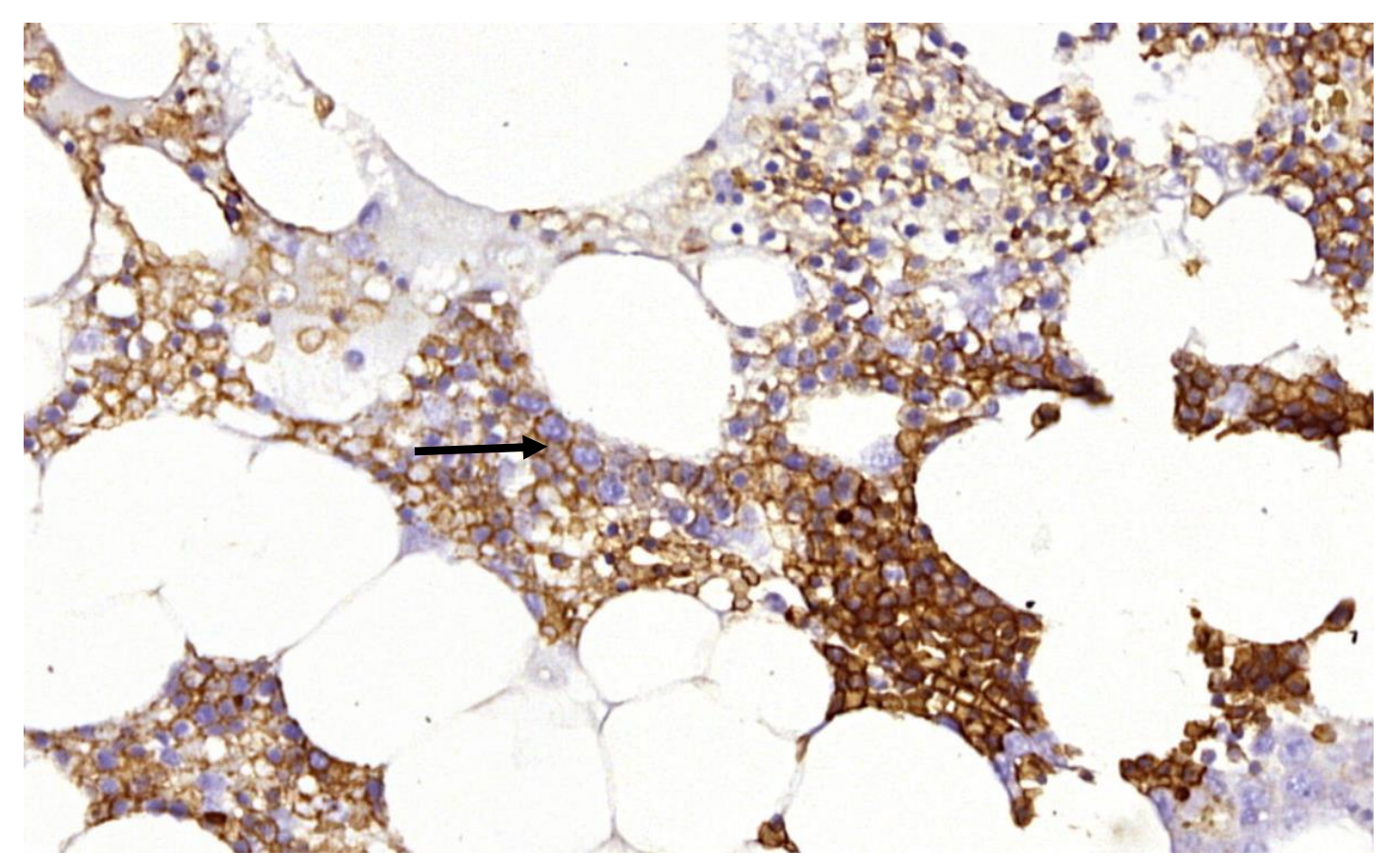

Figura 11 - Agrupamento de mais de 20 células nucleadas da série eritrocítica com formas jovens (seta) (Glicoforina A, 200x)

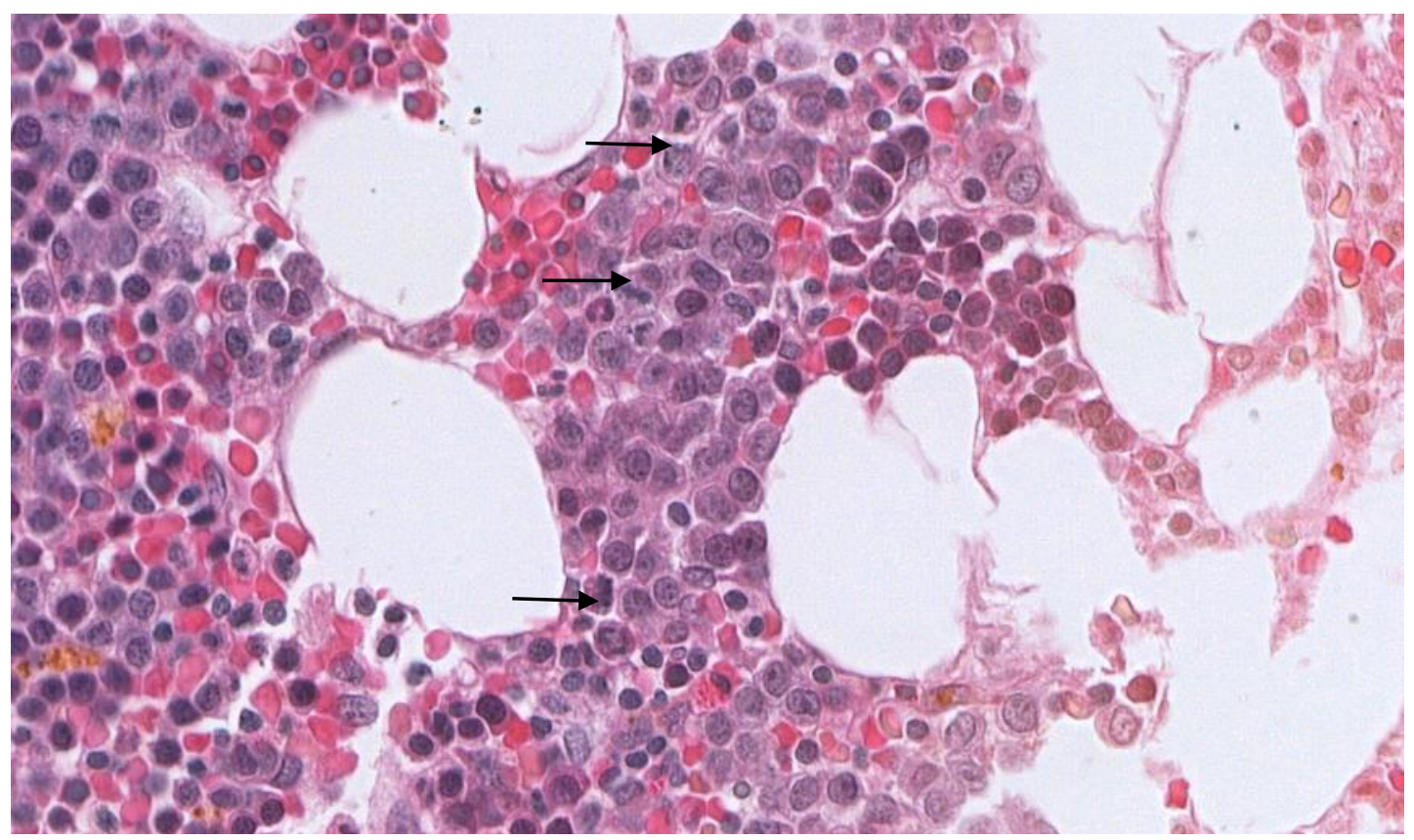

Figura 12 - Agrupamento de mais de 20 células nucleadas da série eritrocítica ao HE (400x) com mitoses (setas) 


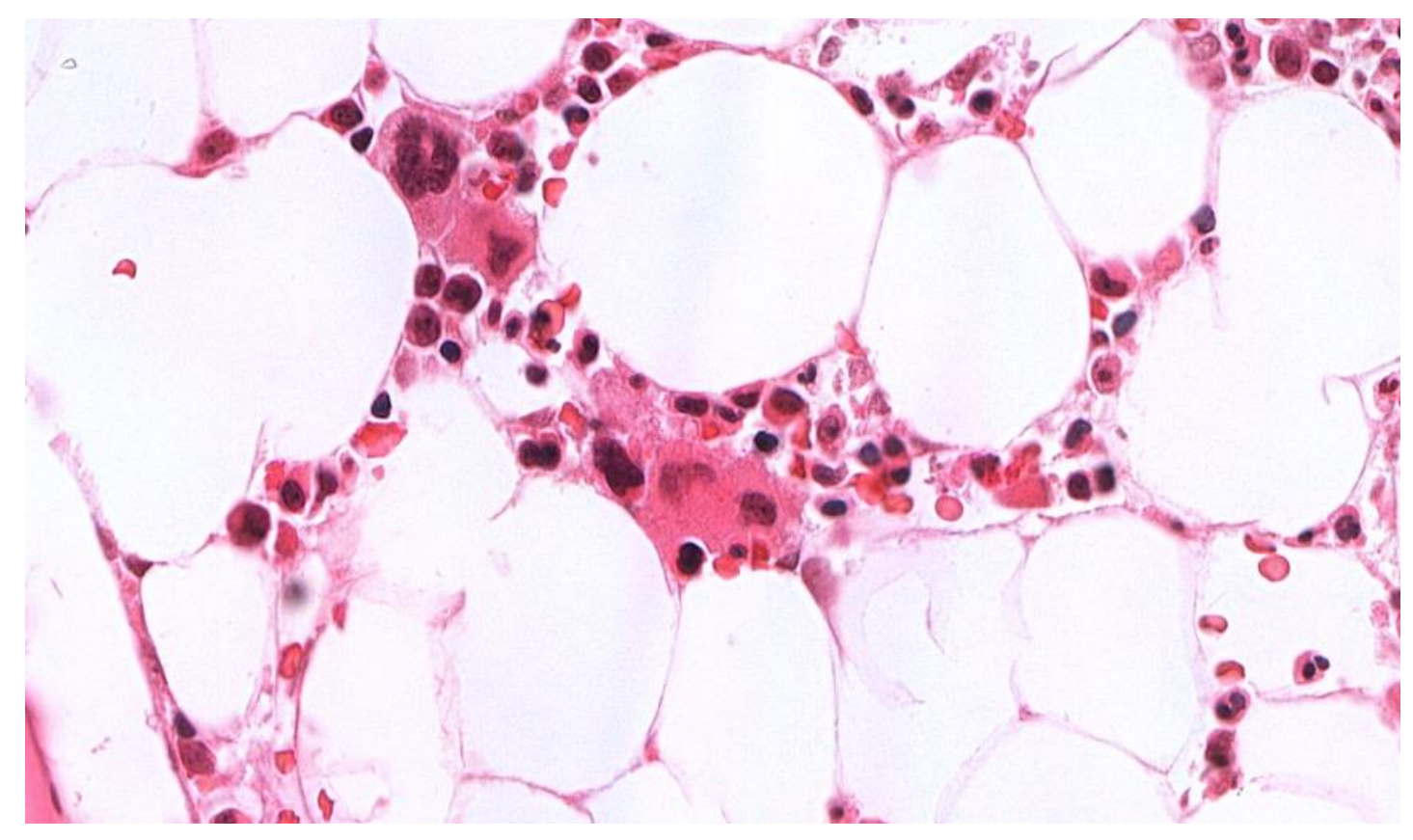

Figura 13 - Megacariócitos em agregados (HE, 200x)

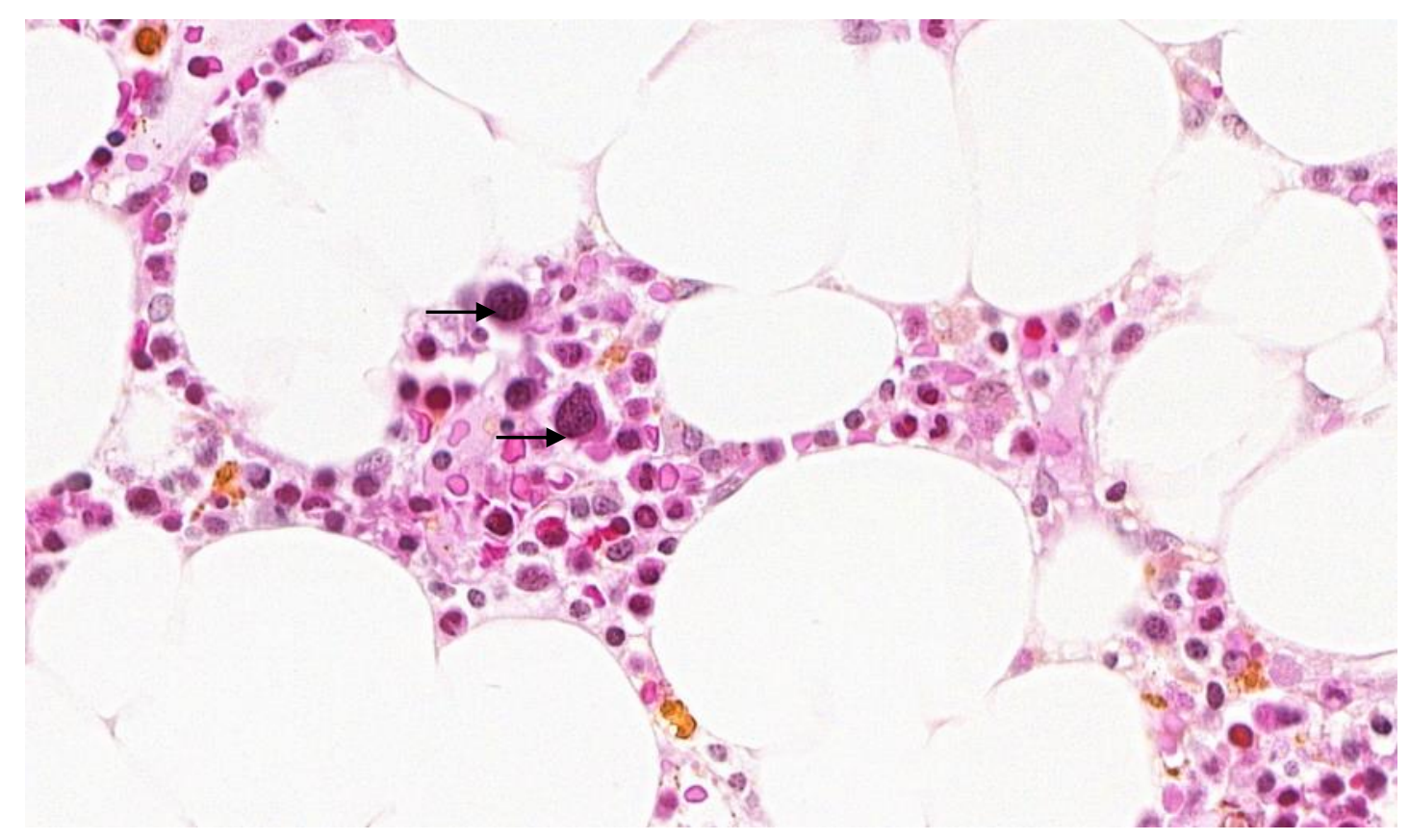

Figura 14 - Megacariócitos hipolobados (setas) (HE, 200x) 


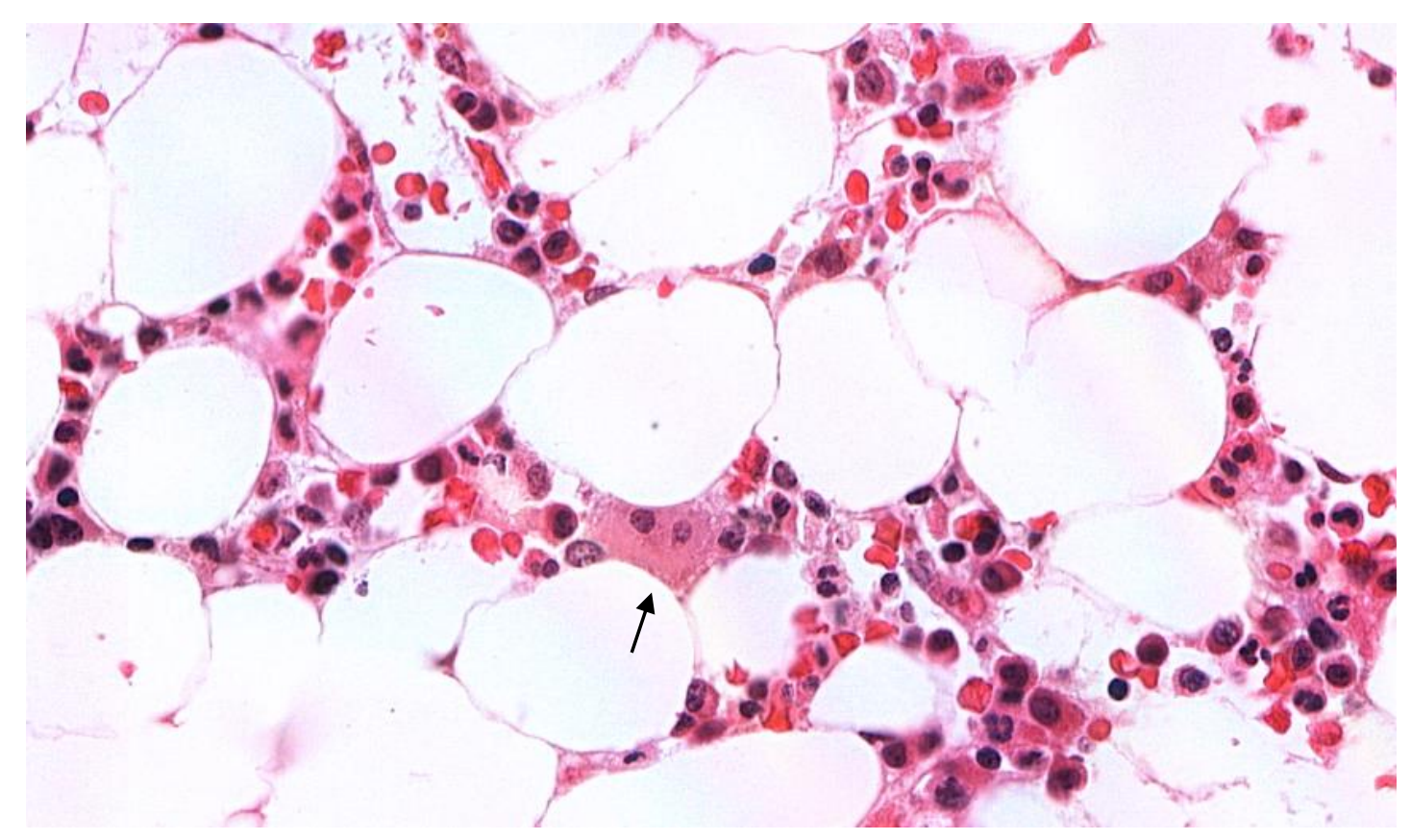

Figura 15 - Megacariócito binucleado (seta) (HE, 200x)

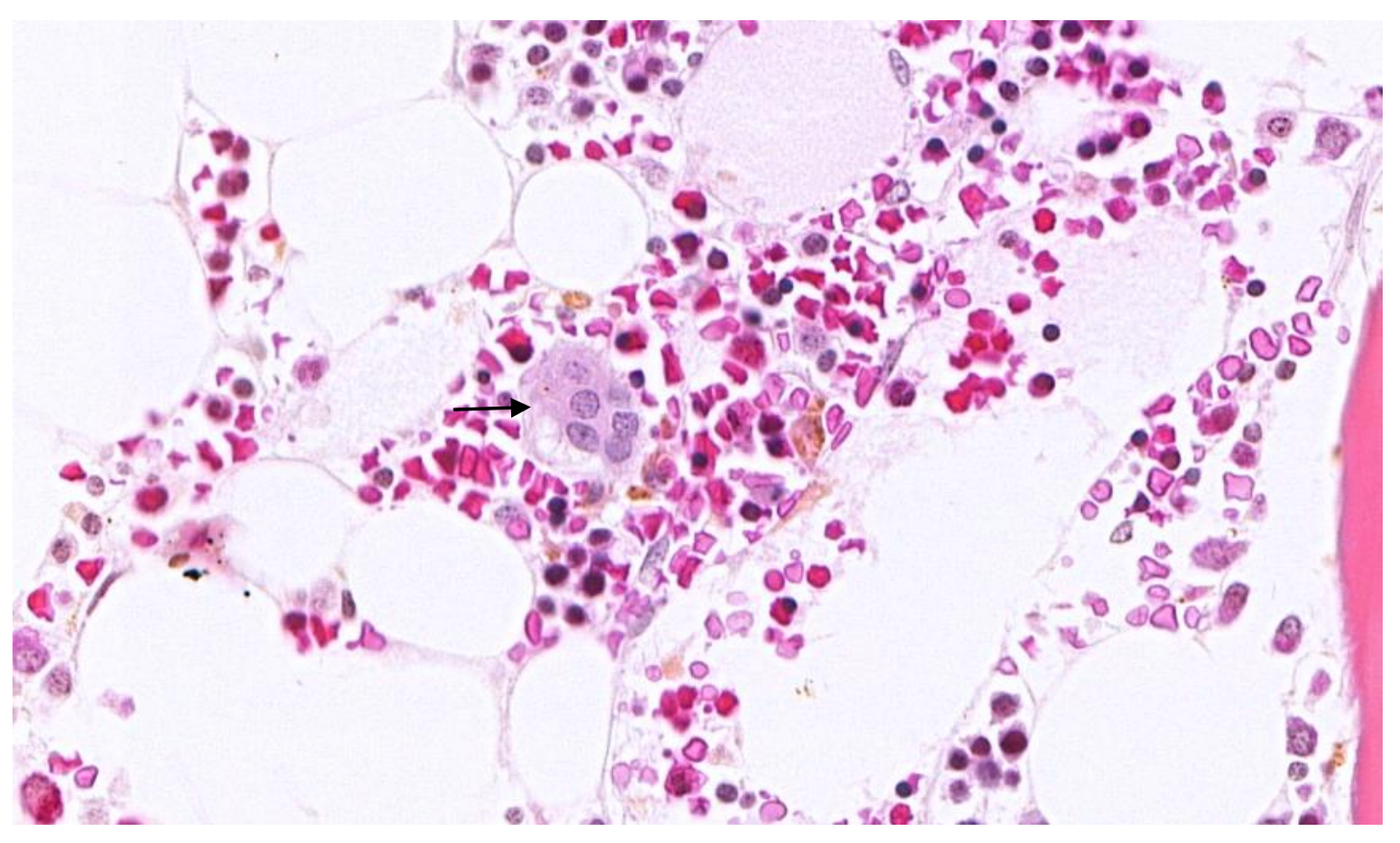

Figura 16 - Megacariócito multinucleado (seta) (HE, 200x) 


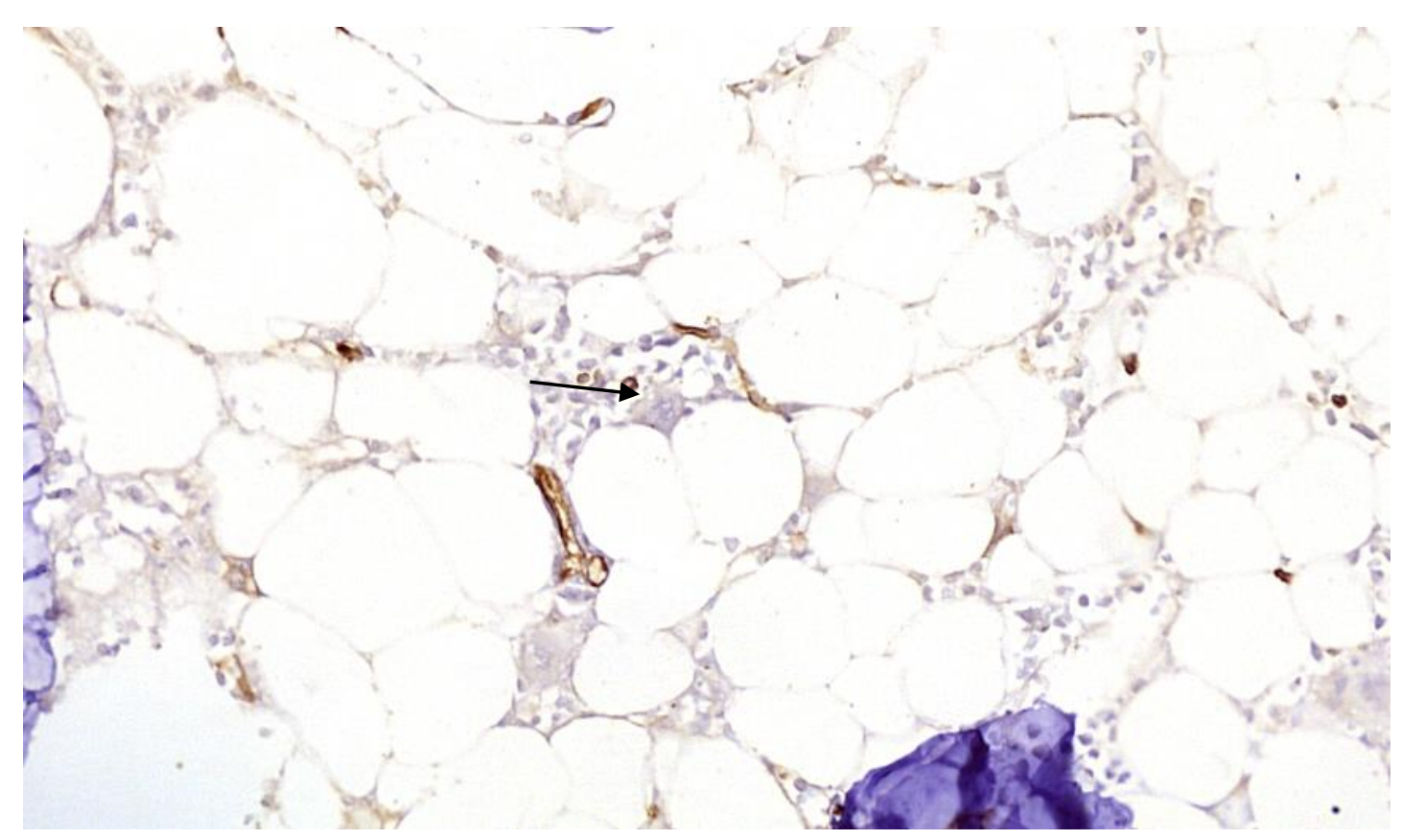

Figura 17 - Blasto CD34-positivo entre dois vasos (seta) (CD34, 200x)

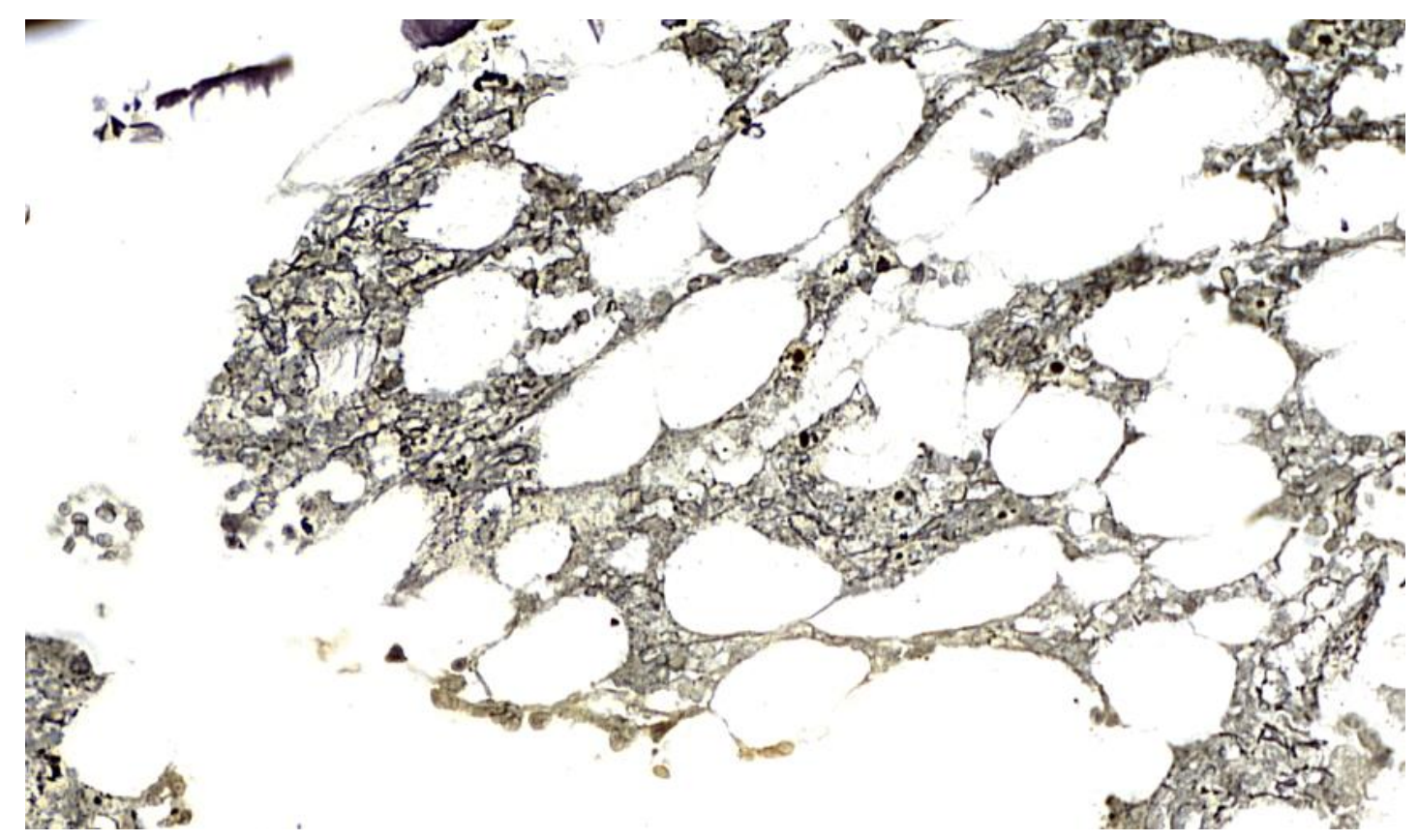

Figura 18 - Reticulogênese grau 2 (de 0 a 4) e grau 1 (de 0 a 3) (coloração para reticulina, 200x) 


\subsubsection{Comparação dos achados morfológicos/ imuno- histoquímicos em crianças e adultos}

As características morfológicas encontradas em biópsias de $\mathrm{MO}$ de adultos e crianças estão descritas nos dados da Tabela 6. A análise comparativa realizada entre crianças com menos de 14 anos e grupo com 14 anos ou mais não mostrou diferença estatística e encontra-se no Anexo 3.

Tabela 6 - Análise comparativa dos parâmetros Ml entre grupo adulto e pediátrico

\begin{tabular}{lcccc}
\hline & $\begin{array}{c}\text { Grupo } \\
\text { total } \\
(\mathrm{n}=118)\end{array}$ & $\begin{array}{c}\text { Grupo } \\
\text { adulto } \\
(\mathrm{n}=76)\end{array}$ & $\begin{array}{c}\text { Grupo } \\
\text { pediátrico } \\
<19 \mathrm{a} \\
(\mathrm{n}=42)\end{array}$ & $\boldsymbol{p}$ \\
Variável & $\mathbf{n}$ & $\mathbf{n}$ & $\mathbf{n}$ & \\
\hline Distribuição irregular do tecido hematopoético & 59 & 42 & 17 & 0,17 \\
Distúrbio maturação da série granulocítica & 3 & 1 & 2 & 0,27 \\
Distúrbio arquitetural da série eritrocítica & 13 & 8 & 5 & 0,51 \\
Agrupamentos da série eritrocítica & 54 & 38 & 16 & 1 \\
Formas jovens da série eritrocítica & 32 & 23 & 9 & 0,81 \\
Mitoses da série eritrocítica & 24 & 18 & 6 & 0,61 \\
Atipias citológicas da série eritrocítica & 35 & 24 & 11 & 0,81 \\
Presença de células da série megacariocítica & 42 & 28 & 14 & 0,84 \\
Displasia da série megacariocítica & 15 & 9 & 6 & 0,51 \\
Megacariócitos binucleados & 2 & 1 & 1 & 1 \\
Megacariócitos multinucleados & 3 & 1 & 2 & 0,25 \\
Megacariócitos não lobulados & 15 & 9 & 6 & 0,51 \\
\hline Distúrbio arquitetural da série megacariocítica & 4 & 1 & 3 & 0,10 \\
Blastos CD34-positivos & 11 & 8 & 3 & 0,74 \\
\hline Reticulogênese grau 1 em escala de 0 a 3 & 3 & 1 & 2 & 0,28 \\
Reticulogênese grau 2 em escala de 0 a 4 & 3 & 1 & 2 & 0,30 \\
Índice proliferativo (Ki-67) (mediana) & 25 & 30 & 15 & 0,198 \\
\hline
\end{tabular}




\subsubsection{Comparação dos achados morfológicos / imuno- histoquímicos em pacientes que evoluíram e que não evoluíram para SMD/LMA}

O risco de evoluir para SMD/LMA foi testado no grupo adulto e pediátrico e não houve diferença entre os dois grupos ao teste exato de Fisher $(p=0,335)$.

Tabela 7 - Análise comparativa dos parâmetros $\mathrm{Ml}$ entre grupo que evoluiu e que não evoluiu para SMD/LMA

\begin{tabular}{|c|c|c|c|c|}
\hline Variável & $\begin{array}{c}\text { Grupo } \\
\text { total } \\
(n=118)\end{array}$ & $\begin{array}{l}\text { Grupo total } \\
\text { que não } \\
\text { evoluiu para } \\
\text { SMD/LMA } \\
(n=106)\end{array}$ & $\begin{array}{l}\text { Grupo total } \\
\text { que } \\
\text { evoluiu para } \\
\text { SMD/LMA } \\
(n=12)\end{array}$ & $p$ \\
\hline & $\mathbf{n}$ & $\mathbf{n}$ & $\mathbf{n}$ & \\
\hline Distribuição irregular do tecido hematopoético & 59 & 53 & 6 & 1 \\
\hline Distúrbio maturação da série granulocítica & 3 & 3 & 0 & 1 \\
\hline Distúrbio arquitetural da série eritrocítica & 13 & 12 & 1 & 1 \\
\hline Agrupamentos da série eritrocítica & 54 & 47 & 7 & 0,30 \\
\hline Formas jovens da série eritrocítica & 32 & 31 & 1 & 0,15 \\
\hline Mitoses da série eritrocítica & 24 & 22 & 2 & 1 \\
\hline Atipias citológicas da série eritrocítica & 35 & 33 & 2 & 0,47 \\
\hline Presença de células da série megacariocítica & 42 & 39 & 3 & 0,53 \\
\hline Displasia da série megacariocítica & 15 & 15 & 0 & 1 \\
\hline Megacariócitos binucleados & 2 & 2 & 0 & 1 \\
\hline Megacariócitos multinucleados & 3 & 3 & 0 & 1 \\
\hline Megacariócitos não lobulados & 15 & 15 & 0 & 1 \\
\hline Distúrbio arquitetural da série megacariocítica & 4 & 4 & 0 & 1 \\
\hline Blastos CD34-positivos & 11 & 11 & 0 & 0,60 \\
\hline Reticulogênese grau 1 em escala de 0 a 3 & 3 & 2 & 1 & 0,27 \\
\hline Reticulogênese grau 2 em escala de 0 a 4 & 3 & 2 & 1 & 0,58 \\
\hline Índice proliferativo (Ki-67) (mediana) & 25 & 30 & 15 & 0,58 \\
\hline
\end{tabular}




\subsubsection{Comparação dos achados morfológicos / imuno-histoquímicos no grupo total, em adultos e crianças que evoluíram e que não evoluíram para SMD/LMA}

Tabela 8 - Análise comparativa dos parâmetros MI entre grupo total, adulto e pediátrico que evoluiu e que não evoluiu para SMD/LMA

\begin{tabular}{|c|c|c|c|c|c|c|}
\hline \multirow[b]{2}{*}{ Parâmetros morfológicos } & \multicolumn{2}{|c|}{ Grupo total $(n=118)$} & \multicolumn{2}{|c|}{ Grupo total adulto $(n=76)$} & \multicolumn{2}{|c|}{ Grupo total pediátrico $(n=42)$} \\
\hline & $\begin{array}{c}\text { Grupo que } \\
\text { não evoluiu para } \\
\text { SMD/LMA }(n=106) \\
\text { n (\%) }\end{array}$ & $\begin{array}{c}\text { Grupo que } \\
\text { evoluiu para } \\
\text { SMD/LMA }(\mathrm{n}=12) \mathrm{n} \\
(\%)\end{array}$ & $\begin{array}{c}\text { Grupo que } \\
\text { não evoluiu para } \\
\text { SMD/LMA }(\mathrm{n}=70) \\
\mathrm{n}(\%)\end{array}$ & $\begin{array}{c}\text { Grupo que } \\
\text { evoluiu para } \\
\text { SMD/LMA }(n=6) \\
n(\%)\end{array}$ & $\begin{array}{c}\text { Grupo que } \\
\text { não evoluiu para } \\
\text { SMD/LMA (n=36) } \\
(\text { n e \%) }\end{array}$ & $\begin{array}{c}\text { Grupo que } \\
\text { evoluiu para } \\
\text { SMD/LMA }(n=6) \\
(n \text { e \%) }\end{array}$ \\
\hline Distribuição irregular do tecido hematopoético & $53(50)$ & $6(50)$ & $39(56)$ & $3(50)$ & $14(39)$ & $3(50)$ \\
\hline Celularidade geral $\leq 20 \%$ & $95(90)$ & $12(100)$ & $68(97)$ & $6(100)$ & $27(75)$ & $6(100)$ \\
\hline Distúrbio maturação da série granulocítica & $3(2)$ & $0(0)$ & $1(1)$ & $0(0)$ & $2(6)$ & $0(0)$ \\
\hline Distúrbio arquitetural da série eritrocítica & $12(11)$ & $1(8)$ & $7(10)$ & $1(17)$ & $5(14)$ & $0(0)$ \\
\hline Agrupamentos da série eritrocítica & $47(44)$ & $7(58)$ & $34(49)$ & $4(67)$ & $13(36)$ & $2(33)$ \\
\hline Formas jovens da série eritrocítica & $31(29)$ & $1(8)$ & $22(31)$ & $1(17)$ & $9(25)$ & $0(0)$ \\
\hline Mitoses da série eritrocítica & $22(21)$ & $2(16)$ & $17(24)$ & $1(17)$ & $5(14)$ & $1(17)$ \\
\hline Atipias citológicas da série eritrocítica & $33(31)$ & $2(16)$ & $23(33)$ & $1(17)$ & $10(27)$ & $1(17)$ \\
\hline Presença de células da série megacariocítica & $39(37)$ & $3(25)$ & $27(39)$ & $1(17)$ & $11(31)$ & $2(33)$ \\
\hline Displasia da série megacariocítica & $15(14,1)$ & $0(0)$ & $8(11)$ & $0(0)$ & $7(19,4)$ & $0(0)$ \\
\hline Megacariócitos binucleados & $2(2)$ & $0(0)$ & $1(1)$ & $0(0)$ & $1(3)$ & $0(0)$ \\
\hline Megacariócitos multinucleados & $3(3)$ & $0(0)$ & $1(1)$ & $0(0)$ & $2(6)$ & $0(0)$ \\
\hline Megacariócitos não lobulados & $15(14,1)$ & $0(0)$ & $9(12,8)$ & $0(0)$ & $6(17)$ & $0(0)$ \\
\hline Distúrbio arquitetural da série megacariocítica & $4(4)$ & $0(0)$ & $1(1)$ & $0(0)$ & $3(8)$ & $0(0)$ \\
\hline Blastos CD34-positivos (até 5\%) & $11(10)$ & $0(0)$ & $8(11)$ & $0(0)$ & $3(8)$ & $0(0)$ \\
\hline Reticulogênese grau 1 em escala de 0 a 3 & $2(2)$ & $1(8)$ & $0(0)$ & $1(17)$ & $2(6)$ & $0(0)$ \\
\hline Reticulogênese grau 2 em escala de 0 a 4 & $2(2)$ & $1(8)$ & $0(0)$ & $1(17)$ & $2(6)$ & $0(0)$ \\
\hline Índice proliferativo ao Ki-67 $\geq 10 \%$ & $70(66)$ & $7(58)$ & $50(71)$ & $4(67)$ & $20(56)$ & $3(50)$ \\
\hline Critérios de Bennett e Orazi para SMD-h & $16(15)$ & $0(0)$ & $8(17)$ & $0(0)$ & $8(22)$ & $0(0)$ \\
\hline Critérios de Baumann et al. para SMD pediátrica & $29(27)$ & $1(8)$ & $20(29)$ & $0(0)$ & $9(25)$ & $1(17)$ \\
\hline
\end{tabular}




\subsubsection{Avaliação de critérios de Bennett e Orazi e de Baumann et al. aos grupos}

Quando aplicados os critérios morfológicos de SMD hipocelular conforme Bennett e Orazi ${ }^{11}$ ao grupo total (118 pacientes) com relação à evolução para SMD/LMA, 16 pacientes dentre os que não evoluíram apresentavam, pelo menos, um desses critérios e nenhum dos que evoluíram apresentava-os; e não houve diferença estatisticamente significante ao teste exato de Fisher $(p=0,366)$.

Quando aplicados os critérios morfológicos de SMD conforme Baumann et al. ${ }^{7}$ ao mesmo grupo, 29 pacientes dentre os que não evoluíram apresentavam esses critérios e apenas um dos que evoluíram apresentavaos; e houve diferença estatisticamente significante ao teste exato de Fisher $(p=0,036)$, denotando que o grupo com as características analisadas apresentava menor risco de evolução para SMD/LMA.

Quando aplicados os critérios morfológicos de SMD hipocelular conforme Bennett e Orazi ${ }^{11}$ ao grupo total (118 pacientes) com relação à faixa etária (grupo adulto e pediátrico), oito pacientes dentre os 76 adultos e oito dentre os 42 pediátricos apresentavam, pelo menos, um desses critérios, e não houve diferença estatisticamente significante ao teste exato de Fisher ( $p=$ $0,261)$.

Quando aplicados os critérios morfológicos de SMD conforme Baumann et al. ${ }^{7}$ ao mesmo grupo com relação à faixa etária (grupo adulto e pediátrico), 20 pacientes dentre os 76 adultos e dez dentre os 42 pediátricos apresentavam-nos, e não houve diferença estatisticamente significante ao teste exato de Fisher $(p=0,657)$. 
Quanto à sobrevida livre de evento (transformação para SMD/LMA), não houve diferença estatisticamente significante entre os grupos que apresentavam e os que não apresentavam critérios morfológicos de SMD hipocelular conforme Bennett e Orazi ${ }^{11}(p=0,224)$ (Figura 19).

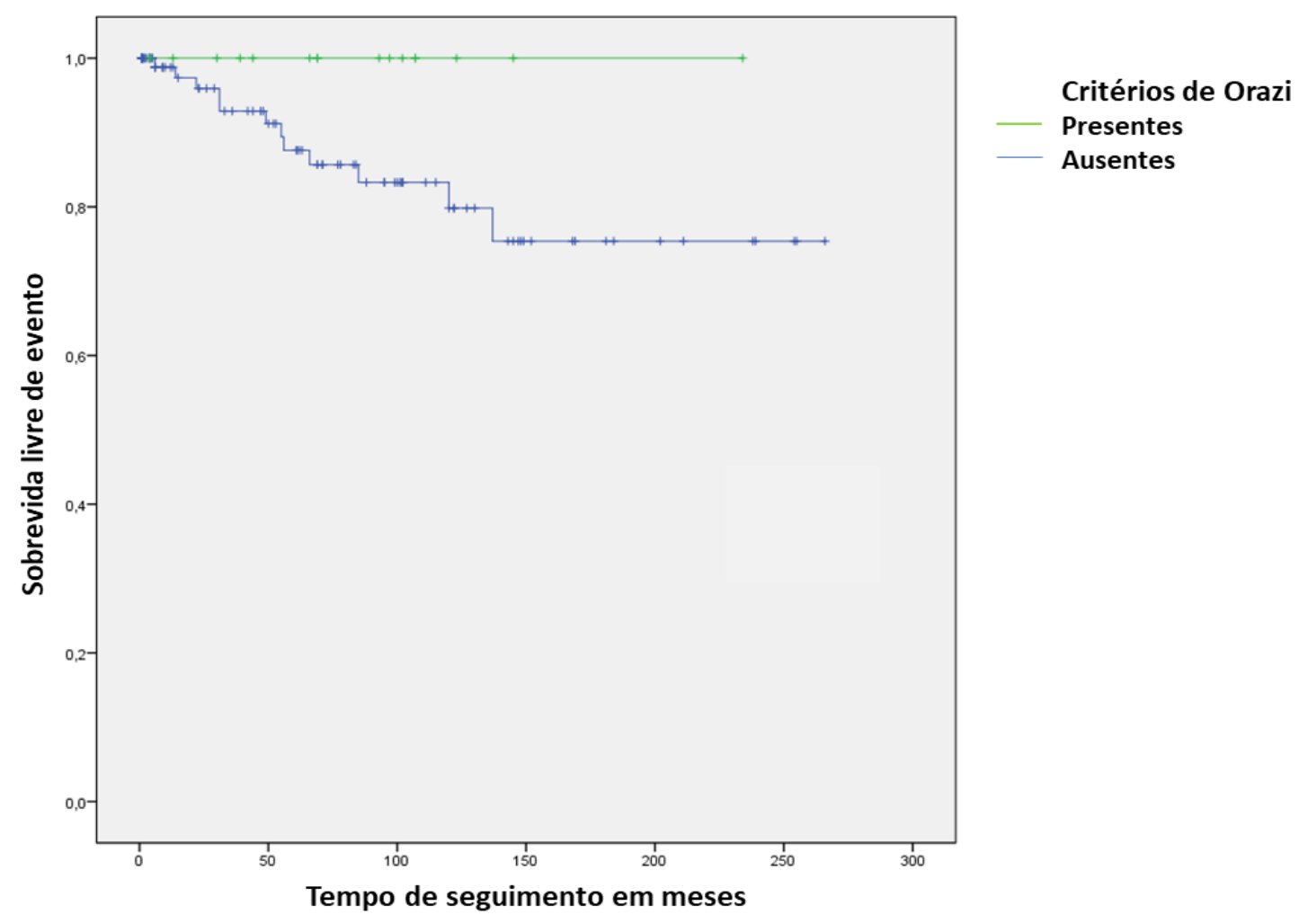

Figura 19 - Sobrevida livre de eventos, conforme os critérios de Bennett e Orazi 
Quanto à sobrevida livre de evento (transformação para SMD/LMA), não houve diferença estatisticamente significante entre os grupos que apresentavam e os que não apresentavam critérios morfológicos de SMD conforme Baumann et al. ${ }^{7}(p=0,555)$ (Figura 20).

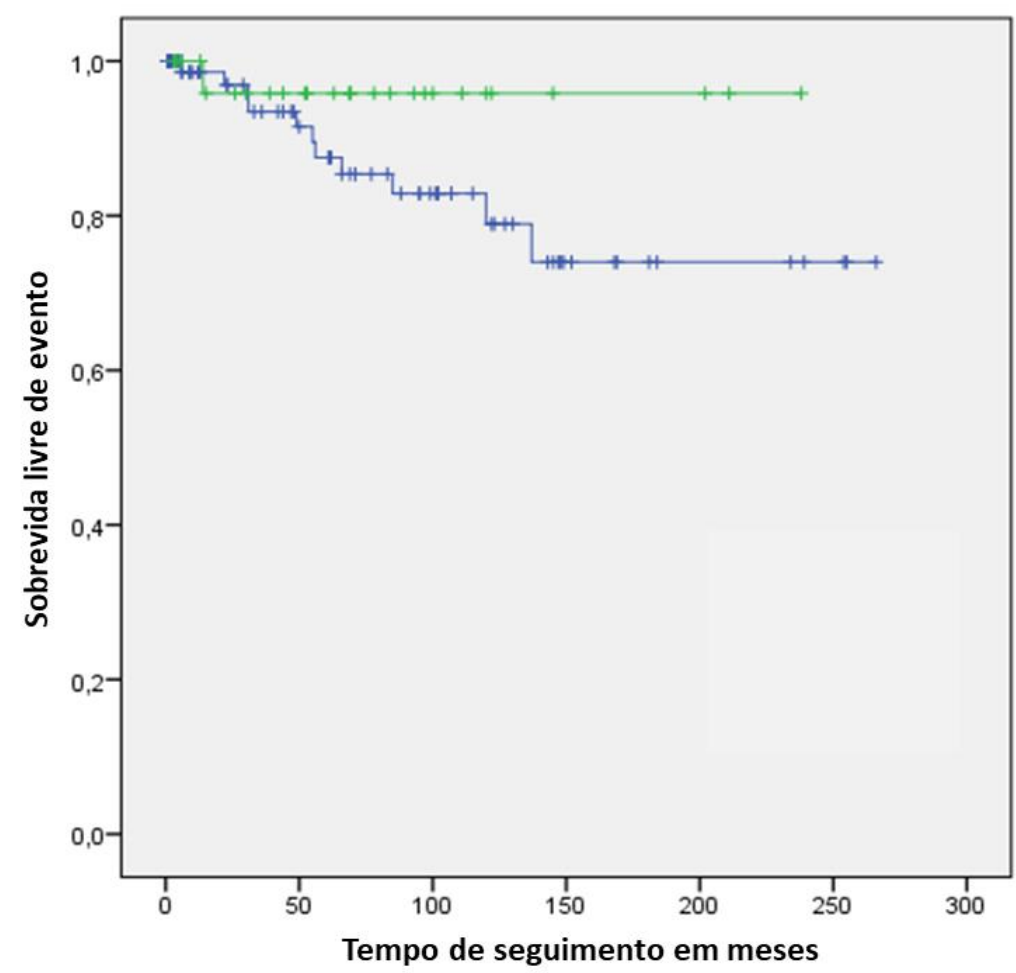

Critérios de Baumann

- Presentes

Ausentes

Figura 20 - Sobrevida livre de eventos, conforme os critérios de Baumann et al. 


\subsubsection{Avaliação do índice proliferativo (Ki-67) em relação à celularidade geral do grupo total}

Índice proliferativo, avaliado pela imunoexpressão do marcador Ki-67, maior que $10 \%$ foi observado em $77(65,2 \%)$ pacientes (Figura 21). Foi observada correlação entre os valores de celularidade geral das amostras e seu índice proliferativo (Figura 22) em porcentagem, avaliada pelo teste não paramétrico Rô de Spearman (Tabela 9). A correlação é estatisticamente significante no nível 0,01 , porém não é preditora. Alguns casos com celularidade baixa tiveram alto índice proliferativo (Figura 23) e alguns com celularidade mais alta tiveram baixo índice (Figura 24).

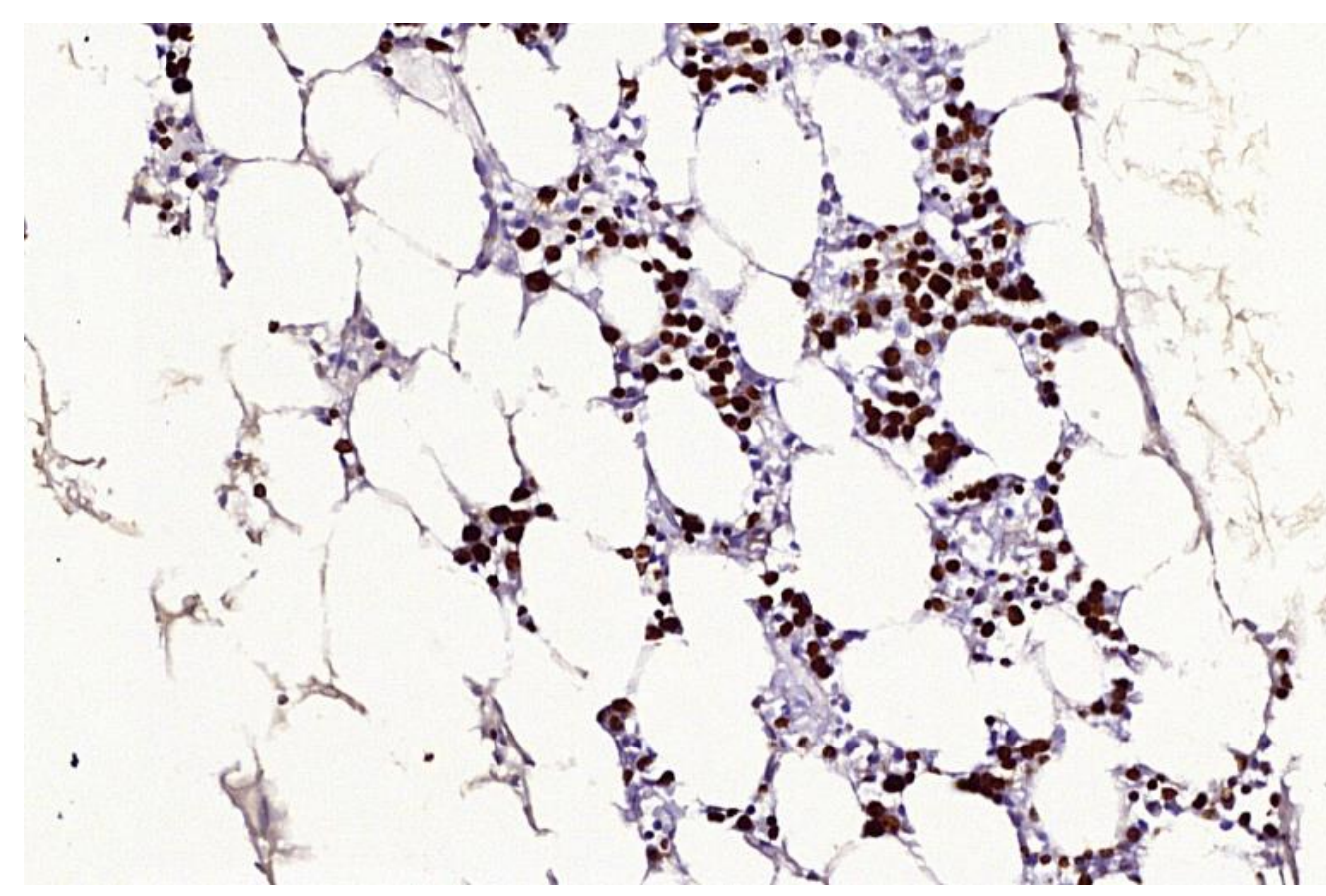

Figura 21 - Índice proliferativo ao Ki-67 alto (90\% das células nesse campo) no tecido hematopoético (Ki-67, 200x) 
Tabela 9 - Correlação entre celularidade e índice proliferativo pelo teste Rô de Spearman

\begin{tabular}{|c|c|c|c|c|}
\hline \multicolumn{5}{|c|}{ Correlações } \\
\hline & & & CEL GERAL & Ki-67 \% \\
\hline \multirow{6}{*}{$\begin{array}{l}\text { Rô de } \\
\text { Spearman }\end{array}$} & \multirow{3}{*}{ CEL GERAL } & Correlações de coeficiente & 1,000 &, $331^{* *}$ \\
\hline & & Sig. (duas extremidades) & &, 000 \\
\hline & & $\mathrm{N}$ & 118 & 118 \\
\hline & \multirow{3}{*}{$\mathrm{Ki}-67 \%$} & Correlações de coeficiente &, $331^{* *}$ & 1,000 \\
\hline & & Sig. (duas extremidades) &, 000 & . \\
\hline & & $\mathrm{N}$ & 118 & 118 \\
\hline
\end{tabular}

**. A correlação é significativa no nível 0,01 (duas extremidades).

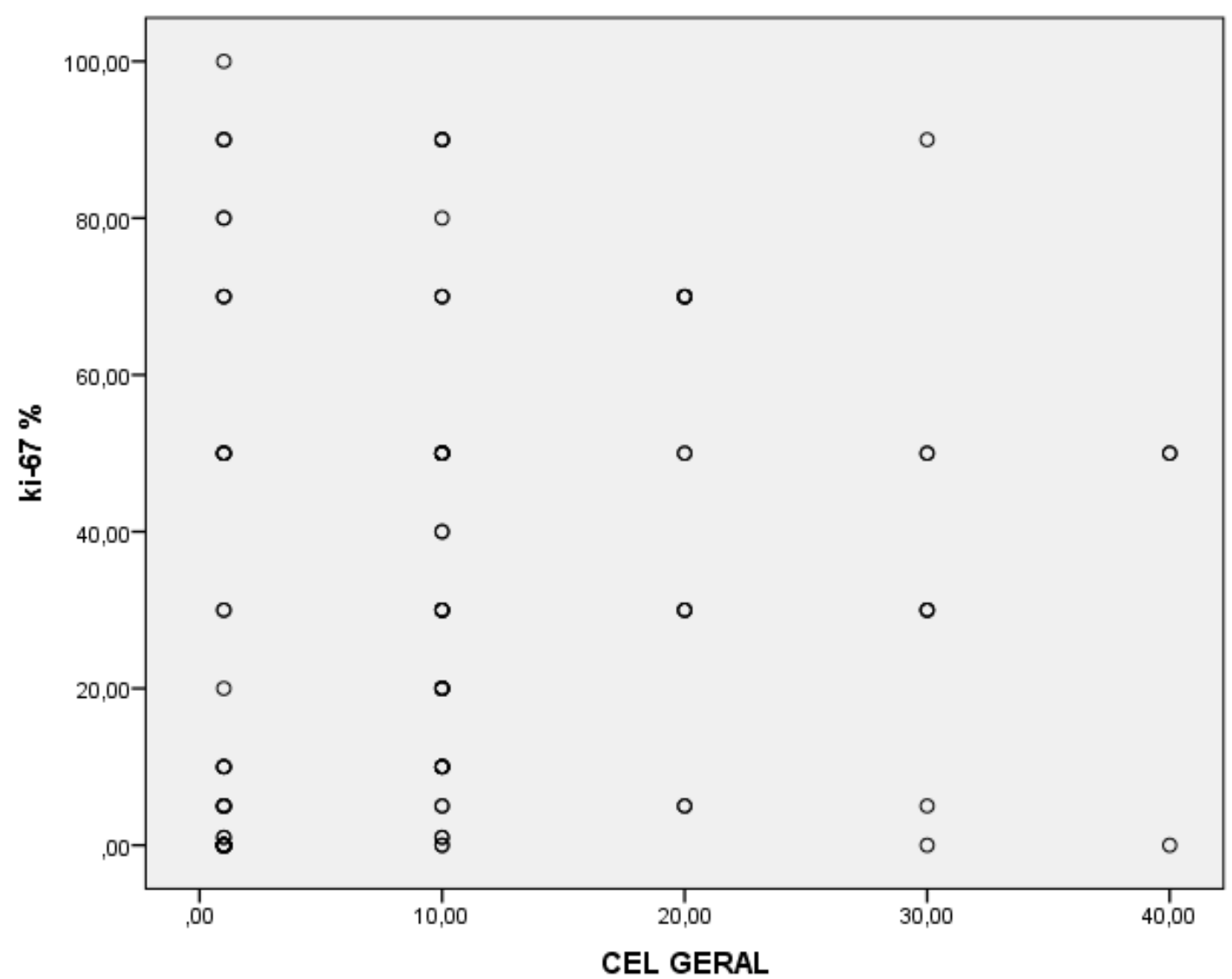

Figura 22 - Correlação positiva entre celularidade medular e índice proliferativo 


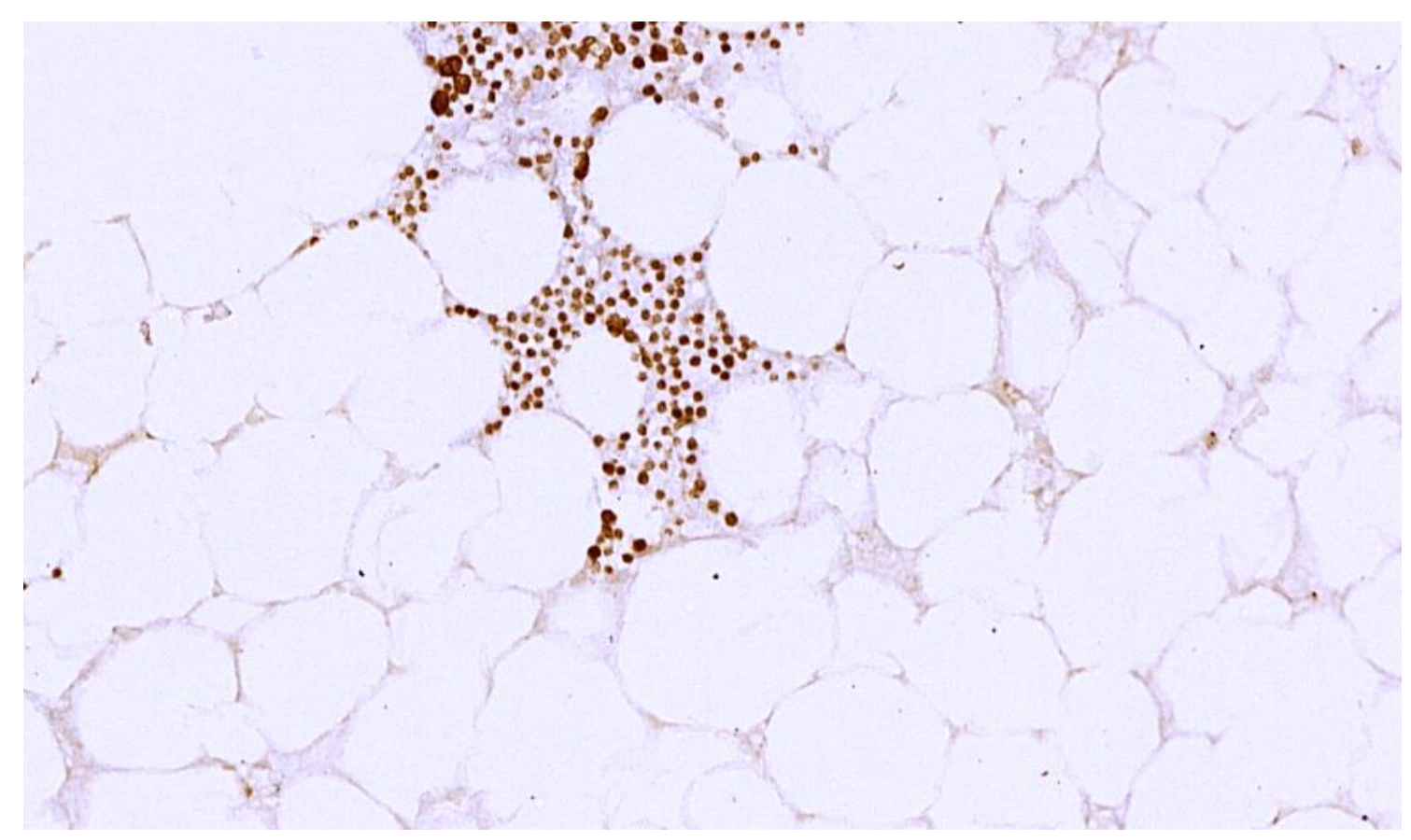

Figura 23 - Índice proliferativo ao Ki-67 alto (aproximadamente 100\% das células nesse campo) no tecido hematopoético de amostra com baixa celularidade (Ki-67, 200x)

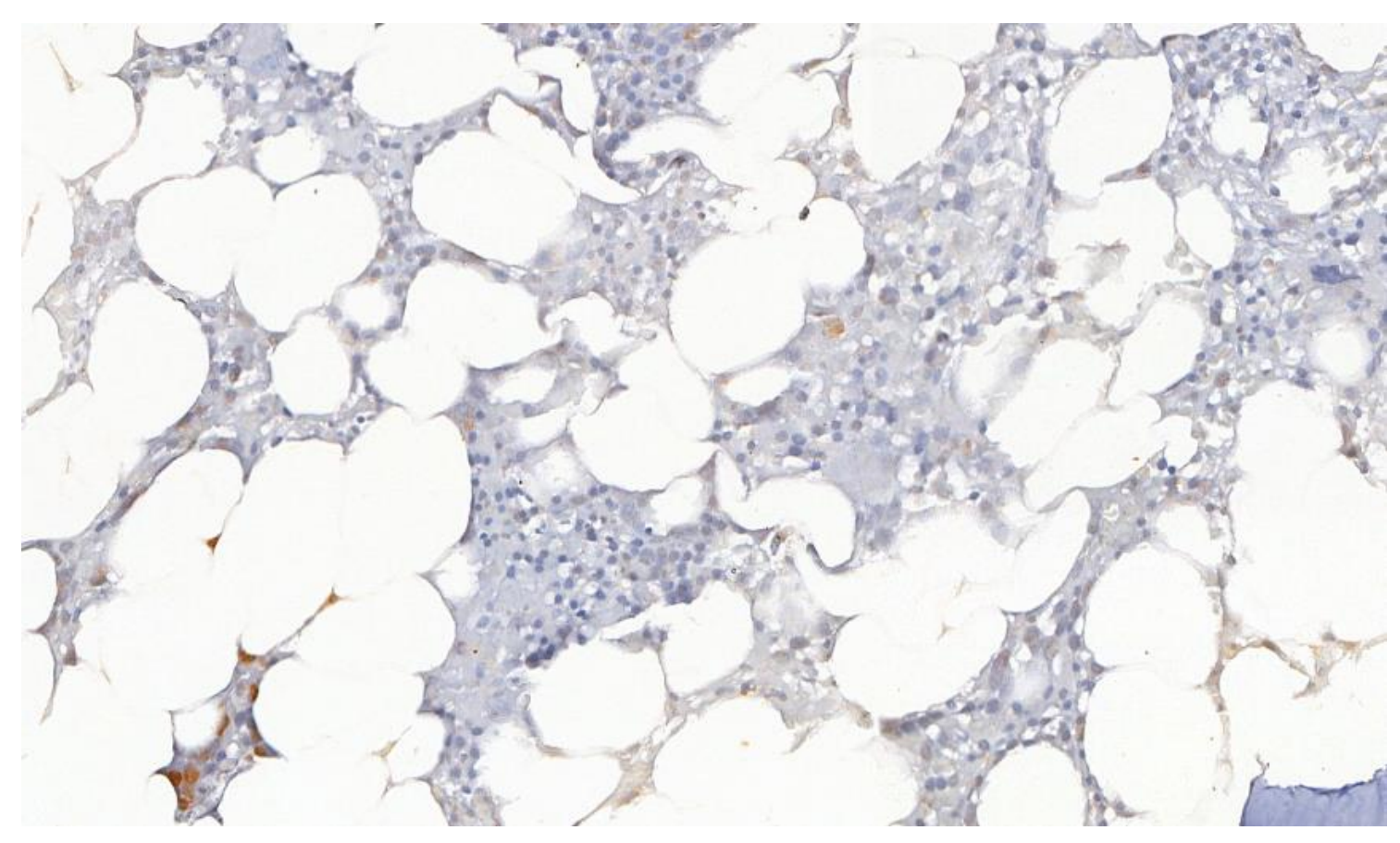

Figura 24 - Índice proliferativo ao Ki-67 baixo (cerca de 5\% das células nesse campo) no tecido hematopoético de amostra com celularidade relativamente mais alta $(\mathrm{Ki}-67,200 \mathrm{x})$ 


\subsection{CITOGENÉTICA}

Dos 118 pacientes (vide Anexo 3 para resultados individuais e Tabela 10 para dados resumidos), 74 tinham resultado conclusivo e normal de citogenética (FISH e/ou cariótipo); 60 tinham resultado citogenético normal ao diagnóstico, 31 apenas por FISH, 10 por cariótipo e 19 por ambos os métodos. Quatorze pacientes tinham resultado de citogenética normal apenas ao seguimento, quatro por FISH, sete por cariótipo e três por ambos. Dez dos 12 pacientes que evoluíram para SMD/LMA tinham alterações do cromossomo 7 (apenas um com deleção 7q e o restante com monossomia do cromossomo 7) à data da evolução, um apenas por cariótipo, cinco apenas por FISH e quatro por ambos os métodos. Seis dos 10 (60\%) pacientes pediátricos com critérios de Bumann et al. e sete de oito $(87,5 \%)$ pacientes adultos com critérios de Bennett e Orazi tinham estudos citogenéticos normais ao diagnóstico, incluindo o paciente pediátrico que evoluiu para SMD/LMA.

Tabela 10 - Resumo dos resultados de citogenética

\begin{tabular}{lccc}
\hline & $\begin{array}{c}\text { Citogenética } \\
\text { normal ao } \\
\text { diagnóstico } \\
(\mathrm{n}=60)\end{array}$ & $\begin{array}{c}\text { Citogenética } \\
\text { normal ao } \\
\text { seguimento } \\
(\mathrm{n}=14)\end{array}$ & $\begin{array}{c}\text { Monossomia ou deleção } \\
\text { do cromossomo } 7 \text { à } \\
\text { evolução para SMD/LMA } \\
(\mathrm{n}=10)\end{array}$ \\
\hline FISH n (\%) & $31(51,7)$ & $4(28,6)$ & $5(50)$ \\
Cariótipo n (\%) & $10(16,6)$ & $7(50)$ & $1(10)$ \\
FISH e cariótipo n $(\%)$ & $19(31,7)$ & $3(21,4)$ & $4(40)$ \\
\hline
\end{tabular}

FISH: fluorescent in situ hybridization. 


\subsection{DESCRIÇÃO DOS 12 PACIENTES QUE EVOLUÍRAM PARA SMD/LMA}

Do grupo total de 118 pacientes, 12 evoluíram para SMD/LMA e sua análise descritiva encontra-se no item 5.1 e a análise da qualidade das amostras no item 5.2.1.

Os achados morfológicos estão descritos nos dados da Tabela 11; e as Figuras 25 a 36 são referentes a cada um dos pacientes. Quanto à distribuição irregular do tecido hematopoético, seis $(50 \%)$ apresentavam-na. A média de celularidade geral foi $7,8 \%$ (mediana de 10 e desvio-padrão 7,18). A série granulocítica constituiu cerca de $64 \%$ do tecido hematopoético (mediana de 70 e desvio-padrão 32,9 ) com a série eritrocítica constituindo os $26 \%$ complementares (mediana de 25 e desvio-padrão 27,3) (proporção normal de cerca de 2,4:1 de série granulocítica em relação à eritrocítica). Não foi observado distúrbio de maturação da série granulocítica em nenhum caso. Presença de distúrbio arquitetural da série eritrocítica em um caso, de agrupamentos da mesma em seis casos, de formas jovens em apenas um e de mitoses desta série em dois casos. A série megacariocítica estava representada em apenas três amostras, sem evidências de displasia. A presença de blastos não foi identificada em nenhumas das amostras. A reticulogênese quando graduada de 0 a 3 estava aumentada (grau 1) em um caso, que também apresentava reticulogênese grau 2 quando graduada de 0 a 4. Um caso apresentava reticulogênese grau 1 (de 0 a 4). $O$ índice proliferativo do tecido hematopoético ao Ki-67 teve média de 36\% (mediana de 15 e desvio-padrão 38,9). Apenas uma das amostras com índice proliferativo de valor nulo (zero). Destes 12 pacientes, dez apresentaram monossomia ou deleção do braço longo do cromossomo 7 ao FISH ou cariótipo ao seguimento (cinco por FISH, nove por cariótipo e quatro por ambos os métodos) e, dos outros dois, um tinha FISH normal, com excesso de blastos ao mielograma e o outro não tinha material disponível para citogenética, mas apresentava excesso de blastos à biópsia de medula óssea. 
Tabela 11 - Descrição morfológica resumida dos 12 pacientes que evoluíram para SMD/LMA

\begin{tabular}{|c|c|c|c|c|c|c|c|c|c|c|c|c|c|c|}
\hline Paciente & $\begin{array}{l}\text { Idade } \\
\text { (anos) }\end{array}$ & $\begin{array}{l}\text { Distribuição } \\
\text { irregular do } \\
\text { tecido } \\
\text { hematopoético }\end{array}$ & $\begin{array}{l}\text { Celula- } \\
\text { ridade } \\
\text { geral } \\
(\%)\end{array}$ & $\begin{array}{l}\mathrm{SE} \\
\text { celula- } \\
\text { ridade } \\
(\%)\end{array}$ & $\begin{array}{c}\text { SE } \\
\text { distúrbio } \\
\text { arquitetural }\end{array}$ & $\begin{array}{c}\mathrm{SE} \\
\text { agrupa- } \\
\text { mentos }\end{array}$ & $\begin{array}{l}\text { Formas } \\
\text { jovens }\end{array}$ & $\begin{array}{c}\text { SE } \\
\text { mitoses }\end{array}$ & $\begin{array}{l}\mathrm{SM} \mathrm{N}^{\circ} \\
\text { células }\end{array}$ & $\begin{array}{c}\text { SM } \\
\text { displasia }\end{array}$ & $\begin{array}{c}\text { Reticulo- } \\
\text { gênese } \\
0 \text { a } 3\end{array}$ & $\begin{array}{c}\mathrm{Ki}-67 \\
(\%)\end{array}$ & $\begin{array}{c}\text { Critérios } \\
\text { de } \\
\text { Bennett e } \\
\text { Orazi }\end{array}$ & $\begin{array}{c}\text { Critérios } \\
\text { de } \\
\text { Baumann } \\
\text { et al }\end{array}$ \\
\hline 1 & 4,75 & $\mathrm{~N}$ & 10 & 30 & $\mathrm{~N}$ & $S$ & $\mathrm{~N}$ & $\mathrm{~N}$ & 0 & & 0 & 20 & $\mathrm{~N}$ & $\mathrm{~N}$ \\
\hline 2 & 14,83 & $S$ & 20 & 50 & $\mathrm{~N}$ & $S$ & $\mathrm{~N}$ & $\mathrm{~N}$ & 1 & $\mathrm{~N}$ & 0 & 70 & $\mathrm{~N}$ & $\mathrm{~N}$ \\
\hline 3 & 4,08 & $\mathrm{~N}$ & 1 & 0 & & & & & 1 & $\mathrm{~N}$ & 0 & 1 & $\mathrm{~N}$ & $\mathrm{~N}$ \\
\hline 4 & 6,75 & $\mathrm{~N}$ & 1 & 0 & & & & & 0 & & 0 & 0 & $\mathrm{~N}$ & $\mathrm{~N}$ \\
\hline 5 & 6,42 & $S$ & 10 & 20 & $\mathrm{~N}$ & $S$ & $S$ & $S$ & 0 & & 0 & 90 & $\mathrm{~N}$ & $S$ \\
\hline 6 & 2,75 & $S$ & 1 & 0 & & & & & 0 & & 0 & 1 & $\mathrm{~N}$ & $\mathrm{~N}$ \\
\hline 7 & 25,25 & $S$ & 10 & 40 & $S$ & $S$ & $\mathrm{~N}$ & $\mathrm{~N}$ & 1 & $\mathrm{~N}$ & 1 & 10 & $\mathrm{~N}$ & $\mathrm{~N}$ \\
\hline 8 & 21,92 & $\mathrm{~N}$ & 10 & 30 & $\mathrm{~N}$ & $\mathrm{~N}$ & $\mathrm{~N}$ & $\mathrm{~N}$ & 0 & & 0 & 5 & $\mathrm{~N}$ & $\mathrm{~N}$ \\
\hline 9 & 23,75 & $S$ & 1 & 90 & $\mathrm{~N}$ & $S$ & $\mathrm{~N}$ & $\mathrm{~N}$ & 0 & & 0 & 90 & $\mathrm{~N}$ & $\mathrm{~N}$ \\
\hline 10 & 21,00 & $\mathrm{~N}$ & 1 & 10 & $\mathrm{~N}$ & $\mathrm{~N}$ & $\mathrm{~N}$ & $S$ & 0 & & 0 & 5 & $\mathrm{~N}$ & $\mathrm{~N}$ \\
\hline 11 & 66,17 & $S$ & 20 & 50 & $\mathrm{~N}$ & $S$ & $\mathrm{~N}$ & $\mathrm{~N}$ & 0 & & 0 & 50 & $\mathrm{~N}$ & $\mathrm{~N}$ \\
\hline 12 & 54,67 & $\mathrm{~N}$ & 10 & 50 & $\mathrm{~N}$ & $S$ & $\mathrm{~N}$ & $\mathrm{~N}$ & 0 & & 0 & 90 & $\mathrm{~N}$ & $N$ \\
\hline
\end{tabular}

S: sim (presente); N: não (ausente); SE: série eritrocítica; SM: série megacariocítica. 


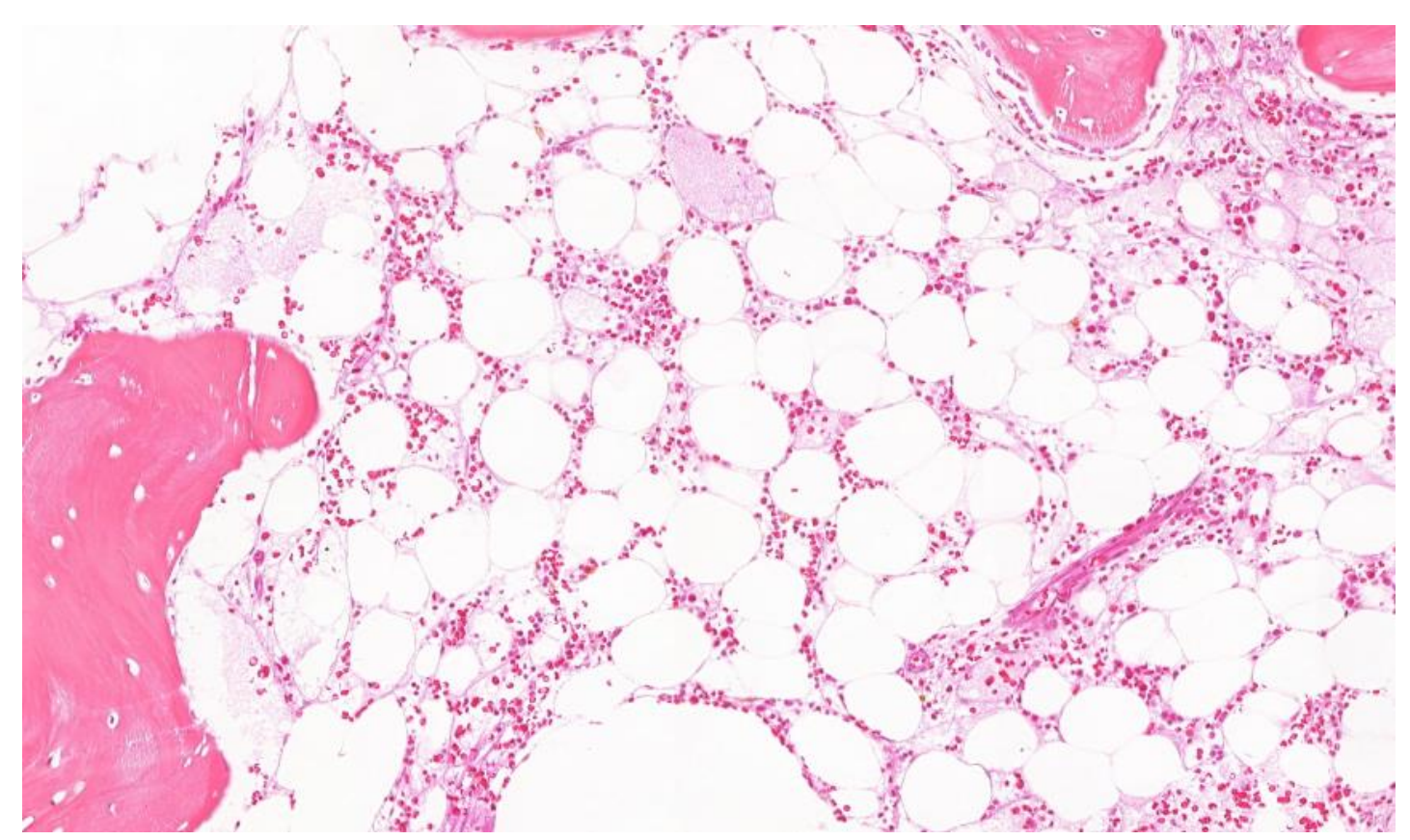

Figura 25 - Biópsia de MO na data do diagnóstico da AAA referente ao paciente 1 (HE, 100x)

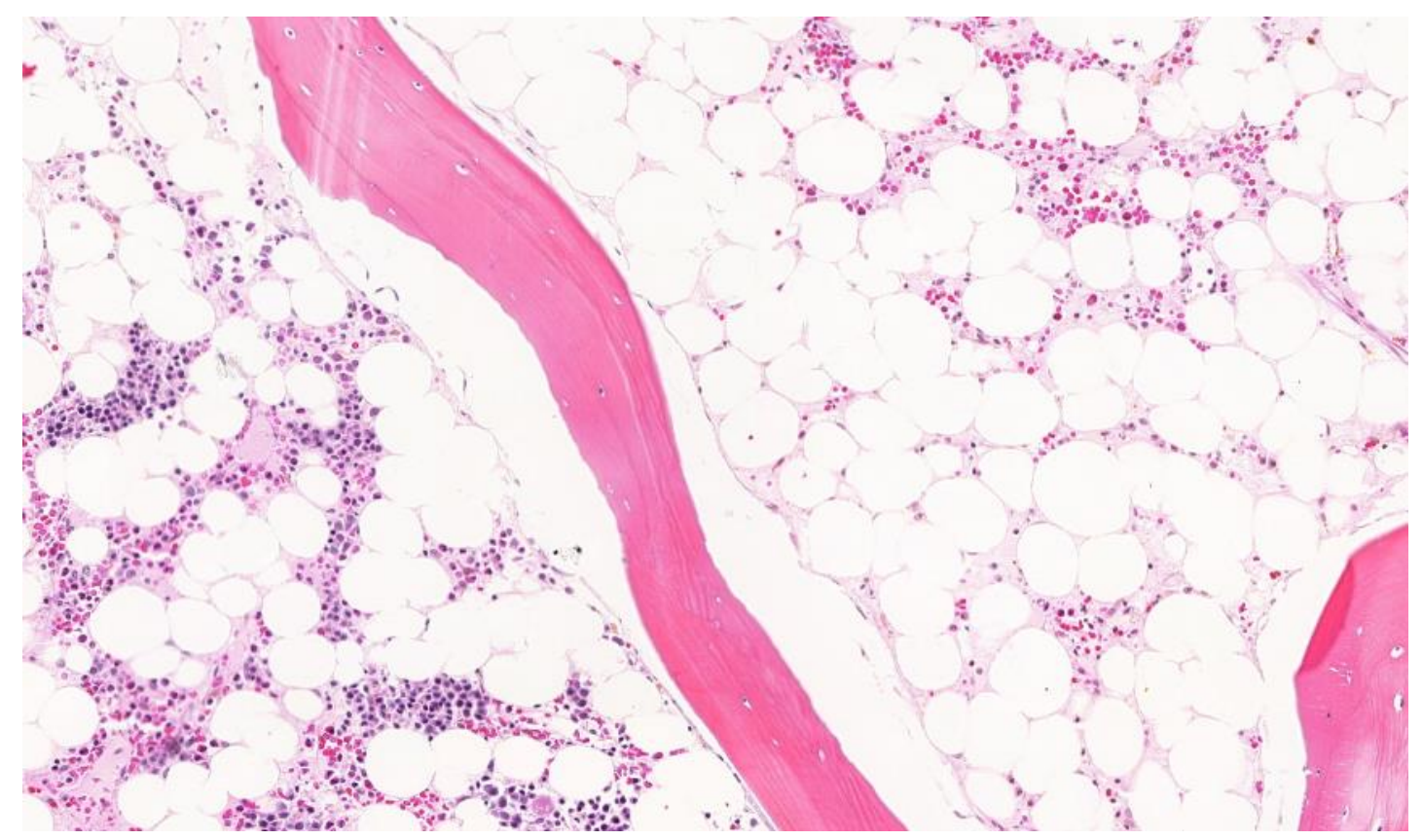

Figura 26 - Biópsia de MO na data do diagnóstico da AAA referente ao paciente 2 (HE, 100x) 


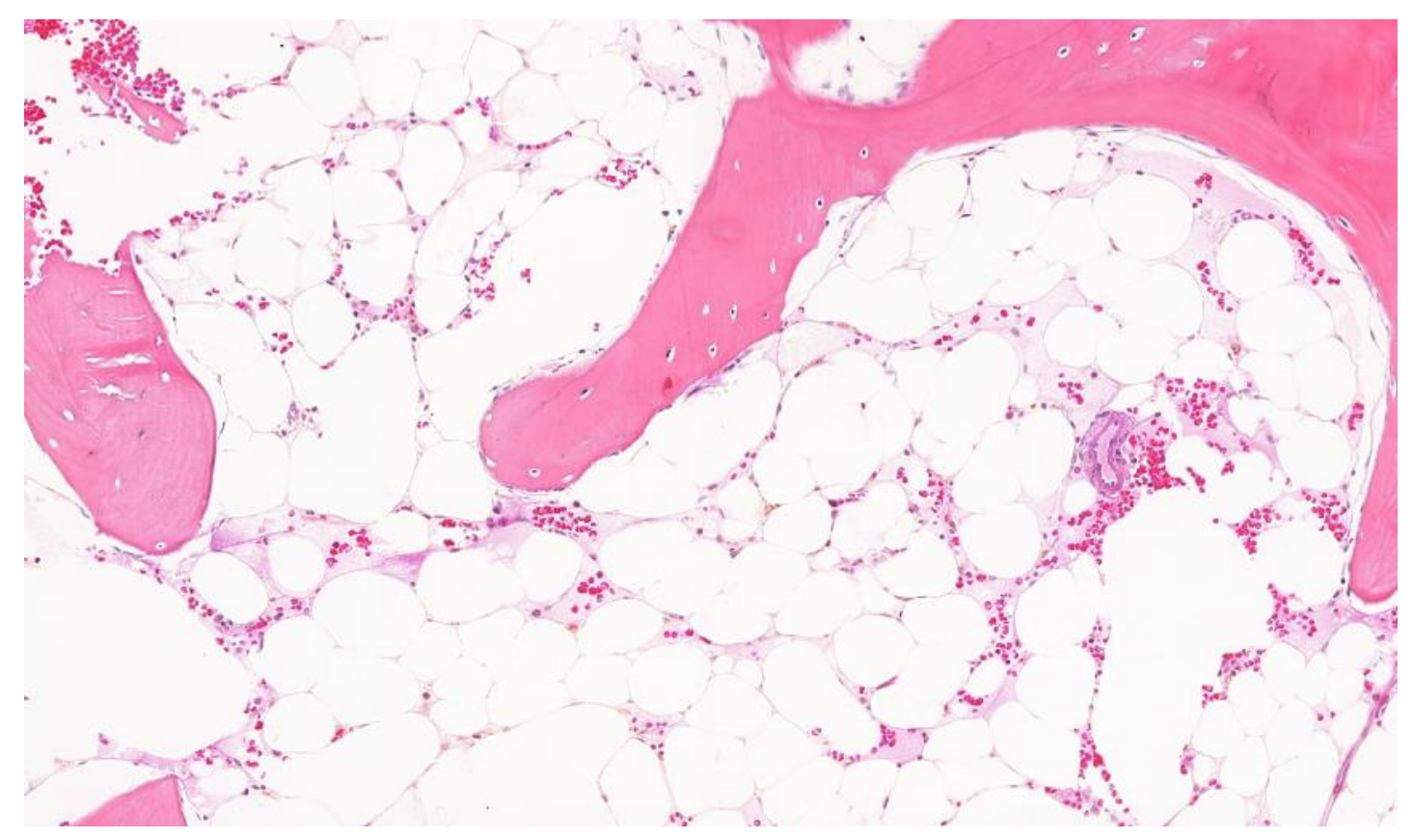

Figura 27 - Biópsia de MO na data do diagnóstico da AAA referente ao paciente 3 (HE, 100x)

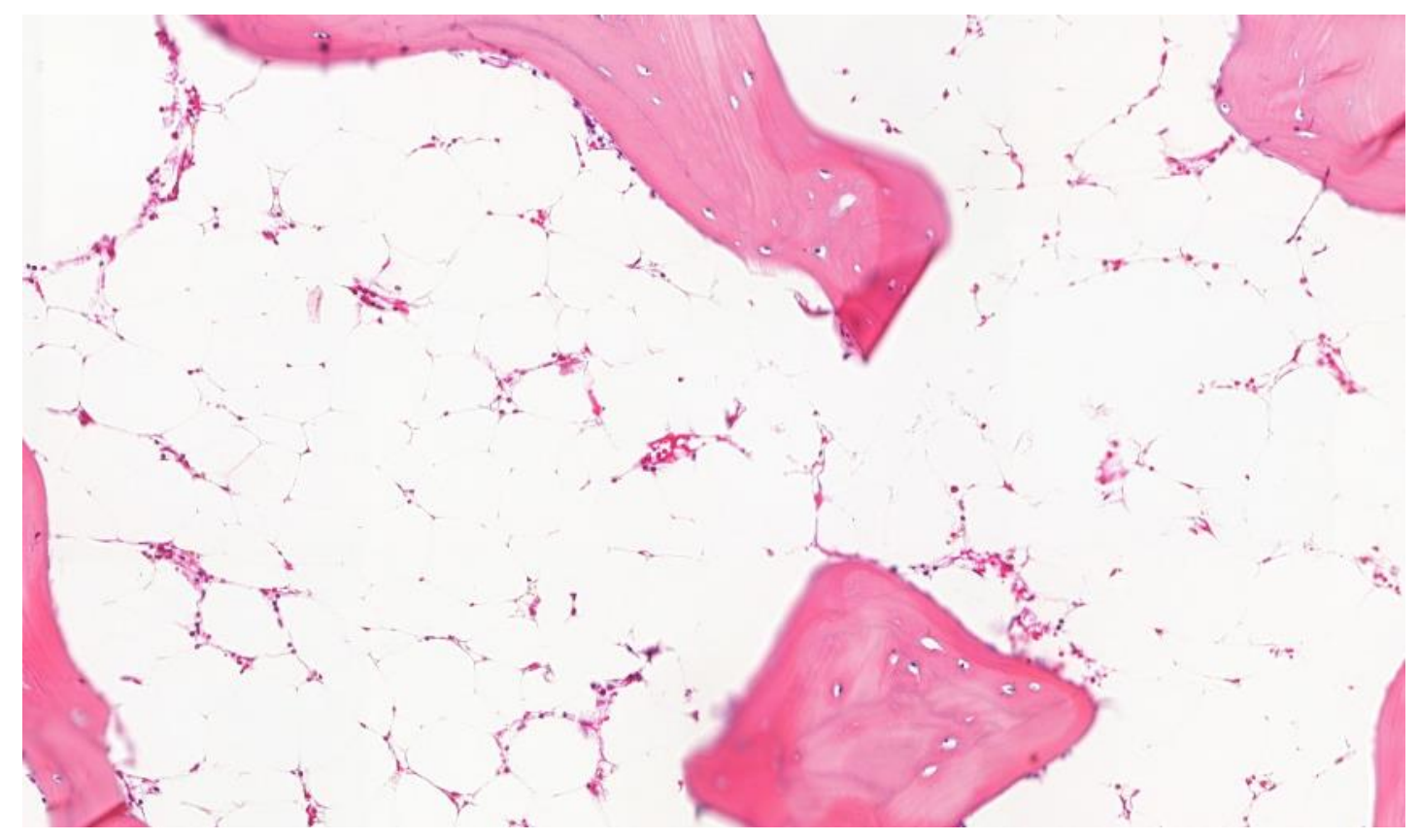

Figura 28 - Biópsia de MO na data do diagnóstico da AAA referente ao paciente 4 (HE, 100x) 


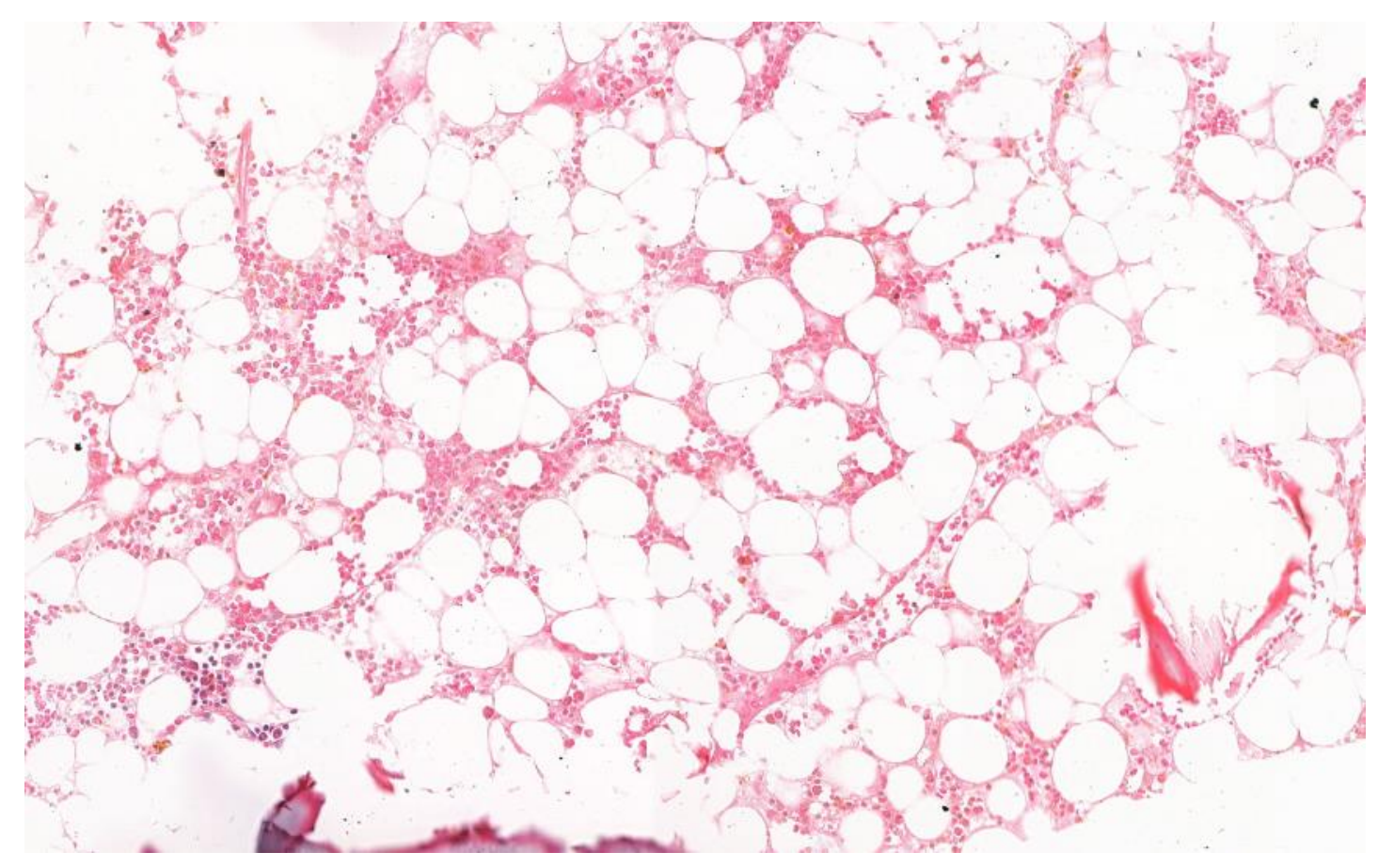

Figura 29 - Biópsia de MO na data do diagnóstico da AAA referente ao paciente 5 (HE, 100x)

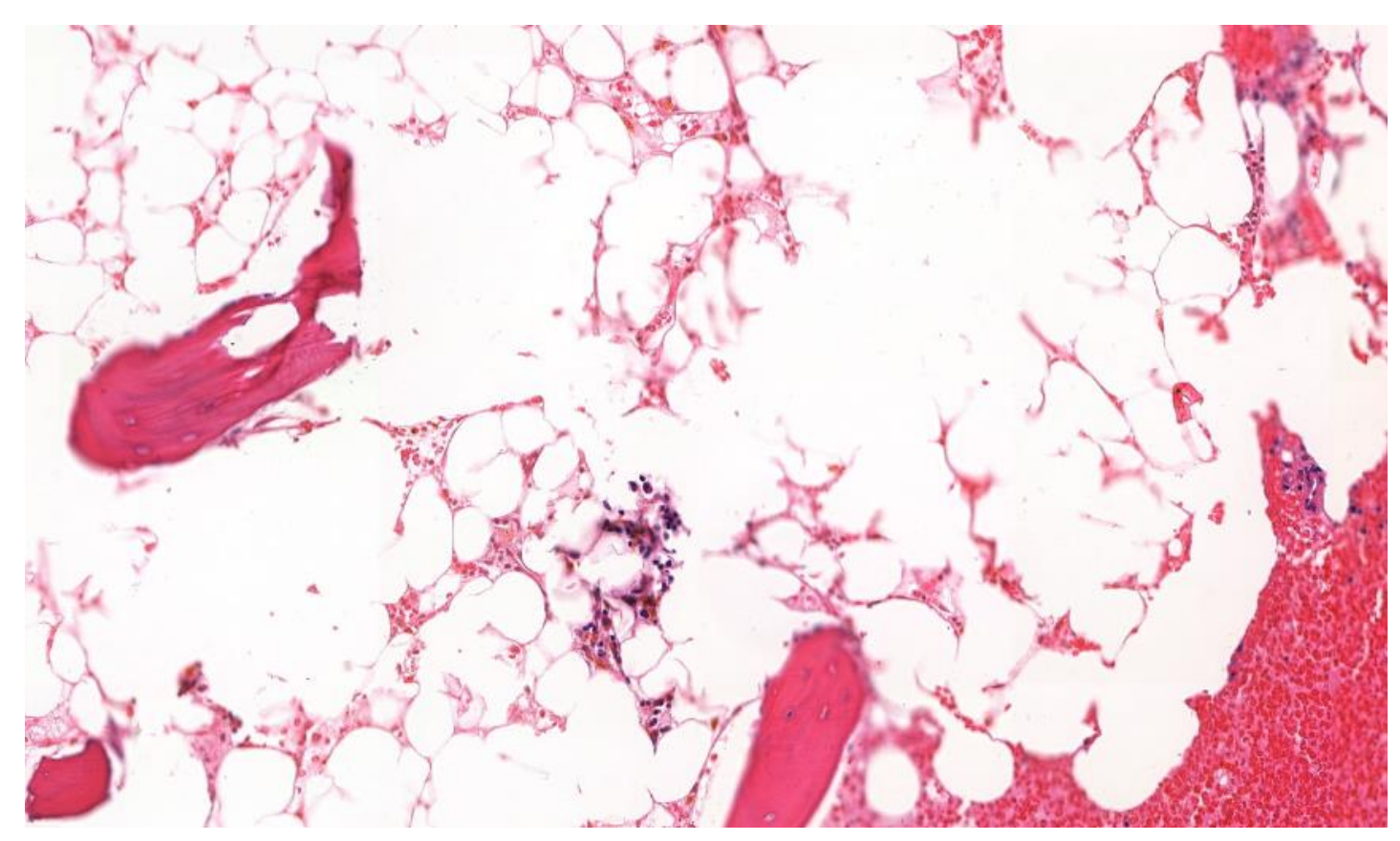

Figura 30 - Biópsia de $M O$ na data do diagnóstico da AAA referente ao paciente $6(\mathrm{HE}, 100 \mathrm{x})$ 


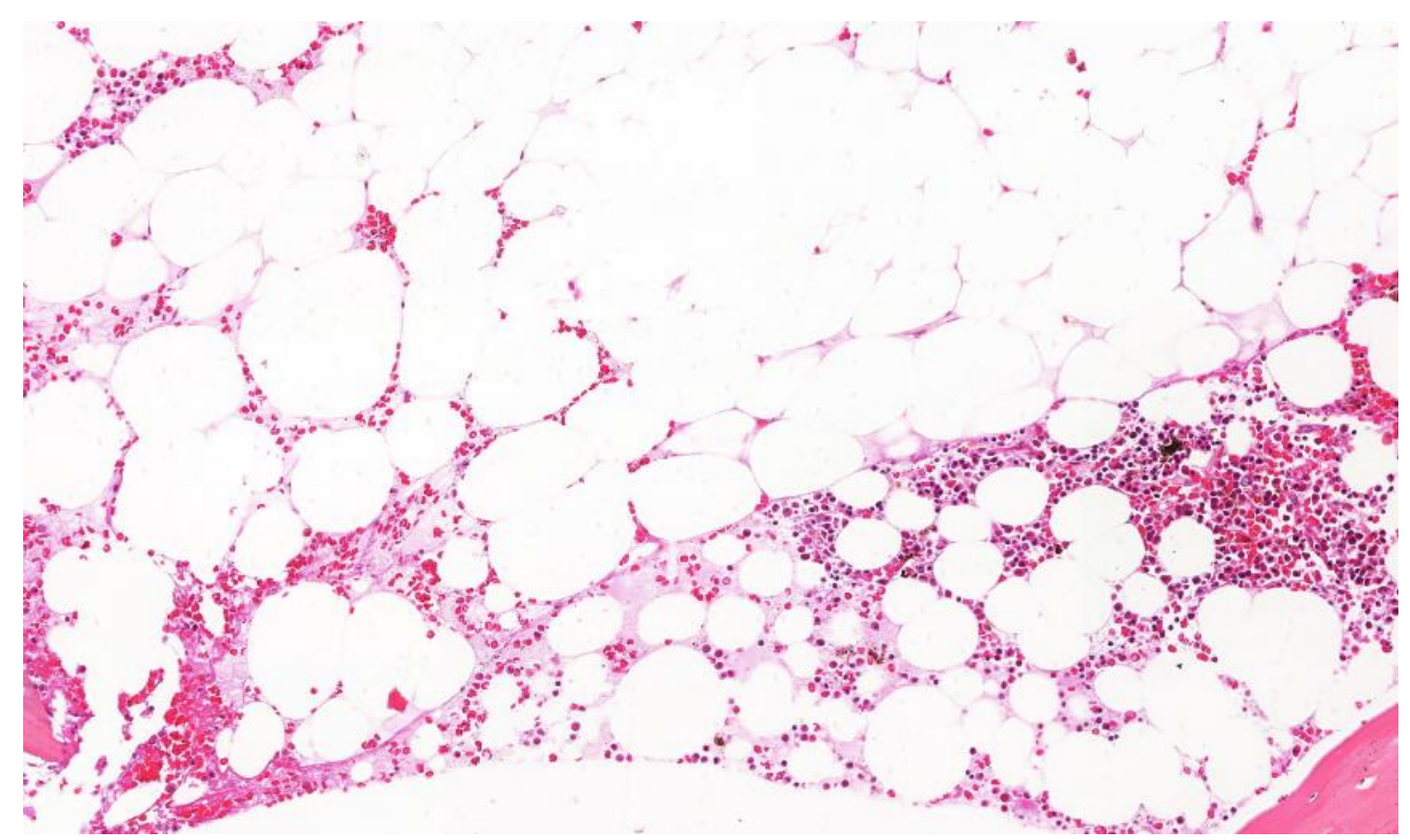

Figura 31 - Biópsia de $M O$ na data do diagnóstico da AAA referente ao paciente 7 (HE, 100x)

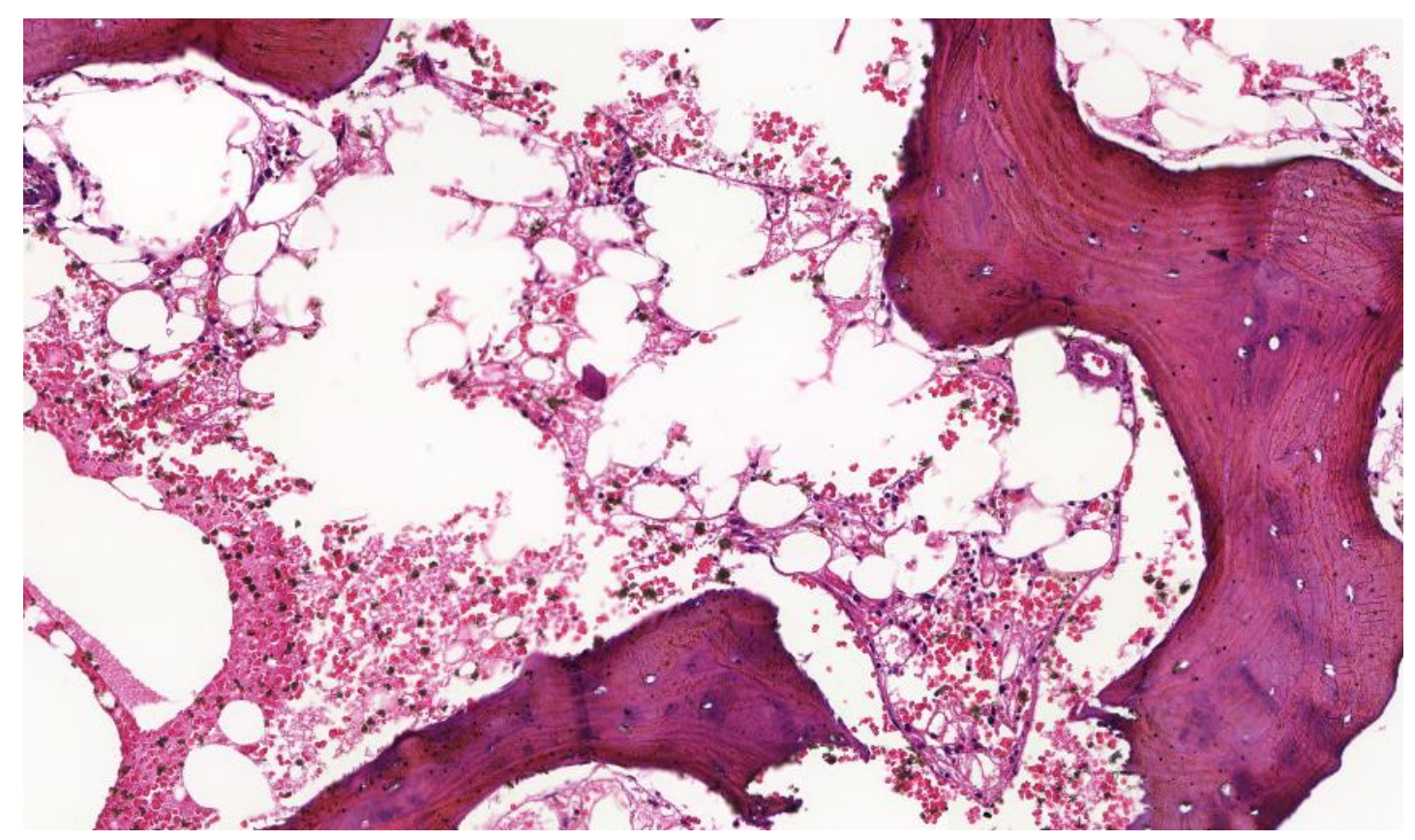

Figura 32 - Biópsia de $M O$ na data do diagnóstico da AAA referente ao paciente 8 (HE, 100x) 


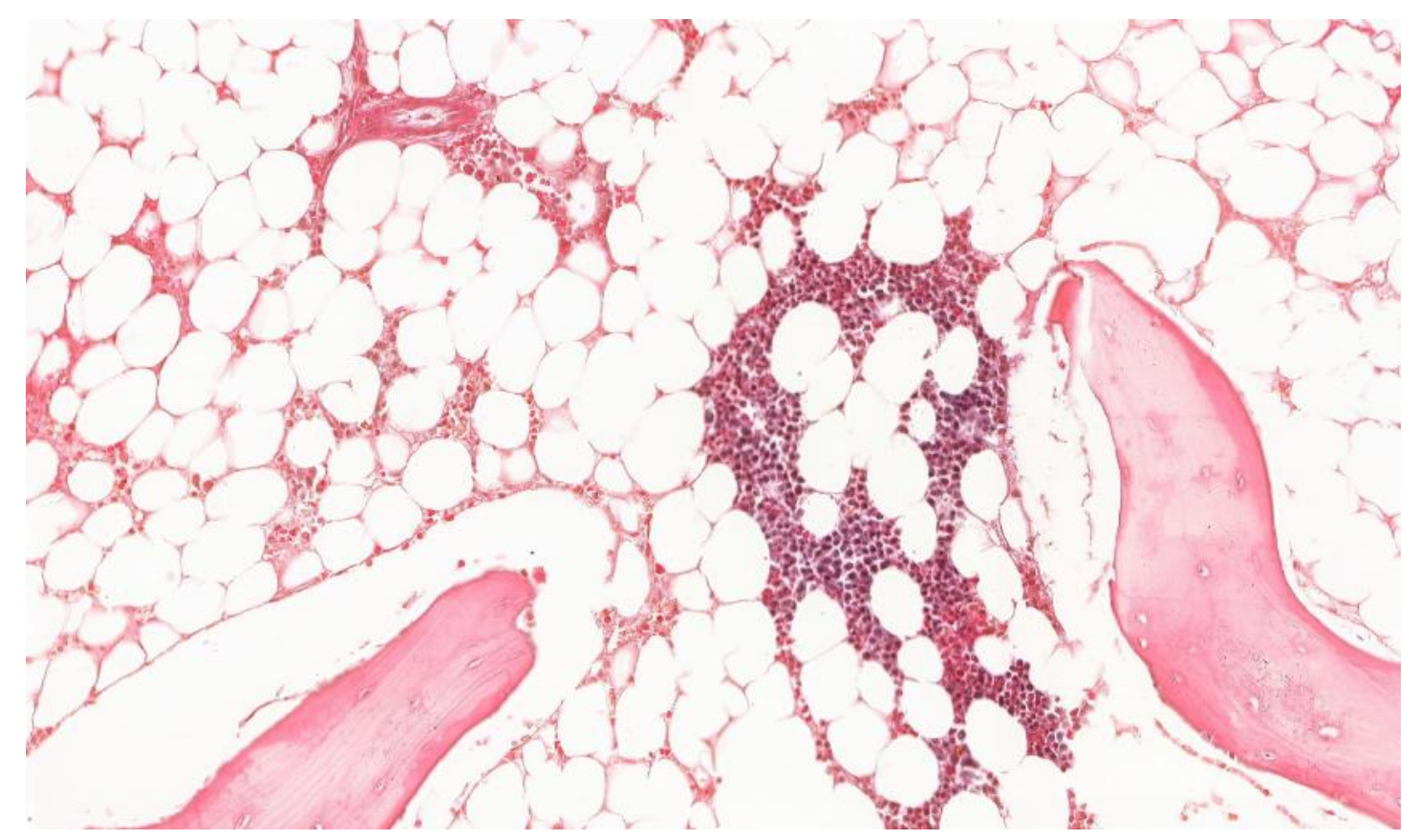

Figura 33 - Biópsia de $\mathrm{MO}$ na data do diagnóstico da AAA referente ao paciente 9 (HE, 100x)

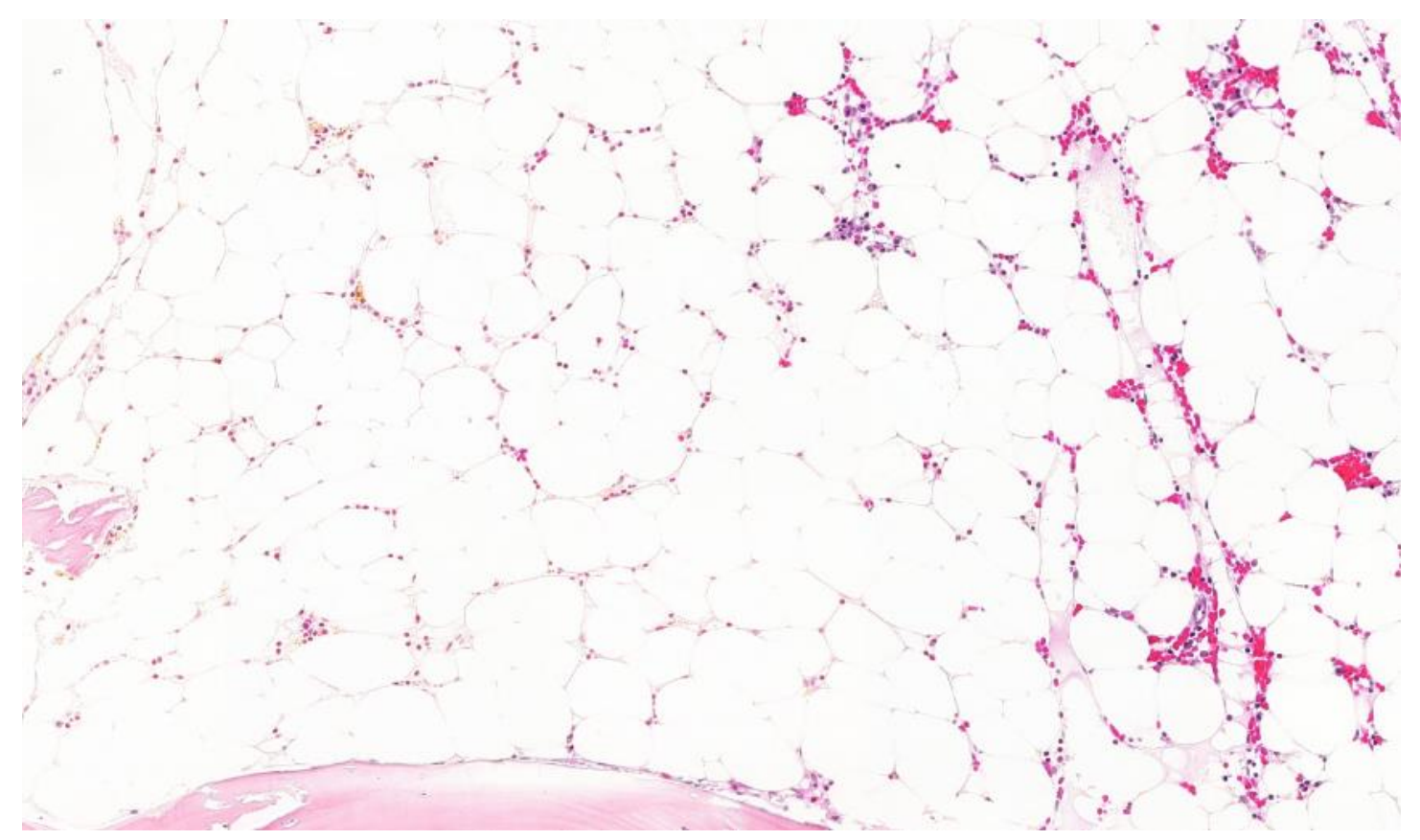

Figura 34 - Biópsia de $M O$ na data do diagnóstico da AAA referente ao paciente 10 (HE, 100x) 


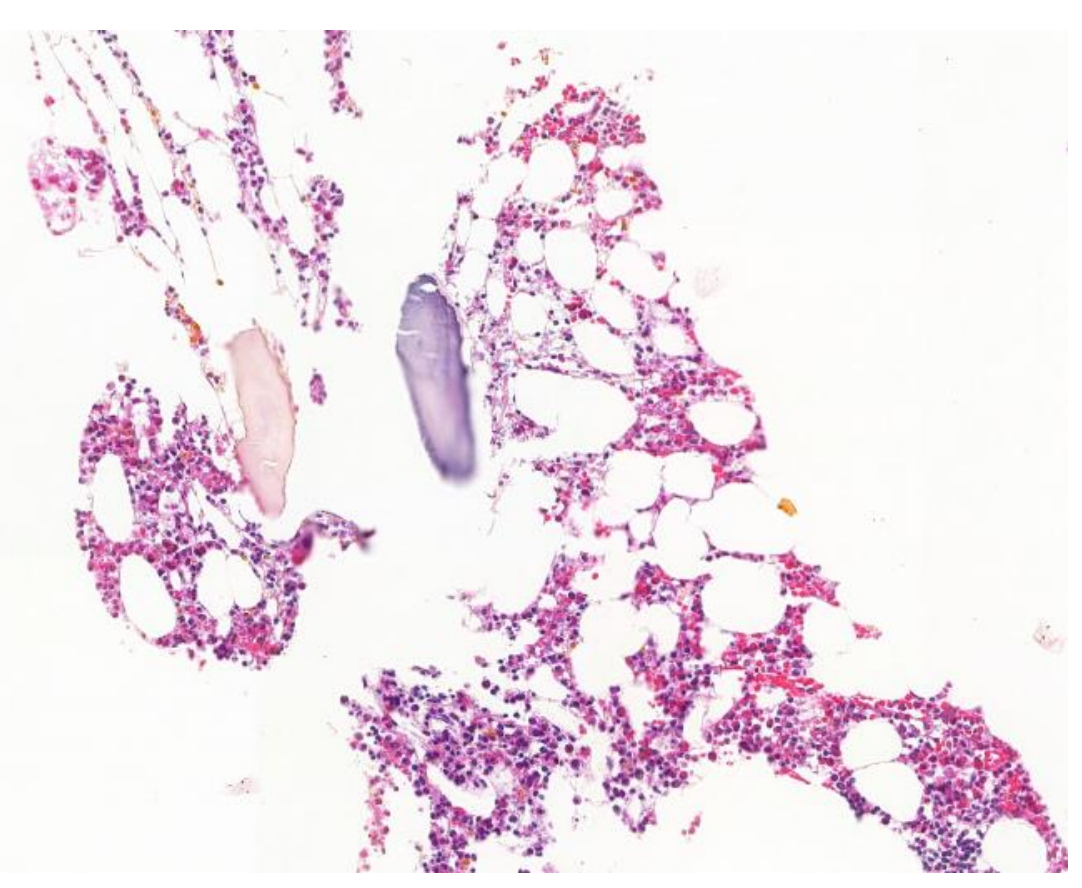

Figura 35 - Biópsia de $\mathrm{MO}$ na data do diagnóstico da AAA referente ao paciente 11 (HE, 100x)

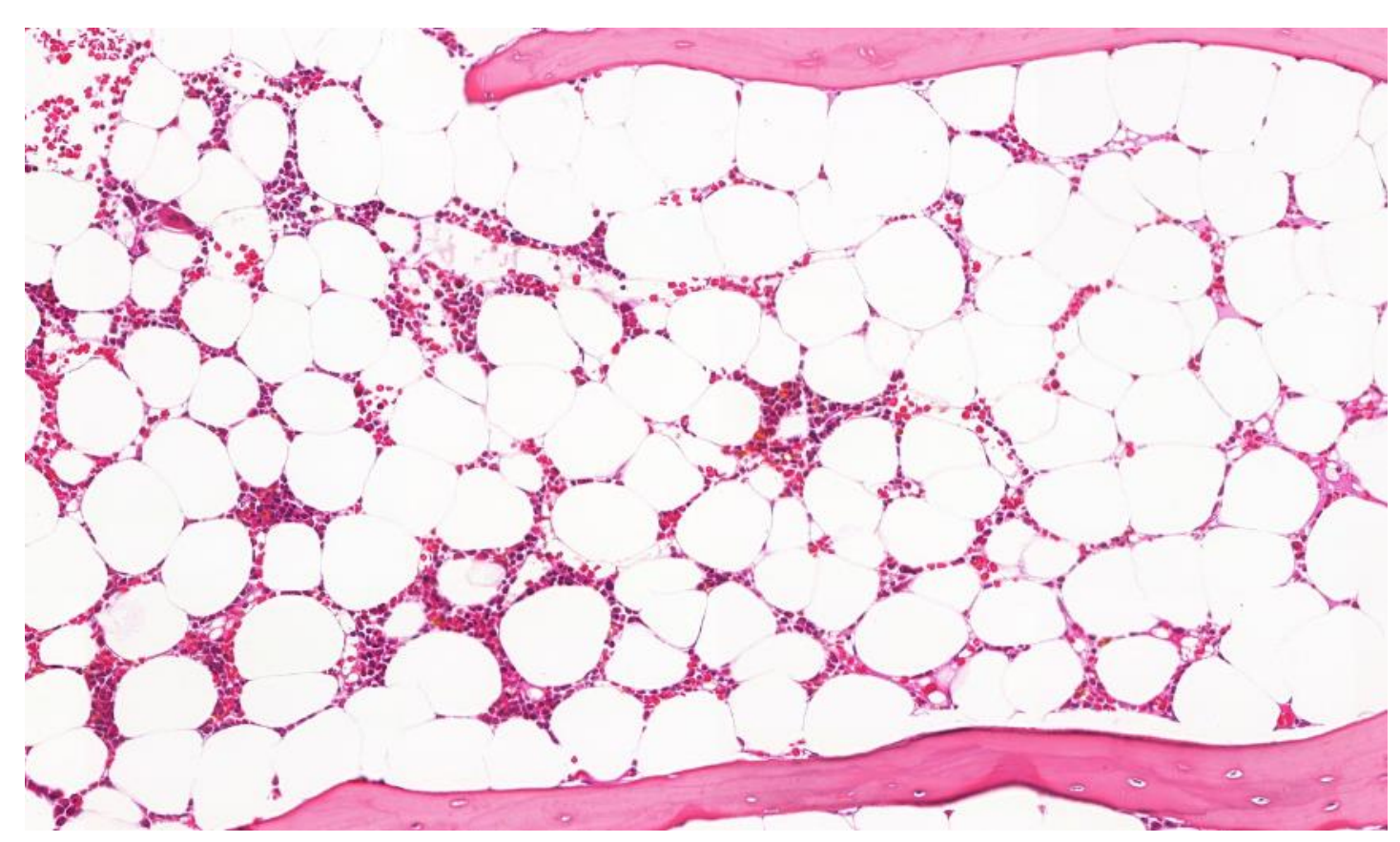

Figura 36 - Biópsia de $M O$ na data do diagnóstico da AAA referente ao paciente 12 (HE, 100x) 
6 Discussão 


\section{DISCUSSÃO}

Uma das complicações mais temíveis da Anemia Aplástica Adquirida é sua evolução para Síndrome Mielodisplásica ou Leucemia Mieloide Aguda. O diagnóstico de certeza de aplasia medular é necessário, mas, muitas vezes, confunde-se com o da SMD hipocelular e também há dúvidas se podem existir dados clínicos ou laboratoriais em aplasia medular que possam ajudar na determinação do risco de evolução para doença clonal medular. Nesse processo, a biópsia de MO é fundamental e decisiva. A iniciativa de realizar este estudo partiu da observação clínica hematológica de evolução dos pacientes com AAA para SMD/LMA e do intuito de reavaliar os critérios diagnósticos de AAA no sentido de se verificar se os casos que evoluíram de forma desfavorável (definida como evolução para SMD/LMA) já poderiam ser diagnosticados como SMD-h desde o início utilizando-se de um protocolo de morfologia detalhado com auxílio de marcadores imuno-histoquímicos. Uma das maiores dificuldades da avaliação de amostras de MO desses pacientes é sua celularidade muito baixa, geralmente com pouco substrato para análise tanto morfológica como genética. Além da dificuldade de obtenção de material, a AAA é uma doença com baixa incidência, tornando nossa casuística limitada, mesmo tendo sido o estudo realizado em centro de referência nacional com acompanhamento clínico rigoroso dos pacientes. Nesse contexto, a evolução de pequeno número de pacientes para SMD/LMA $(9,7 \%)$ é significativa. É importante salientar que a Citopenia Refratária da Infância (CRI) continua sendo uma entidade provisória na OMS de $2016{ }^{41}$, tornando seu estudo importante para determinar seu estabelecimento como entidade diagnóstica definitiva.

Os grupos adulto e pediátrico não tiveram diferenças quanto à frequência na incidência dos gêneros masculino e feminino (maior frequência no sexo masculino nos dois grupos, 1,4:1 e 1,6:1, respectivamente). No entanto, o grupo pediátrico apresentou maior frequência de pacientes com AAA secundária (seis pacientes) que o grupo adulto (dois pacientes) e maior 
frequência de diagnóstico de AAmG (28,5\% contra $14,8 \%$ do grupo adulto). $O$ tempo de seguimento dos pacientes foi em média de 6,5 anos, tempo suficiente e adequado ${ }^{5}$ para avaliar possível evolução para SMD/LMA. Dos 123 pacientes com AAA, $12(9,7 \%)$ evoluíram para SMD/LMA, taxa semelhante à encontrada na literatura de $15 \%{ }^{28}$, variando entre 1,7 a $57 \%$ em um período observacional entre 5 e 11 anos ${ }^{5}$. A maioria dos pacientes apresentava AA grave, tanto no grupo adulto como no pediátrico, e o risco de evolução para SMD/LMA não mostrou diferença estatisticamente significante entre eles $(p=0,335)$.

Dos 137 pacientes do grupo total analisado, 15 já se encontravam em tratamento com algum agente imunossupressor (resultados descritos no Anexo 1). À avaliação destas amostras, nota-se que a média e mediana de celularidade geral são semelhantes às do grupo total não tratado; no entanto, quatro pacientes apresentavam celularidade igual ou maior que $40 \%$ (dois tratados com corticoide e dois com ciclosporina, e os tratados com ciclosporina tinham $70 \%$ e $90 \%$ de celularidade), o que aumenta a chance de encontrar todos os elementos hematopoéticos, incluindo megacariócitos, que apresentavam displasia caracterizada, sobretudo, por hipolobulação. Esta não é a caraterística displástica mais específica para SMD, mas, estatisticamente tornou o grupo previamente tratado diferente do não tratado, o que nos levou à exclusão deste grupo da casuística. Pode-se assumir que a celularidade pode estar aumentada em pacientes tratados por recuperação medular, ainda que parcial, pela diminuição da agressão das células $T$ aos precursores hematopoéticos.

No que se refere à análise morfológica das $\mathrm{BMO}$, a distribuição irregular do tecido hematopoético teve alta frequência, tanto no grupo adulto como no pediátrico, no que evoluiu para SMD/LMA e também no que não evoluiu. Esta característica não é comumente observada em casos AAA e sim nos de SMD e SMD-h. No entanto, em nossa visão, isso pode se explicar pela forma de evolução da doença, ou seja, conforme se dá a destruição de precursores hematopoéticos na MO, podem restar "ilhas" de tecido hematopoético ${ }^{76 ; 77}$, resultando em um quadro morfológico com irregularidade de distribuição. 
O distúrbio de maturação da série granulocítica, com localização anormal de precursores imaturos (ALIP), bastante clássico na SMD, foi encontrado em raros casos de AAA em casos de crianças e adultos, mas, diferentemente do esperado, em nenhum caso dentre os que evoluíram para SMD/LMA. Isso pode ser parcialmente explicado pela diferença de celularidade entre as amostras dos pacientes com ED e EF, pois apesar da mediana ter sido igual a 10 nos dois grupos, a média de celularidade foi 11,3 no EF e 7,9 no ED, diminuindo a chance de encontrar algumas características.

Características menos típicas de AAA, como distúrbio arquitetural da série eritrocítica, agrupamentos, formas jovens e mitoses foram identificadas com frequência semelhante nos grupos adulto, pediátrico, que evoluíram e que não evoluíram para SMD/LMA. Inicialmente, estas características foram descritas como critérios diagnósticos para a SMD pediátrica (CRI) ${ }^{7} \mathrm{e}$, em nosso trabalho, foram observadas em casos de AAA, mostrando que estes critérios devem ser associados a outros mais específicos para definição diagnóstica. No grupo adulto, características como agrupamentos de mais 20 células nucleadas com mitoses ou formas jovens não são descritas como sugestivas de SMD, e sim são características como multinucleação, lobulação nuclear, grânulos citoplasmáticos e elementos megaloblastoides ${ }^{67}$. Assim, as primeiras tornaram-se um achado interessante e novo em nosso estudo, já que foram identificadas no grupo adulto que evoluiu e que não evoluiu para SMD/LMA.

Megacariócitos constituem a série hematopoética menos frequente encontrada na AAA (menos da metade dos casos em todos os grupos). Quando identificados, são em número muito baixo, de um a nove no total da amostra, geralmente, como é esperado em casos de AAA. Nesse contexto, a identificação de raros elementos hipolobados, como ocorreu em nosso estudo, torna a amostra displástica em relação à série megacariocítica. De fato, a displasia mais encontrada foi a hipo/monolobação, que não tem a mesma relevância que a binucleação e a multinucleação, identificadas em raros casos dentre os que não evoluíram para SMD/LMA e em nenhum dos que evoluíram. 
A presença de blastos CD34-positivos foi também um achado surpreendente, já estas células precursoras são alvo dos linfócitos na AAA. Eles foram identificados em 9,7\% das amostras dos adultos e em 7,1\% das de crianças, sempre em baixo número (menos de $5 \%$ da celularidade) e de forma isolada. Também diferentemente do esperado, todos os casos que apresentavam blastos estavam dentre os que não evoluíram para SMD/LMA.

As fibras reticulínicas estavam aumentadas em raros casos em todos os grupos e em baixa quantidade, como esperado na AAA.

A avaliação do índice proliferativo celular ao marcador Ki-67 é pouco estudada e sabe-se que o índice é baixo em MO normais (até 3\%), em AA e em SMD e mais elevado nos casos de falência congênita de MO ${ }^{78}$. Em nosso estudo, a mediana desse índice foi 30,0 no grupo adulto e 15,0 no pediátrico, sem diferença estatisticamente significante entre eles. No entanto, este índice já se mostrou mais elevado que o considerado normal, com índice maior que $3 \%$, na grande maioria (87 de 118) das amostras. De maneira interessante, o índice proliferativo associa-se à celularidade quantitativa da $\mathrm{MO}$, mostrando que há uma relação positiva entre estes parâmetros $(p=0,01)$, mas não se pode dizer que sempre que há maior celularidade há maior proliferação, ou seja, a relação não é preditora, pois houve casos de muito baixa celularidade com índice muito alto, já que havia poucas células nas amostras e a maior parte delas marcava ki-67 e também amostras com maior celularidade e índice muito baixo. Neste último caso, a presença de artefatos e a degeneração do material ao longo dos anos podem ter diminuído a antigenicidade do tecido ao marcador.

Quanto à citogenética, 62,7\% (74 pacientes) tiveram resultado normal. A alteração mais comumente encontrada ao cariótipo na evolução foi a monossomia do cromossomo 7 (nove dos 10 pacientes), conforme observado na literatura, assim sendo, para os testes de FISH foram usadas sondas para verificar esta alteração. A maior parte dos resultados adveio do exame de FISH, que apresentou maior sensibilidade que o cariótipo nos casos hipocelulares, em que a obtenção de metáfases é mais difícil. Do total de 74 pacientes, 37,3\% não tiveram nenhum resultado conclusivo. Apesar desse 
número ser grande e da citogenética ser ferramenta importante e decisiva no diagnóstico de CRI ou SMD-h, nem sempre o material é adequado para a realização desse exame. Isto é descrito na literatura, na qual 16\% dos pacientes com CRI hipocelular não obtiveram resultados à cariotipagem ${ }^{6}$, mostrando que a citogenética exerce papel limitado em muitos dos casos hipocelulares. Um trabalho mostrou resultados inconclusivos de cariótipo em $3 \%$ dos pacientes com AAA e $12 \%$ dos com SMD-h, problema que foi resolvido com análise de cariótipo baseado em matriz de polimorfismos de nucleotídeo único (SNP-array), que não requer células em divisão para detectar alterações cromossômicas ${ }^{79}$. Uma das limitações com relação a nosso estudo foi a impossibilidade técnica e financeira de realizar pesquisa de mutações somáticas e alterações cromossômicas usando métodos moleculares mais avançados nos pacientes com AAA, o que, conforme alguns trabalhos da literatura, poderia se associar a pior prognóstico e maior taxa de transformação maligna.

Nossos resultados mostraram que AAA pode ter alterações displásicas leves e que isso não se correlacionou com pior prognóstico em nossa coorte, o que sugere que AAA e CRI/SMD hipocelulares podem representar um espectro do mesmo processo. A relação entre essas doenças vem sendo estudada há, pelo menos, 50 anos $62 ; 80 ; 81 ; 82$. Muitos estudos têm sido feitos a respeito da fisiopatologia dessas doenças, pois, vários de seus aspectos são sugestivos de que elas pertençam a um mesmo espectro, incluindo aspectos clínico-epidemiológicos, resposta a imunossupressores em maior ou menor grau nas duas doenças, além do desenvolvimento de SMD após uso de imunossupressores na AAA, sugerindo que a vigilância imune pode ser importante na supressão de clones malignos ${ }^{21}$. Um estudo mostrou que algumas células $T$ que atacam as células progenitoras da $\mathrm{MO}$ têm restrição de HLA classe I. Tal possibilidade foi avaliada por sequenciamento completo do exoma humano que identificou um grupo de pacientes com mutações do HLA que levam à perda de função celular e tem uma doença mais grave com maior frequência de complicações clonais ${ }^{83}$. Há evidências de que a inibição de hematopoese mediada por linfócitos $T$ também ocorre em SMD, 
contribuindo para a pancitopenia em alguns pacientes que pode ser revertida por tratamento imunossupressor com regressão dos clones predominantes. Mas, há pacientes que não respondem a esse tipo de tratamento e nestes foram identificadas células $T$ clonais não responsivas ${ }^{84}$. Há a possibilidade de que a diminuição da população de células-tronco da AAA torne-se uma doença oligoclonal, e na SMD há a expansão de um clone aberrante que se sobressai dentre as outras células-tronco ${ }^{32 ; 79}$. Nessa linha de pensamento, a destruição imunomediada da MO pode ocorrer ao mesmo tempo que evolui um clone maligno, ou seja, cuja proliferação não é mais compatível com hematopoese normal, causando uma sobreposição diagnóstica entre esses conceitos de doença ${ }^{22}$. Os achados de hematopoese clonal desfavorável em contexto clínico de AAA, na ausência de evidências morfológicas ou citogenéticas de SMD, indicam que pode ser necessária uma redefinição de SMD, especialmente, para diferenciar SMD-h de AAA ${ }^{23}$. É relevante salientar o contexto clínico em que as mutações genéticas aparecem para que sejam interpretadas com cautela ${ }^{32}$. Embora nosso estudo não apresente dados genéticos detalhados, os aspectos morfológicos encontrados são condizentes com a possibilidade de uma sobreposição entre essas doenças. 


\section{Conclusões}




\section{CONCLUSÕES}

1. Nenhum dos parâmetros morfológicos/imuno-histoquímicos da BMO estudados se associou à evolução para SMD/LMA em portadores de AAA.

2. Pacientes adultos e pediátricos com AAA e pacientes adultos e pediátricos com AAA que evoluem para SMD/LMA têm características morfológicas e imuno-histoquímicas semelhantes dentro de suas limitações de amostragem.

3. As alterações descritas por Baumann et al. para SMD pediátrica também são encontradas em casos de AAA pediátricos e adultos.

4. Algumas alterações descritas por Bennett e Orazi para SMD hipocelular foram identificadas em casos de crianças e adultos com AAA.

5. Índice de proliferação celular avaliado por meio da imunoexpressão de Ki67 esteve, frequentemente, presente ( $>3 \%$ em $74,8 \%$ dos casos) e elevado (>10\% em $56,9 \%$ dos casos) nos casos de AAA.

6. A imunoexpressão de Ki-67 não apresentou correlação com desfecho desfavorável neste estudo.

7. Blastos CD34-positivos isolados ( $<5 \%$ ) foram identificados nas crianças e adultos ( $7 \%$ e $10 \%$, respectivamente) sem correlação com a evolução desfavorável. 


\section{Referências}




\section{REFERÊNCIAS}

1 Marsh JC, Ball SE, Cavenagh J, Darbyshire P, Dokal I, Gordon-Smith EC, Keidan J, Laurie A, Martin A, Mercieca J, Killick SB, Stewart R, Yin JA; British Committee for Standards in Haematology. Guidelines for the diagnosis and management of aplastic anaemia. $\mathbf{B r} \mathbf{J}$ Haematol. 2009;147(1):43-70.

2 Young NS. Current concepts in the pathophysiology and treatment of aplastic anemia. Hematology Am Soc Hematol Educ Program. 2013;2013:76-81.

3 Camitta BM, Rappeport JM, Parkman R, Natha DG. Selection of patients for bone-marrow transplantation in severe aplastic-anemia. Blood. 1975;45(3):355-63.

4 Camitta BM. What is the definition of cure for aplastic anemia? Acta Haematol. 2000;103(1):16-8.

5 Afable II MG, Tiu RV, Maciejewski JP. Clonal evolution in aplastic anemia. Hematology. 2011;2011:90-5.

6 Niemeyer CM, Baumann I. Classification of childhood aplastic anemia and myelodysplastic syndrome. Hematology Am Soc Hematol Educ Program, 2011;2011:84-9.

7 Baumann I, et al. Childhood Myelodisplastic Syndrome. In: Swerdlow $S$, Campo E, et al. (Ed.). WHO Classification of Tumours of Haematopoietic and Lymphoid Tissues. Fourth Edition. Lyon: IARC Press, 2008. cap. Childhood myelodysplastic syndrome, p.104-7. (World Health Organization). 
8 Forester CM, Sartain SE, Guo D, Harris MH, Weinberg OK, Fleming MD, London WB, Williams DA, Hofmann I. Pediatric aplastic anemia and refractory cytopenia: A retrospective analysis assessing outcomes and histomorphologic predictors. Am J Hematol. 2015;90(4):320-6.

9 Orazi A, et al. Immunohistochemistry of bone marrow biopsy as a diagnostic tool for distinguishing hypoplastic myelodysplastic syndrome from acquired aplastic anemia. Lab Invest. 1996;74(1):692692.

10 Orazzi A, Albitar M, Heerema NA, Haskins S, Neiman RS. Hypoplastic myelodysplastic syndromes can be distinguished from acquired aplastic anemia by CD34 and PCNA immunostaining of bone marrow biopsy specimens. Am J Clin Pathol. 1997;107(3):268-74.

11 Bennett JM, Orazi A. Diagnostic criteria to distinguish hypocellular acute myeloid leukemia from hypocellular myelodysplastic syndromes and aplastic anemia: recommendations for a standardized approach. Haematologica. 2009;94(2):264-9.

12 Foucar K, Reichard K, Czuchlewski D. Aplastic anemia and multilineage bone marrow failure disorders. In: American Society for Clinical Pathology. (Ed.). Bone Marrow Pathology. Third Edition. Chicago, USA: American Society for Clinical Pathology, 2010. v.1, cap. 7, p.131-149.

13 Young NS, Kaufman DW. The epidemiology of acquired aplastic anemia. Haematologica. 2008;93(4):489-92.

14 Killick SB, Bown N, Cavenagh J, Dokal I, Foukaneli T, Hill A, Hillmen P, Ireland R, Kulasekararaj A, Mufti G, Snowden JA, Samarasinghe S, Wood A, Marsh JC; British Society for Standards in Haematology. 
Guidelines for the diagnosis and management of adult aplastic anaemia. Br J Haematol. 2016;172(2):187-207.

Jeong, D. C, Chung NG, Kang HJ, Koo HH, Kook H, Kim SK, Kim SY, Kim HS, Kim HM, Park KD, Park SK, Park JS, Park JE, Park HJ, Park YS, Seo JJ, Sung KW, Shin HY, Ahn HS, Ryu KH, Ryu KH, Yoo ES, Lyu CJ, Lee KS, Lee KC, Lee SY, Lee YH, Lim YT, Lim YJ, Jung HL, Cho B, Choi YM, Hah JO, Hwang TJ, Kim HK. Epidemiology and clinical long-term outcome of childhood aplastic anemia in Korea for 15 years: retrospective study of the Korean Society of Pediatric Hematology Oncology (KSPHO). J Pediatr Hematol Oncol. 2011;33(3):172-8.

Maluf E, Hamerschlak N, Cavalcanti AB, Júnior AA, Eluf-Neto J, Falcão RP, Lorand-Metze IG, Goldenberg D, Santana CL, Rodrigues Dde O, Passos LN, Rosenfeld LG, Pitta M, Loggetto S, Ribeiro AA, Velloso ED, Kondo AT, Coelho EO, Pintão MC, de Souza HM, Borbolla JR, Pasquini R. Incidence and risk factors of aplastic anemia in Latin American countries: the LATIN case-control study.

Haematologica. 2009;94(9):1220-6.

17 Barone A, Lucarelli A, Onofrillo D, Verzegnassi F, Bonanomi S, Cesaro S, Fioredda F, lori AP, Ladogana S, Locasciulli A, Longoni D, Lanciotti M, Macaluso A, Mandaglio R, Marra N, Martire B, Maruzzi M, Menna G, Notarangelo LD, Palazzi G, Pillon M, Ramenghi U, Russo G, Svahn J, Timeus F, Tucci F, Cugno C, Zecca M, Farruggia P, Dufour C, Saracco P; Marrow Failure Study Group of the Pediatric Haemato-Oncology Italian Association. Diagnosis and management of acquired aplastic anemia in childhood. Guidelines from the Marrow Failure Study Group of the Pediatric Haemato-Oncology Italian Association (AIEOP). Blood Cells Mol Dis. 2015;55(1):40-7. 
18 Timeus F, Crescenzio N, Lorenzati A, Doria A, Foglia L, Pagliano S, Quarello P, Ramenghi U, Saracco P. Paroxysmal nocturnal haemoglobinuria clones in children with acquired aplastic anaemia: a prospective single centre study. Br J Haematol. 2010;150(4):483-5.

19 Young NS, Scheinberg P, Calado RT. Aplastic anemia. Curr Opin Hematol. 2008;15(3):162-8.

20 Baumann I. Führer M, Behrendt S, Campr V, Csomor J, Furlan I, de Haas V, Kerndrup G, Leguit RJ, De Paepe P, Noellke P, Niemeyer C, Schwarz S. Morphological differentiation of severe aplastic anemia from hypocellular refractory cytopenia of childhood: reproducibility of histopathological diagnostic criteria. Histopathology. 2012;61(1):107.

21 Stanley N, Olson TS, Babushok DV. Recent advances in understanding clonal haematopoiesis in aplastic anaemia. $\mathbf{B r} \mathbf{J}$ Haematol. 2017;177(4):509-25.

22 Ogawa S. Clonal hematopoiesis in acquired aplastic anemia. Blood. 2016;128(3):337-47.

23 Yoshizato T, Dumitriu B, Hosokawa K, Makishima H, Yoshida K, Townsley D, Sato-Otsubo A, Sato Y, Liu D, Suzuki H, Wu CO, Shiraishi Y, Clemente MJ, Kataoka K, Shiozawa Y, Okuno Y, Chiba K, Tanaka H, Nagata Y, Katagiri T, Kon A, Sanada M, Scheinberg P, Miyano S, Maciejewski JP, Nakao S, Young NS, Ogawa S. Somatic mutations and clonal hematopoiesis in aplastic anemia. $\mathbf{N}$ Engl $\mathbf{J}$ Med. 2015;373(1):35-47.

24 Babushok DV, Perdigones N, Perin JC, Olson TS, Ye W, Roth JJ, Lind C, Cattier C, Li Y, Hartung H, Paessler ME, Frank DM, Xie HM, Cross S, Cockroft JD, Podsakoff GM, Monos D, Biegel JA, Mason PJ, 
Bessler M. Emergence of clonal hematopoiesis in the majority of patients with acquired aplastic anemia. Cancer Genet. 2015;208(4):115-28.

25 Yoshizato T. [Chronologic analysis of clonal evolution in acquired aplastic anemia and sMDS]. Rinsho Ketsueki. 2016;57(4):430-9.

26 Kunimoto $\mathrm{H}$, Nakajima $\mathrm{H}$. Epigenetic dysregulation of hematopoietic stem cells and preleukemic state. Int J Hematol. 2017;106(1):34-44.

27 Abkowitz JL. Clone wars--the emergence of neoplastic blood-cell clones with aging. N Engl J Med. 2014;371(26):2523-5.

28 Kulasekararaj AG, Jiang J, Smith AE, Mohamedali AM, Mian S, Gandhi S, Gaken J, Czepulkowski B, Marsh JC, Mufti GJ. Somatic mutations identify a subgroup of aplastic anemia patients who progress to myelodysplastic syndrome. Blood. 2014;124(17):2698704.

29 Boddu PC, Kadia TM. Updates on the pathophysiology and treatment of aplastic anemia: a comprehensive review. Expert Rev Hematol. 2017;10(5):433-48.

30 Park HS, Park SN, Im K, Kim SM, Kim JA, Hwang SM, Lee DS. Telomere length and somatic mutations in correlation with response to immunosuppressive treatment in aplastic anaemia. $\mathbf{B r} \mathbf{J}$ Haematol. 2017;178(4):603-15.

31 Dumitriu B, Feng X, Townsley DM, Ueda Y, Yoshizato T, Calado RT, Yang Y, Wakabayashi Y, Kajigaya S, Ogawa S, Zhu J, Young NS. Telomere attrition and candidate gene mutations preceding monosomy 7 in aplastic anemia. Blood. 2015;125(4):706-9. 
32 Cooper JN, Young NS. Clonality in context: hematopoietic clones in their marrow environment. Blood. 2017;130(22):2363-72.

33 Swerdlow S, et al. World Health Organization Classification of Tumors. In: (Ed.). WHO Classification of Tumors of Haematopoietic and Lymphoid Tissues. Fourth Edition. Lyon, France: IARC Press, 2008. v.1, cap. Myelodysplastic syndromes, p.87-108.

34 Zhou JH, Orazi A, Czader MB. Myelodysplastic syndromes. Semin Diagn Pathol. 2011;28(4):258-72.

35 Greenberg PL, Stone RM, Al-Kali A, Barta SK, Bejar R, Bennett JM, Carraway H, De Castro CM, Deeg HJ, DeZern AE, Fathi AT, Frankfurt O, Gaensler K, Garcia-Manero G, Griffiths EA, Head D, Horsfall R, Johnson RA, Juckett M, Klimek VM, Komrokji R, Kujawski LA, Maness LJ, O'Donnell MR, Pollyea DA, Shami PJ, Stein BL, Walker AR, Westervelt P, Zeidan A, Shead DA, Smith C. Myelodysplastic Syndromes, Version 2.2017, NCCN Clinical Practice Guidelines in Oncology. J Natl Compr Canc Netw. 2017;15(1):60-87.

36 Ma X, Does M, Raza A, Mayne ST. Myelodysplastic syndromes Incidence and survival in the United States. Cancer. 2007;109(8):1536-42.

37 Belli CB, Pinheiro RF, Bestach Y, Larripa IB, da Silva Tanizawa RS, Alfonso G, Gonzalez J, Rosenhain M, Watman N, Cavalcante de Andrade Silva M, Negri Aranguren P, García Rivello H, Magalhaes SM, Valladares X, Undurraga MS, Velloso ER. Myelodysplastic syndromes in South America: a multinational study of 1080 patients. Am J Hematol. 2015;90(10):851-8.

38 Pellagatti A, Boultwood J. The molecular pathogenesis of the myelodysplastic syndromes. Eur J Haematol. 2015;95(1):3-15. 
Valent $\mathrm{P}$, Orazi A, Steensma DP, Ebert BL, Haase D, Malcovati L, van de Loosdrecht AA, Haferlach T, Westers TM, Wells DA, Giagounidis A, Loken M, Orfao A, Lübbert M, Ganser A, Hofmann WK, Ogata K, Schanz J, Béné MC, Hoermann G, Sperr WR, Sotlar K, Bettelheim P, Stauder R, Pfeilstöcker M, Horny HP, Germing U, Greenberg P, Bennett JM. Proposed minimal diagnostic criteria for myelodysplastic syndromes (MDS) and potential pre-MDS conditions. Oncotarget. 2017;8(43):73483-500.

40 Valent P, Horny HP, Bennett JM, Fonatsch C, Germing U, Greenberg $P$, Haferlach T, Haase D, Kolb HJ, Krieger O, Loken M, van de Loosdrecht A, Ogata K, Orfao A, Pfeilstöcker M, Rüter B, Sperr WR, Stauder R, Wells DA. Definitions and standards in the diagnosis and treatment of the myelodysplastic syndromes: Consensus statements and report from a working conference. Leuk Res. 2007;31(6):727-36.

41 Arber DA, Orazi A, Hasserjian R, Thiele J, Borowitz MJ, Le Beau MM, Bloomfield CD, Cazzola M, Vardiman JW. The 2016 revision to the World Health Organization classification of myeloid neoplasms and acute leukemia. Blood. 2016;127(20):2391-405.

42 Orazi A. Histopathology in the diagnosis and classification of acute myeloid leukemia, myelodysplastic syndromes, and myelodysplastic/myeloproliferative diseases. Pathobiology. 2007;74(2):97-114.

43 Horny HP, Sotlar K, Valent P. Diagnostic value of histology and immunohistochemistry in myelodysplastic syndromes. Leuk Res. 2007;31(12):1609-16.

44 Kremer M, Quintanilla-Martínez L, Nährig J, von Schilling C, Fend F. Immunohistochemistry in bone marrow pathology: a useful adjunct for morphologic diagnosis. Virchows Arch. 2005;447(6):920-37. 
45 Dunphy CH, O'Malley DP, Perkins SL, Chang CC. Analysis of immunohistochemical markers in bone marrow sections to evaluate for myelodysplastic syndromes and acute myeloid leukemias. Appl Immunohistochem Mol Morphol. 2007;15(2):154-9.

46 Della Porta MG, Malcovati L, Boveri E, Travaglino E, Pietra D, Pascutto C, Passamonti F, Invernizzi R, Castello A, Magrini U, Lazzarino M, Cazzola M. Clinical relevance of bone marrow fibrosis and CD34-positive cell clusters in primary myelodysplastic syndromes. J Clin Oncol. 2009;27(5):754-62.

47 Torlakovic EE, Naresh K, Kremer M, van der Walt J, Hyjek E, Porwit A. Call for a European programme in external quality assurance for bone marrow immunohistochemistry; report of a European Bone Marrow Working Group pilot study. J Clin Pathol. 2009;62(6):547-51.

48 Velloso ED, Chauffaille ML, Peliçario LM, Tanizawa RS, Toledo SR, Gaiolla RD, Lopes LF. Cytogenetic studies of Brazilian pediatric myelodysplastic syndrome cases: challenges and difficulties in a large and emerging country. Braz J Med Biol Res. 2013;46(1):85-90.

49 Silva AG, Maschietto M, Vidal DO, Peliçario LM, Velloso ED, Lopes LF, Krepischi AC, Rosenberg C. Array-CGH as an adjuvant tool in cytogenetic diagnosis of pediatric MDS and JMML. Med Oncol. 2013;30(4):734.

50 Giagounidis A, Haase D. Morphology, cytogenetics and classification of MDS. Best Pract Res Clin Haematol. 2013;26(4):337-53.

51 De Souza DC, Fernandez Cde S, Camargo A, Apa AG, da Costa ES, Bouzas LF, Abdelhay E, Fernandez Tde S. Cytogenetic as an important tool for diagnosis and prognosis for patients with 
hypocellular primary myelodysplastic syndrome. Biomed Res Int. 2014;2014:542395.

52 Schanz J, Tüchler H, Solé F, Mallo M, Luño E, Cervera J, Granada I, Hildebrandt B, Slovak ML, Ohyashiki K, Steidl C, Fonatsch C, Pfeilstöcker M, Nösslinger T, Valent P, Giagounidis A, Aul C, Lübbert M, Stauder R, Krieger O, Garcia-Manero G, Faderl S, Pierce S, Le Beau MM, Bennett JM, Greenberg P, Germing U, Haase D. New comprehensive cytogenetic scoring system for primary myelodysplastic syndromes (MDS) and oligoblastic acute myeloid leukemia after MDS derived from an international database merge. $\mathbf{J}$ Clin Oncol. 2012;30(8):820-9.

53 Greenberg P, Cox C, LeBeau MM, Fenaux P, Morel P, Sanz G, Sanz M, Vallespi T, Hamblin T, Oscier D, Ohyashiki K, Toyama K, Aul C, Mufti G, Bennett J. International scoring system for evaluating prognosis in myelodysplastic syndromes. Blood. 1997;89(6):2079-88.

54 Greenberg PL, Tuechler H, Schanz J, Sanz G, Garcia-Manero G, Solé F, Bennett JM, Bowen D, Fenaux P, Dreyfus F, Kantarjian H, Kuendgen A, Levis A, Malcovati L, Cazzola M, Cermak J, Fonatsch C, Le Beau MM, Slovak ML, Krieger O, Luebbert M, Maciejewski J, Magalhaes SM, Miyazaki Y, Pfeilstöcker M, Sekeres M, Sperr WR, Stauder R, Tauro S, Valent P, Vallespi T, van de Loosdrecht AA, Germing $U$, Haase D. Revised international prognostic scoring system for myelodysplastic syndromes. Blood. 2012;120(12):2454-65.

55 Tanizawa RS, Kumeda CA, de Azevedo Neto RS, Leal Ade M, Ferreira Pde B, Velloso ED. Karyotypic and fluorescent in situ hybridization study of the centromere of chromosome 7 in secondary myeloid neoplasms. Rev Bras Hematol Hemoter. 2011;33(6):425-31. 
Haider M, Duncavage EJ, Afaneh KF, Bejar R, List AF. New insight into the biology, risk stratification, and targeted treatment of myelodysplastic syndromes. Am Soc Clin Oncol Educ Book. 2017;37:480-94.

57 Jonas BA, Greenberg PL. MDS prognostic scoring systems - past, present, and future. Best Pract Res Clin Haematol. 2015;28(1):3-13.

58 Hasle H. Myelodysplastic and myeloproliferative disorders of childhood. Hematology Am Soc Hematol Educ Program., 2016;2016(1):598-604.

59 Elghetany MT. Myelodysplastic syndromes in children - A critical review of issues in the diagnosis and classification of 887 cases from 13 published series. Arch Pathol Lab Med. 2007;131(7):1110-6.

60 Kardos G, Baumann I, Passmore SJ, Locatelli F, Hasle H, Schultz KR, Starý J, Schmitt-Graeff A, Fischer A, Harbott J, Chessells JM, Hann I, Fenu S, Rajnoldi AC, Kerndrup G, Van Wering E, Rogge T, Nollke P, Niemeyer CM. Refractory anemia in childhood: a retrospective analysis of 67 patients with particular reference to monosomy 7 . Blood. 2003;102(6):1997-2003.

61 Göhring G, Michalova K, Beverloo HB, Betts D, Harbott J, Haas OA, Kerndrup G, Sainati L, Bergstraesser E, Hasle H, Stary J, Trebo M, van den Heuvel-Eibrink MM, Zecca M, van Wering ER, Fischer A, Noellke P, Strahm B, Locatelli F, Niemeyer CM, Schlegelberger B. Complex karyotype newly defined: the strongest prognostic factor in advanced childhood myelodysplastic syndrome. Blood. 2010;116(19):3766-9.

62 Fohlmeister I, Fischer R, Mödder B, Rister M, Schaefer HE. Aplastic anemia and the hypocellular myelodysplastic syndrome - 
histomorphological, diagnostic, and prognostic features. J Clin Pathol. 1985;38(11):1218-24.

Koh Y, Lee HR, Song EY, Kim HK, Kim I, Park S, Park MH, Kim BK, Yoon SS, Lee DS. Hypoplastic myelodysplastic syndrome (h-MDS) is a distinctive clinical entity with poorer prognosis and frequent karyotypic and FISH abnormalities compared to aplastic anemia (AA). Leuk Res. 2010;34(10):1344-50.

64 Mufti GJ, Bennett JM, Goasguen J, Bain BJ, Baumann I, Brunning R, Cazzola M, Fenaux P, Germing U, Hellström-Lindberg E, Jinnai I, Manabe A, Matsuda A, Niemeyer CM, Sanz G, Tomonaga M, Vallespi T, Yoshimi A; International Working Group on Morphology of Myelodysplastic Syndrome. Diagnosis and classification of myelodysplastic syndrome: International Working Group on Morphology of myelodysplastic syndrome (IWGM-MDS) consensus proposals for the definition and enumeration of myeloblasts and ring sideroblasts. Haematologica. 2008;93(11):1712-7.

65 Lee SH, Erber WN, Porwit A, Tomonaga M, Peterson LC; International Council for Standardization In Hematology. ICSH guidelines for the standardization of bone marrow specimens and reports. Int J Lab Hematol. 2008;30(5):349-64.

66 Tuzuner N, Bennett JM. Reference-standards for bone-marrow cellularity. Leuk Res. 1994;18(8):645-7.

67 Rajnoldi AC, Fenu S, Kerndrup G, van Wering ER, Niemeyer CM, Baumann I; European WorkingGroup on Myelodysplastic Syndromes in Childhood (EWOG-MDS). Evaluation of dysplastic features in myelodysplastic syndromes: experience from the morphology group of the European Working Group of MDS in Childhood (EWOG-MDS). Ann Hematol. 2005;84(7):429-33. 
68 Matsuda A, Germing U, Jinnai I, Iwanaga M, Misumi M, Kuendgen A, Strupp C, Miyazaki Y, Tsushima H, Sakai M, Bessho M, Gattermann $\mathrm{N}$, Aul C, Tomonaga M. Improvement of criteria for refractory cytopenia with multilineage dysplasia according to the WHO classification based on prognostic significance of morphological features in patients with refractory anemia according to the FAB classification. Leukemia. 2007;21(4):678-86.

69 Thiele J, Quitmann H, Wagner S, Fischer R. Dysmegakaryopoiesis in myelodysplastic syndromes (MDS) - an immunomorphometric study of bone-marrow trephine biopsy specimens. J Clin Pathol. $1991 ; 44(4): 300-5$.

70 Tang GL, Wang SA, Menon M, Dresser K, Woda BA, Hao S. Highlevel CD34 expression on megakaryocytes independently predicts an adverse outcome in patients with myelodysplastic syndromes. Leuk Res. $2011 ; 35(6): 766-70$.

71 Thiele J, Kvasnicka HM, Facchetti F, Franco V, van der Walt J, Orazi A. European consensus on grading bone marrow fibrosis and assessment of cellularity. Haematologica. 2005;90(8):1128-32.

72 Bauermeister DE. Quantitation of bone marrow reticulin - A normal range. Am J Clin Pathol. 1971;56(1):24-31.

73 Yunis JJ, Sawyer JR, Ball DW. The characterization of high-resolution G-banded chromosomes of man. Chromosoma. 1978;67(4):293-307.

74 Simons A, Shaffer LG, Hastings RJ. Cytogenetic Nomenclature: Changes in the ISCN 2013 Compared to the 2009 Edition. Cytogenet Genome Res. 2013;141(1):1-6. 
75 Wolff DJ. Shaffer LG, Hastings RJ. Guidance for fluorescence in situ hybridization testing in hematologic disorders. J Mol Diagn. 2007;9(2):134-43.

76 Richman J, Ferber A. Severe aplastic anemia with hot pockets following daily Ecstasy ingestion. Am J Hematol. 2008;83(4):321-2.

77 Brodsky RA, Jones RJ. Aplastic anaemia. Lancet. 2005;365(9471):1647-56.

78 Al-Rahawan MM, Alter BP, Bryant BJ, Elghetany MT. Bone marrow cell cycle markers in inherited bone marrow failure syndromes. Leuk Res. 2008;32(12):1793-9.

79 Afable MG 2nd, Wlodarski M, Makishima H, Shaik M, Sekeres MA, Tiu RV, Kalaycio M, O'Keefe CL, Maciejewski JP. SNP array-based karyotyping: differences and similarities between aplastic anemia and hypocellular myelodysplastic syndromes. Blood. 2011;117(25):687684.

80 Barrett J, Saunthararajah Y, Molldrem J. Myelodysplastic syndrome and aplastic anemia: distinct entities or diseases linked by a common pathophysiology? Semin Hematol. 2000;37(1):15-29.

81 Barrett J. Myelodysplastic syndrome and aplastic anemia--diagnostic and conceptual uncertainties. Leuk Res. 2000;24(7):595-6.

82 Dameshek W. Riddle: what do aplastic anemia, paroxysmal nocturnal hemoglobinuria $(\mathrm{PNH})$ and "hypoplastic" leukemia have in common? Blood. 1967;30(2):251-4.

83 Babushok DV, Duke JL, Xie HM, Stanley N, Atienza J, Perdigones N, Nicholas P, Ferriola D, Li Y, Huang H, Ye W, Morrissette JJD, Kearns 
J, Porter DL, Podsakoff GM, Eisenlohr LC, Biegel JA, Chou ST, Monos DS, Bessler M, Olson TS. Somatic HLA mutations expose the role of class i-mediated autoimmunity in aplastic anemia and its clonal complications. Blood Adv. 2017;1(22):1900-10.

84 Kochenderfer JN, Kobayashi S, Wieder ED, Su C, Molldrem JJ. Loss of T-lymphocyte clonal dominance in patients with myelodysplastic syndrome responsive to immunosuppression. Blood. 2002;100(10):3639-45. 


\section{Anexos}




\section{ANEXO 1: ANÁLISE DOS PACIENTES PREVIAMENTE TRATADOS}

Do grupo total de 133 pacientes, quinze haviam sido previamente tratados em relação à data da biópsia, 7 deles com corticoide (prednisona) e 7 deles com ciclosporina e/ou anti-timoglobulina e um deles com eritropoetina.

Para a análise estatística, o grupo total foi dividido em grupo com tratamento prévio à biópsia e grupo que não havia sido previamente tratado (virgem de tratamento). Observamo diferença estisticamente significante entre eles quanto à presença de displasia da série megacariocítica com $p=0,004$ ao teste exato de Fisher (megacariócitos não lobulados com $p=0,004)$. Assim sendo, o grupo tratado foi excluído do trabalho, restando 0 grupo de 118 não tratados (76 adultos e 42 crianças).

\begin{tabular}{lccc}
\hline & $\begin{array}{c}\text { Grupo total } \\
\text { tratado }(\mathrm{n}=15)\end{array}$ & $\begin{array}{c}\text { Grupo total } \\
\text { não tratado } \\
(\mathrm{n}=118)\end{array}$ & $\boldsymbol{p}$ \\
\hline Distribuição irregular do tecido hematopoético & $\mathbf{n}$ & $\mathbf{n}$ & \\
\hline Distúrbio maturação da série granulocítica & 6 & 59 & 0,58 \\
Distúrbio arquitetural da série eritrocítica & 1 & 3 & 0,4 \\
Agrupamentos da série eritrocítica & 2 & 13 & 0,66 \\
Formas jovens da série eritrocítica & 7 & 54 & 1 \\
Mitoses da série eritrocítica & 5 & 32 & 0,52 \\
Atipias citológicas da série eritrocítica & 6 & 24 & 0,07 \\
Presença de células da série megacariocítica & 6 & 42 & 0,19 \\
Displasia da série megacariocítica & 6 & 42 & 0,77 \\
Megacariócitos binucleados & 6 & 15 & $\mathbf{0 , 0 0 4}$ \\
Megacariócitos multinucleados & 0 & 2 & 1 \\
\hline Megacariócitos não lobulados & 1 & 3 & 0,42 \\
Distúrbio arquitetural da série megacariocítica & 2 & 15 & $\mathbf{0 , 0 0 4}$ \\
Blastos CD34-positivos & 2 & 4 & 0,15 \\
Reticulogênese grau 1 em escala de 0 a 3 & 0 & 11 & 0,64 \\
Reticulogênese grau 2 em escala de 0 a 4 & 0 & 3 & 1 \\
Índice proliferativo (Ki-67) (mediana) & 30 & 3 & 0,41 \\
\hline
\end{tabular}




\section{ANEXO 2: AVALIAÇÃO DE SOBREVIDA LIVRE DE EVENTO DOS PACIENTES SEGUNDO FAIXA ETÁRIA E GRAVIDADE DA ANEMIA APLÁSTICA}

Do grupo total de pacientes (118), obteve-se mediana de idade ao diagnóstico de 24,4 anos (7 meses de vida até 76 anos), sendo que 42 pacientes tinham menos de 19 anos. Setenta e sete tiveram diagnóstico de Anemia Aplástica Grave (AAG), 17 não grave (AAnG) e 24 muito grave (AAmG). Todos os pacientes foram acompanhados clinicamente com tempo médio de seguimento de 6,0 anos (mediana de 5,0).

Realizada análise de sobrevida livre de evento dos pacientes segundo sua faixa etária e não foi observada diferença estatística entre os grupos pediátrico e adulto $(p=0,295)$ (Figura 1).

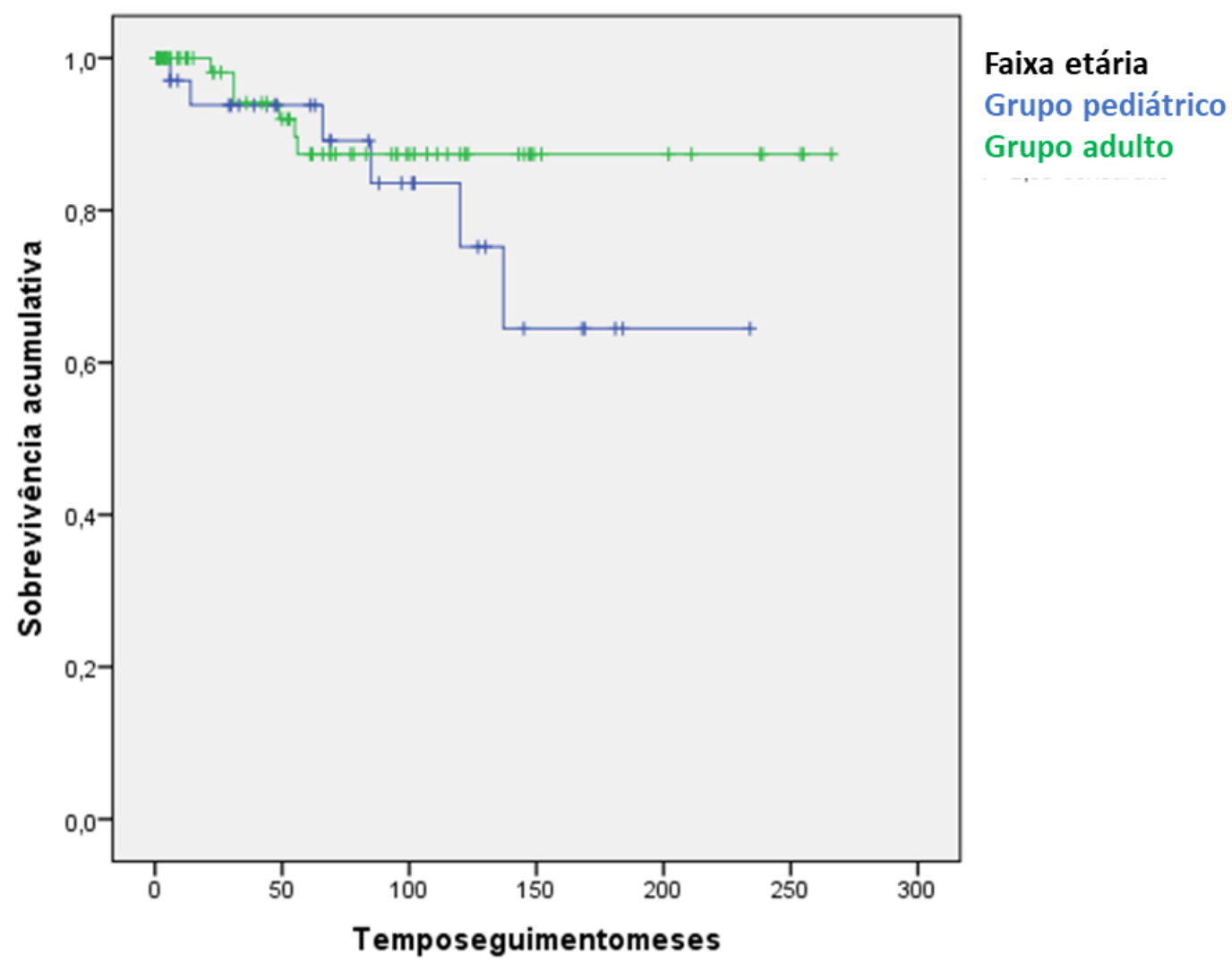

Figura 1 - Sobrevida livre de evento dos pacientes com AAA segundo faixa etária 
Quando realizada análise de sobrevida livre de evento dos pacientes segundo a gravidade da AAA, foi observada diferença estatisticamente significante entre os grupos ( $p=0,002)$, com maior sobrevida dos graves e nãograves em relação aos muito graves (Figura 2), denotando a validade das informações clínicas e evolutivas da casuística deste estudo.

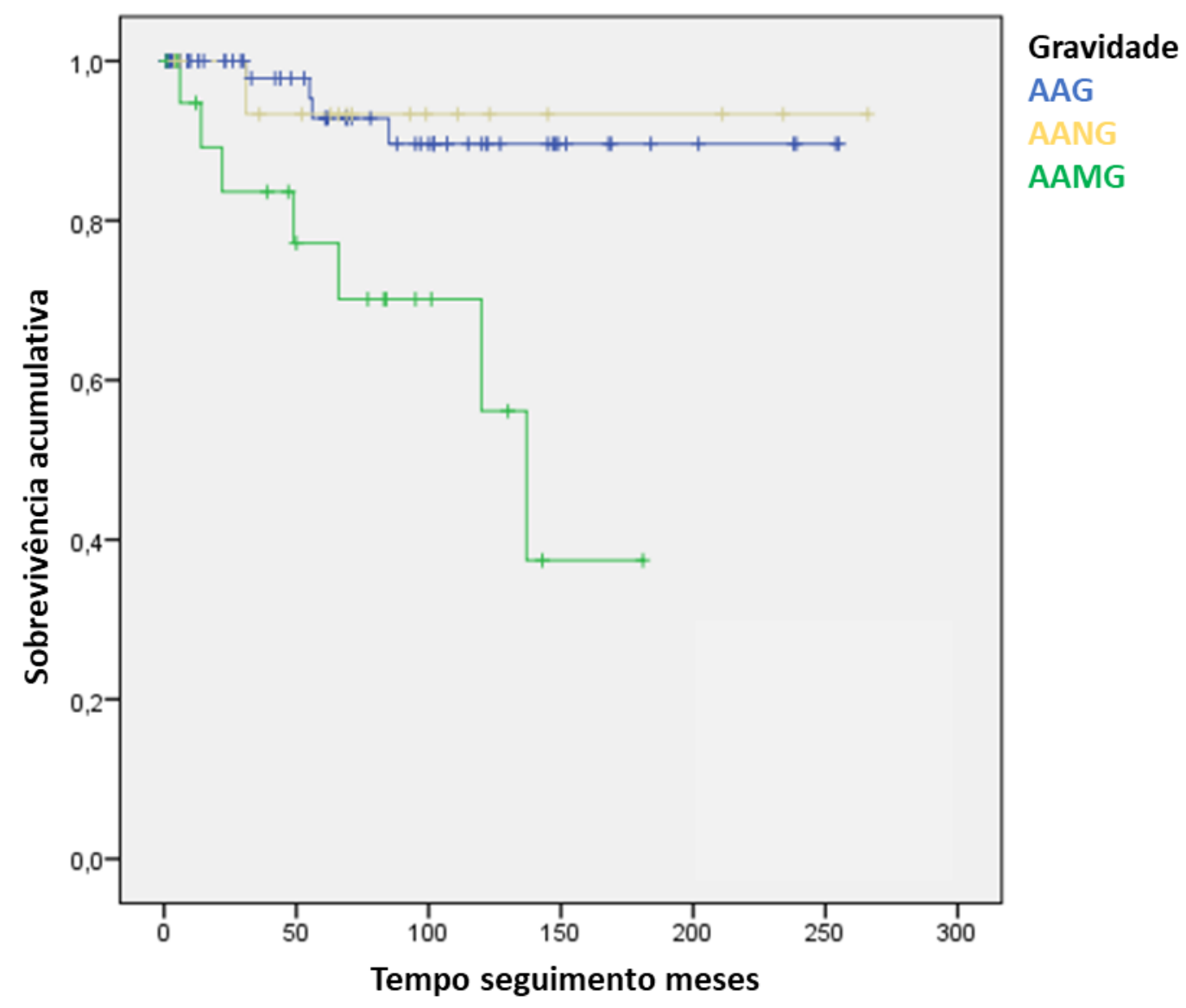

Figura 2 - Análise de sobrevida livre de evento dos pacientes com AAA segundo classificação por gravidade da doença. AAG: anemia aplástica grave; AANG: anemia aplástica não-grave; AAMG: anemia aplástica muito grave 


\section{ANEXO 3: COMPARAÇÃO DOS ACHADOS MORFOLÓGICOS/IMUNO- HISTOQUÍMICOS EM CRIANÇAS COM MENOS DE 14 ANOS E GRUPO COM 14 ANOS OU MAIS}

O capítulo da OMS referente a CRI considera os critérios diagnósticos que descreve para crianças abaixo de 14 anos e a OMS reconhece como pediátricos os pacientes com menos de 19 anos. Assim, fizemos uma análise comparativa dos dados entre grupo maior e grupo menor que 14 anos para avaliar possíveis diferenças, mas não houve nenhum resultado estatisticamente significante.

\begin{tabular}{lccc}
\hline Variável & $\begin{array}{c}\text { Grupo } \geq 14 \mathrm{a} \\
(\mathrm{n}=93)\end{array}$ & $\begin{array}{c}\text { Grupo }<14 \mathrm{a} \\
(\mathrm{n}=25)\end{array}$ & $\boldsymbol{p}$ \\
\hline Distribuição irregular do tecido hematopoético & $\mathbf{n}$ & $\mathbf{n}$ & \\
\hline Distúrbio maturação da série granulocítica & 31 & 8 & 0,07 \\
Distúrbio arquitetural da série eritrocítica & 11 & 2 & 1 \\
Agrupamentos da série eritrocítica & 47 & 7 & 1 \\
Formas jovens da série eritrocítica & 29 & 3 & 0,26 \\
Mitoses da série eritrocítica & 20 & 4 & 1 \\
Atipias citológicas da série eritrocítica & 30 & 5 & 0,77 \\
Presença de células da série megacariocítica & 36 & 6 & 0,23 \\
Displasia da série megacariocítica & 14 & 1 & 0,39 \\
Megacariócitos binucleados & 2 & 0 & 1 \\
Megacariócitos multinucleados & 3 & 0 & 1 \\
Megacariócitos não lobulados & 14 & 1 & 0,39 \\
\hline Distúrbio arquitetural da série megacariocítica & 3 & 1 & 0,47 \\
Blastos CD34-positivos & 9 & 2 & 1 \\
\hline Reticulogênese grau 1 em escala de 0 a 3 & 2 & 1 & 0,51 \\
Reticulogênese grau 2 em escala de 0 a 4 & 2 & 1 & 0,30 \\
Índice proliferativo (Ki-67) (mediana) & 30 & 10 & 0,39 \\
\hline
\end{tabular}




\section{ANEXO 4: RESULTADOS DE ESTUDOS CITOGENÉTICOS}

Estudo Citogenético (cariótipo e FISH) dos pacientes ao diagnóstico, ao seguimento e à evolução para SMD/LMA

\begin{tabular}{|c|c|c|c|c|c|}
\hline Paciente & $\begin{array}{l}\text { Idade } \\
\text { (anos) }\end{array}$ & Cariótipo e/ou FISH ao diagnóstico & $\begin{array}{c}\text { Cariótipo e/ou FISH ao seguimento pré- } \\
\text { evolução para SMD / LMA }\end{array}$ & $\begin{array}{l}\text { Evolução para } \\
\text { SMD / LMA }\end{array}$ & Cariótipo e/ou FISH à evolução para SMD / LMA \\
\hline 1 & 2,6 & NR & NR & $\mathrm{N}$ & \\
\hline 2 & 9,3 & NR & NR & $\mathrm{N}$ & \\
\hline 3 & 4,8 & NR & $N R$ & S & $45, X X,-7[16] ;$ nuc ish(D7Z1,D7S486)x1[23/100] \\
\hline 4 & 17,3 & NR & $46, X Y[8] ;$ nuc ish(D7Z1,D7S486)x2[100] & $\mathrm{N}$ & \\
\hline 5 & 15,9 & NR & NR & $\mathrm{N}$ & \\
\hline 6 & 6,3 & NR & nuc ish(D7Z1,D7S486)x1[11/100] & $\mathrm{N}$ & \\
\hline 7 & 26,6 & NR & NR & $\mathrm{N}$ & \\
\hline 8 & 18,8 & NR & NR & $\mathrm{N}$ & \\
\hline 9 & 0,6 & $46, X Y[13]$ & nuc ish(D7Z1,D7S486)x2[100] & $\mathrm{N}$ & \\
\hline 10 & 18,3 & AM & $\mathrm{NR}$ & $\mathrm{N}$ & \\
\hline 11 & 18,8 & 46, XX[10]; nuc ish(D7Z1,D7S486)×2[100] & NR & $\mathrm{N}$ & \\
\hline 12 & 18,4 & AM & NR & $\mathrm{N}$ & \\
\hline 13 & 5,8 & $46, X X[8]$ & 46, XX[8]; nuc ish(D7Z1,D7S486)x2[98/100] & $\mathrm{N}$ & \\
\hline 14 & 3,7 & NR & NR & $\mathrm{N}$ & \\
\hline 15 & 14,8 & $46, X Y[10]$ & NR & $S$ & \\
\hline 16 & 8,3 & $46, \mathrm{XY}[10]$ & AM & $\mathrm{N}$ & \\
\hline 17 & 15,1 & NR & NR & $\mathrm{N}$ & \\
\hline 18 & 10,3 & $\mathrm{AM}$ & NR & $\mathrm{N}$ & \\
\hline 19 & 18,5 & $46, X Y[16]$ & $46, X Y[19]$ & $\mathrm{N}$ & \\
\hline 20 & 7,5 & $\mathrm{AM}$ & $46, \mathrm{XY}[9]$ & $\mathrm{N}$ & \\
\hline 21 & 2,3 & nuc ish(D7Z1,D7S486)x2[100] & $46, X Y[20]$ & $\mathrm{N}$ & \\
\hline 22 & 14,7 & $\mathrm{NR}$ & NR & $\mathrm{N}$ & \\
\hline 23 & 1,9 & AM & NR & $\mathrm{N}$ & \\
\hline 24 & 16,3 & AM & NR & $\mathrm{N}$ & \\
\hline
\end{tabular}


Estudo Citogenético (cariótipo e FISH) dos pacientes ao diagnóstico, ao seguimento e à evolução para SMD/LMA (continuação)

\begin{tabular}{|c|c|c|c|c|c|}
\hline Paciente & $\begin{array}{l}\text { Idade } \\
\text { (anos) }\end{array}$ & Cariótipo e/ou FISH ao diagnóstico & $\begin{array}{c}\text { Cariótipo e/ou FISH ao seguimento pré- } \\
\text { evolução para SMD / LMA }\end{array}$ & $\begin{array}{c}\text { Evolução para } \\
\text { SMD / LMA }\end{array}$ & Cariótipo e/ou FISH à evolução para SMD / LMA \\
\hline 25 & 4,1 & 46, XX[15]; nuc ish(D7Z1,D7S486)x2[100] & $46, X X[20]$ & $S$ & \\
\hline 26 & 5,8 & $46, \mathrm{XX}[19]$ & NR & $\mathrm{N}$ & \\
\hline 27 & 19,8 & nuc ish(D7Z1,D7S486)x2[98/100] & 46, XY[20] & $\mathrm{N}$ & \\
\hline 28 & 5,2 & nuc ish(D7Z1,D7S486)x2[99/100] & NR & $\mathrm{N}$ & \\
\hline 29 & 14,4 & AM & NR & $\mathrm{N}$ & \\
\hline 30 & 1,2 & $46, \mathrm{XY}[5]$; nuc ish(D7Z1,D7S486)×2[97/100] & NR & $\mathrm{N}$ & \\
\hline 31 & 17,3 & nuc ish(D7Z1,D7S486)×2[98/100] & NR & $\mathrm{N}$ & \\
\hline 32 & 4,9 & nuc ish(D7Z1,D7S486)x2[99/100] & NR & & \\
\hline 33 & 11,1 & $\mathrm{NR}$ & NR & $\mathrm{N}$ & \\
\hline 34 & 6,8 & NR & NR & $S$ & $46, X X, \operatorname{del}(7)(q 22 q 32)[11]$ \\
\hline 35 & 3,4 & $\mathrm{AM}$ & NR & $\mathrm{N}$ & \\
\hline 36 & 17,8 & nuc ish(D7Z1,D7S486)x2[100] & $46, \mathrm{XX}[3]$ & $\mathrm{N}$ & \\
\hline 37 & 19,8 & $46, \mathrm{XX}[23]$ & NR & $\mathrm{N}$ & \\
\hline 38 & 12,1 & $46, \mathrm{XY}[3] ;$ nuc ish(D7Z1,D7S486)×2[100] & NR & $\mathrm{N}$ & \\
\hline 39 & 2,6 & $46, X X[19] ;$ nuc ish(D7Z1,D7S486)×2[100] & NR & $\mathrm{N}$ & \\
\hline 40 & 6,4 & $\begin{array}{c}\text { 46,XY[15]; nuc } \\
\text { ish(D7Z1,D7S486)x2[98/100] }\end{array}$ & NR & S & $45, X Y,-7[20]$ \\
\hline 41 & 2,8 & $\mathrm{AM}$ & nuc ish(D7Z1,D7S486)x2[99/100] & $S$ & $\begin{array}{c}\text { 45,XY,-7[2]/46,XY[7]; nuc } \\
\text { ish(D7Z1,D7S486)x1[50/200] }\end{array}$ \\
\hline 42 & 11,2 & $46, X X[18]$ & $46, \mathrm{XX}[8]$ & $\mathrm{N}$ & \\
\hline 43 & 32,6 & $\mathrm{AM}$ & nuc ish (D7Z1,D7S486)x2[99/100] & $\mathrm{N}$ & \\
\hline 44 & 47,7 & NR & NR & $\mathrm{N}$ & \\
\hline 45 & 25,3 & NR & NR & $S$ & $\begin{array}{c}45 \mathrm{XY},-7[9] / 46, \mathrm{XY}[4] ; 45, \mathrm{XY},-7[2] / 46, \mathrm{XY},-7+21[8] \\
\text { nuc ish (D7Z1, D7S486) }\end{array}$ \\
\hline 46 & 23,6 & NR & NR & $\mathrm{N}$ & \\
\hline 47 & 28,3 & NR & NR & $\mathrm{N}$ & \\
\hline 48 & 34,8 & NR & NR & $\mathrm{N}$ & \\
\hline
\end{tabular}




\section{Estudo Citogenético (cariótipo e FISH) dos pacientes ao diagnóstico, ao seguimento e à evolução para SMD/LMA (continuação)}

\begin{tabular}{|c|c|c|c|c|c|}
\hline Paciente & $\begin{array}{l}\text { Idade } \\
\text { (anos) }\end{array}$ & Cariótipo e/ou FISH ao diagnóstico & $\begin{array}{c}\text { Cariótipo e/ou FISH ao seguimento pré- } \\
\text { evolução para SMD / LMA }\end{array}$ & $\begin{array}{l}\text { Evolução para } \\
\text { SMD / LMA }\end{array}$ & Cariótipo e/ou FISH à evolução para SMD / LMA \\
\hline 49 & 45,8 & AM & NR & $\mathrm{N}$ & \\
\hline 50 & 32,3 & AM & NR & $\mathrm{N}$ & \\
\hline 51 & 22,8 & NR & NR & $\mathrm{N}$ & \\
\hline 52 & 28,1 & $46, X X[9]$ & nuc ish $(D 7 Z 1, D 7 S 486) \times 2[100]$ & $\mathrm{N}$ & \\
\hline 53 & 49,3 & 46,XY[10]; nuc ish (D7Z1,D7S486)x2[100] & NR & $\mathrm{N}$ & \\
\hline 54 & 68,3 & $N R$ & NR & $\mathrm{N}$ & \\
\hline 55 & 26,2 & $46, X X[10]$ & NR & $\mathrm{N}$ & \\
\hline 56 & 27,8 & AM & AM & $\mathrm{N}$ & \\
\hline 57 & 19,6 & nuc ish $(D 7 Z 1, D 7 S 486) \times 2[100]$ & NR & $\mathrm{N}$ & \\
\hline 58 & 21,9 & $\mathrm{NR}$ & NR & $S$ & $46, X X,-7,+21[20]$ \\
\hline 59 & 63,2 & NR & NR & $\mathrm{N}$ & \\
\hline 60 & 48,3 & NR & NR & $\mathrm{N}$ & \\
\hline 61 & 21,4 & NR & NR & $\mathrm{N}$ & \\
\hline 62 & 29,3 & nuc ish (D7Z1,D7S486)x2[100] & NR & $\mathrm{N}$ & \\
\hline 63 & 76,0 & $\mathrm{AM}$ & NR & $\mathrm{N}$ & \\
\hline 64 & 30,4 & $N R$ & NR & $\mathrm{N}$ & \\
\hline 65 & 58,8 & nuc ish (D7Z1,D7S486)x2[100] & NR & $\mathrm{N}$ & \\
\hline 66 & 66,9 & $\mathrm{NR}$ & NR & $\mathrm{N}$ & \\
\hline 67 & 29,7 & NR & NR & $\mathrm{N}$ & \\
\hline 68 & 45,8 & NR & NR & $\mathrm{N}$ & \\
\hline 69 & 60,4 & 46, XY[10]; nuc ish (D7Z1,D7S486)×2[99/100] & AM & $\mathrm{N}$ & \\
\hline 70 & 29,9 & nuc ish $(\mathrm{D} 7 \mathrm{Z1}, \mathrm{D} 7 \mathrm{~S} 486) \times 2[100]$ & NR & $\mathrm{N}$ & \\
\hline 71 & 69,8 & 46, XX[3]; nuc ish (D7Z1,D7S486)x2[100] & $46, \mathrm{XX}[3]$ & $\mathrm{N}$ & \\
\hline 72 & 20,3 & AM & NR & $\mathrm{N}$ & \\
\hline 73 & 26,8 & NR & 46,XY[8]; nuc ish(D7Z1,D7S486)x2[100] & $\mathrm{N}$ & \\
\hline
\end{tabular}


Estudo Citogenético (cariótipo e FISH) dos pacientes ao diagnóstico, ao seguimento e à evolução para SMD/LMA (continuação)

\begin{tabular}{|c|c|c|c|c|c|}
\hline Paciente & $\begin{array}{l}\text { Idade } \\
\text { (anos) }\end{array}$ & Cariótipo e/ou FISH ao diagnóstico & $\begin{array}{c}\text { Cariótipo e/ou FISH ao seguimento pré- } \\
\text { evolução para SMD / LMA }\end{array}$ & $\begin{array}{l}\text { Evolução para } \\
\text { SMD / LMA }\end{array}$ & Cariótipo e/ou FISH à evolução para SMD / LMA \\
\hline 74 & 26,8 & nuc ish $(D 7 Z 1, D 7 S 486) \times 2[100]$ & NR & $\mathrm{N}$ & \\
\hline 75 & 51,0 & 46, XX[12]; nuc ish (D7Z1,D7S486)×2[100] & NR & $\mathrm{N}$ & \\
\hline 76 & 19,1 & nuc ish $(D 7 Z 1, D 7 S 486) \times 2[100]$ & AM & $\mathrm{N}$ & \\
\hline 77 & 45,6 & 46,XX [8]; nuc ish (D7Z1,D7S486)x2[100] & NR & $\mathrm{N}$ & \\
\hline 78 & 49,0 & nuc ish (D7Z1,D7S486)x2[100] & $46, X Y[24]$ & $\mathrm{N}$ & \\
\hline 79 & 35,4 & $\mathrm{AM}$ & $46, \mathrm{XY}[13] ;$ nuc ish (D7Z1,D7S486)x2[100] & $\mathrm{N}$ & \\
\hline 80 & 49,1 & NR & $\begin{array}{c}\text { 46,XX[20]; nuc ish } \\
\text { (D7Z1,D7S486)×2[95/100] }\end{array}$ & $\mathrm{N}$ & \\
\hline 81 & 71,8 & $46, \mathrm{XY}[18]$ & NR & $\mathrm{N}$ & \\
\hline 82 & 56,2 & AM & nuc ish $(D 7 Z 1, D 7 S 486) \times 2[100]$ & $\mathrm{N}$ & \\
\hline 83 & 25,3 & AM & $\mathrm{NR}$ & $\mathrm{N}$ & \\
\hline 84 & 23,8 & $\mathrm{AM}$ & $A M$ & $\mathrm{~S}$ & nuc ish (D7Z1,D7S486)x1[76/100] \\
\hline 85 & 50,0 & 46, XY[20]; nuc ish (D7Z1,D7S486)×2[100] & NR & $\mathrm{N}$ & \\
\hline 86 & 40,7 & 46, XX[15]; nuc ish (D7Z1,D7S486)×2[100] & NR & $\mathrm{N}$ & \\
\hline 87 & 34,0 & 46, XY[20]; nuc ish (D7Z1,D7S486)×2[100] & NR & $\mathrm{N}$ & \\
\hline 88 & 24,3 & AM & NR & $\mathrm{N}$ & \\
\hline 89 & 23,8 & $\begin{array}{c}\text { 46, XX[20]; nuc ish } \\
\text { (D7Z1,D7S486)x2[98/100] }\end{array}$ & NR & $\mathrm{N}$ & \\
\hline 90 & 23,5 & $46, X Y[20]$ & $46, \mathrm{XY}[16] ;$ nuc ish (D7Z1,D7S486)×2[100] & $\mathrm{N}$ & \\
\hline 91 & 46,3 & $N R$ & NR & $\mathrm{N}$ & \\
\hline 92 & 29,1 & nuc ish $(\mathrm{D} 7 Z 1, \mathrm{D} 7 \mathrm{~S} 486) \times 2[100]$ & NR & $\mathrm{N}$ & \\
\hline 93 & 21,0 & 46, XY[17]; nuc ish (D7Z1,D7S486)x2[100] & NR & $\mathrm{N}$ & \\
\hline 94 & 71,4 & NR & NR & $\mathrm{N}$ & \\
\hline 95 & 67,8 & 46, XY[7]; nuc ish (D7Z1,D7S486)×2[98/100] & $46, \mathrm{XY}[20]$ & $\mathrm{N}$ & \\
\hline 96 & 38,1 & 46, XY[20]; nuc ish (D7Z1,D7S486)x2[100] & NR & $\mathrm{N}$ & \\
\hline 97 & 51,9 & $46, X X[10]$ & NR & $\mathrm{N}$ & \\
\hline 98 & 35,1 & AM & NR & $\mathrm{N}$ & \\
\hline
\end{tabular}


Estudo Citogenético (cariótipo e FISH) dos pacientes ao diagnóstico, ao seguimento e à evolução para SMD/LMA (conclusão)

\begin{tabular}{|c|c|c|c|c|c|}
\hline Paciente & $\begin{array}{l}\text { Idade } \\
\text { (anos) }\end{array}$ & Cariótipo e/ou FISH ao diagnóstico & $\begin{array}{c}\text { Cariótipo e/ou FISH ao seguimento pré- } \\
\text { evolução para SMD / LMA }\end{array}$ & $\begin{array}{l}\text { Evolução para } \\
\text { SMD / LMA }\end{array}$ & Cariótipo e/ou FISH à evolução para SMD / LMA \\
\hline 99 & 26,4 & $46, X X[4]$ & NR & $\mathrm{N}$ & \\
\hline 100 & 35,6 & 46, XY[6]; nuc ish (D7Z1,D7S486)x2[100] & NR & $\mathrm{N}$ & \\
\hline 101 & 21,0 & $46, X X[3] ;$ nuc ish (D7Z1,D7S486)x2[100] & NR & $S$ & $45, X X,-7[9] / 46, X X[1]$ \\
\hline 102 & 16,4 & $\mathrm{AM}$ & NR & $\mathrm{N}$ & \\
\hline 103 & 26,1 & $\begin{array}{c}\text { 46,XX[20]; nuc ish } \\
\text { (D7Z1,D7S486)x2[99/100] }\end{array}$ & NR & $\mathrm{N}$ & \\
\hline 104 & 24,7 & $46, X X[8] ;$ nuc ish $(D 7 Z 1, D 7 S 486) \times 2[100]$ & $46, X X[15]$ & $\mathrm{N}$ & \\
\hline 105 & 71,4 & $46, \mathrm{XY}[9] ;$ nuc ish (D7Z1,D7S486)×2[100] & AM & $\mathrm{N}$ & \\
\hline 106 & 30,8 & nuc ish (D7Z1,D7S486)x2[100] & NR & $\mathrm{N}$ & \\
\hline 107 & 35,0 & $\mathrm{NR}$ & NR & $\mathrm{N}$ & \\
\hline 108 & 66,2 & nuc ish (D7Z1,D7S486)x2[100] & NR & $S$ & $45, X Y,-7[2] / 46, X Y,-7,+21[17] / 46, X Y[1]$ \\
\hline 109 & 17,7 & nuc ish (D7Z1,D7S486)x2[97/100] & NR & $\mathrm{N}$ & \\
\hline 110 & 20,7 & $46, \mathrm{XY}[20]$; nuc ish (D7Z1,D7S486)×2[100] & AM & $\mathrm{N}$ & \\
\hline 111 & 39,8 & nuc ish $(\mathrm{D} 7 Z 1, \mathrm{D} 7 \mathrm{~S} 486) \times 2[100]$ & NR & $\mathrm{N}$ & \\
\hline 112 & 18,1 & $N R$ & NR & $\mathrm{N}$ & \\
\hline 113 & 19,8 & 46,XX[20]; nuc ish (D7Z1,D7S486)x2[100] & NR & $\mathrm{N}$ & \\
\hline 114 & 72,4 & 46,XY[5]; nuc ish(D7Z1,D7S486)×2[98/100] & NR & $\mathrm{N}$ & \\
\hline 115 & 66,6 & nuc ish(D7Z1,D7S486)x2[100] & NR & $\mathrm{N}$ & \\
\hline 116 & 54,7 & NR & NR & $S$ & $\begin{array}{l}\text { 45,XX,-7[12]/46,XX,-7,+21[3]; nuc } \\
\text { ish(D7Z1,D7S486)x1[58/100] }\end{array}$ \\
\hline 117 & 36,8 & $46, X X[10] ;$ nuc ish(D7Z1,D7S486)x2[99/100] & NR & $\mathrm{N}$ & \\
\hline 118 & 32,3 & nuc ish(D7Z1,D7S486)x2[100] & NR & $\mathrm{N}$ & \\
\hline
\end{tabular}

FISH: hibridização "in situ” por imunofluorescência; NR: não realizado; AM: ausência de metáfase. Nomenclatura de cariótipo e FISH de acordo com ISCN2013. 